\title{
Steady-state modeling of extrusion cast film process, neck-in phenomenon, and related experimental research: A review
}

Cite as: Phys. Fluids 32, 061302 (2020); https://doi.org/10.1063/5.0004589

Submitted: 12 February 2020 . Accepted: 01 May 2020 . Published Online: 05 June 2020

Tomas Barborik (D), and Martin Zatloukal (D)

COLLECTIONS

EP This paper was selected as an Editor's Pick

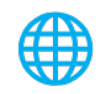

\section{ARTICLES YOU MAY BE INTERESTED IN}

\section{Fluvial instabilities}

Physics of Fluids 32, 061301 (2020); https://doi.org/10.1063/5.0010038

On coughing and airborne droplet transmission to humans

Physics of Fluids 32, 053310 (2020); https://doi.org/10.1063/5.0011960

Likelihood of survival of coronavirus in a respiratory droplet deposited on a solid surface

Physics of Fluids 32, 061704 (2020); https://doi.org/10.1063/5.0012009 


\title{
Steady-state modeling of extrusion cast film process, neck-in phenomenon, and related experimental research: A review
}

\author{
Cite as: Phys. Fluids 32, 061302 (2020); doi: 10.1063/5.0004589 \\ Submitted: 12 February 2020 - Accepted: 1 May 2020 • \\ Published Online: 5 June 2020
}

Tomas Barborik (D) and Martin Zatloukal ${ }^{\text {a) }}$ (D)

\section{AFFILIATIONS}

Polymer Centre, Faculty of Technology, Tomas Bata University in Zlin, Vavreckova 275, 760 01 Zlin, Czech Republic

\author{
a) Author to whom correspondence should be addressed: mzatloukal@utb.cz
}

\begin{abstract}
This review provides the current state of knowledge of steady-state modeling of the extrusion cast film process used to produce flat polymer films, as well as related experimental research with a particular focus on the flow instability neck-in. All kinematic models used (i.e., 1-, 1.5-, 2-, and 3-dimensional models) together with the utilized constitutive equations, boundary conditions, simplified assumptions, and numerical methods are carefully summarized. The effect of draw ratio, Deborah number (i.e., melt relaxation time related to experimental time), film cooling, second to first normal stress difference ratio at the die exit, uniaxial extensional strain hardening, and planar-to-uniaxial extensional viscosity ratio on the neck-in is discussed.
\end{abstract}

Published under license by AIP Publishing. https://doi.org/10.1063/5.0004589

\section{NOMENCLATURE}

\section{Latin symbols}

A

a

B

b

$\mathrm{b}_{\mathrm{c}}$

c

$\stackrel{\underline{\mathrm{C}}^{-1}}{\stackrel{\mathrm{c}}{\mathrm{c}}}$

D Deformation rate tensor $\left(\mathrm{s}^{-1}\right)$

De Deborah number (1)

DR draw ratio (1)

$\mathrm{DR}_{\mathrm{C}} \quad$ critical draw ratio (1)

E elasticity matrix in Hooke's law $(\mathrm{Pa})$

$\overline{\overline{\mathrm{e}}} \quad$ half-thickness of the film at any $x$ location (m)

$\mathrm{e}_{0} \quad$ die half-gap (half-thickness of the film at the die exit) (m)

${ }_{-}^{e} \quad$ irreversible rate of the strain tensor in the modified Leonov model $\left(\mathrm{s}^{-1}\right)$ $f(x)$

G

$\mathrm{G}^{\prime}$

$\mathrm{G}^{\prime \prime}$

$\mathrm{g}(\mathrm{x})$

HTC

$\mathrm{h}_{\mathrm{f}}^{\text {edge }}$

$h_{f}^{\text {center }}$

$\mathrm{II}_{\underline{\underline{D}}}$

$\mathrm{I}_{\underline{\underline{c}}}$

$\underline{\underline{\underline{c}}} \mathrm{II}_{\underline{\mathrm{c}}}$

$\mathrm{I}_{\underline{\mathrm{C}}^{-1}}$

$\mathrm{II}_{\underline{\underline{C}}^{-1}}$

$\mathrm{i}$

$\mathrm{J}_{\mathrm{E}}^{0}$

j

L

$\stackrel{\mathrm{L}}{\mathrm{G}} \mathrm{v}$

$\mathrm{L}_{0}$

$\mathrm{m}$ rate of deformation in the transverse $y$-direction $\left(\mathrm{s}^{-1}\right)$

linear Hookean elastic modulus $(\mathrm{Pa})$

storage modulus $(\mathrm{Pa})$

loss modulus $(\mathrm{Pa})$

rate of deformation in the thickness $\mathrm{z}$-direction $\left(\mathrm{s}^{-1}\right)$

heat transfer coefficient $\left(\mathrm{J} \mathrm{s}^{-1} \mathrm{~K}^{-1} \mathrm{~m}^{-2}\right)$

edge final film thickness ( $\mathrm{mm}$ )

center final film thickness ( $\mathrm{mm}$ )

second invariant of the deformation rate tensor $\left(\mathrm{s}^{-1}\right)$

first invariant of the recoverable Finger tensor (1)

second invariant of the recoverable Finger tensor (1)

first invariant of the Finger strain tensor (1)

second invariant of the Finger strain tensor (1)

index $i$, noting the spatial direction (1)

linear steady-state elastic compliance $\left(\mathrm{Pa}^{-1}\right)$

relaxation mode identification number (1)

half-width of the film at any $x$ location (m)

velocity gradient tensor $\left(\mathrm{s}^{-1}\right)$

half-width of the die (half-width of the film at the die exit) (m)

flow consistency index in the power-law model $\left(\mathrm{Pa} \mathrm{s}{ }^{\mathrm{n}}\right)$ 
MFR, m mass flow rate $\left(\mathrm{kg} \mathrm{h}^{-1}\right)$

$\mathrm{Mn} \quad$ number average molar mass $\left(\mathrm{g} \mathrm{mol}^{-1}\right)$

$\mathrm{Mw} \quad$ mass average molar mass $\left(\mathrm{g} \mathrm{mol}^{-1}\right)$

$\mathrm{N} \quad$ presents the highest value available (-)

$\mathrm{n}$ flow behavior index in GNM (1)

$\mathrm{n}_{\mathrm{L}} \quad$ non-linear Leonov model parameter (1)

$\mathrm{n}^{\prime} \quad$ adjustable parameter in the relaxation time function in the generalized UCM model (1)

NI maximum attainable neck-in $(\mathrm{m})$

$\mathrm{N}_{1} \quad$ first normal stress difference $(\mathrm{Pa})$

$\mathrm{N}_{2} \quad$ second normal stress difference $(\mathrm{Pa})$

$-\mathrm{N}_{2} / \mathrm{N}_{1} \quad$ stress state at the die exit (1)

$\mathrm{q} \quad$ number of arms in the XPP model (1)

$\mathrm{T} \quad$ melt temperature $\left({ }^{\circ} \mathrm{C}\right)$

$\mathrm{t} \quad$ present time in the K-BKZ model (s)

$\mathrm{t}^{\prime} \quad$ past time in the K-BKZ model (s)

$\mathrm{v}_{\mathrm{X}} \quad$ axial velocity component of the film at any $x$ location ( $\mathrm{m}$ $\left.\mathrm{s}^{-1}\right)$

$\mathrm{v}_{\mathrm{x}}(0)$ axial velocity component at the die exit (velocity in the machine direction) $\left(\mathrm{m} \mathrm{s}^{-1}\right)$

$\mathrm{v}_{\mathrm{X}}(\mathrm{X}) \quad$ chill roll speed (take-up rate) $\left(\mathrm{m} \mathrm{s}^{-1}\right)$

$\mathrm{v}_{\mathrm{y}} \quad$ velocity component of the film in the transverse $\mathrm{y}$ direction at any $x$ location $\left(\mathrm{m} \mathrm{s}^{-1}\right)$

$\mathrm{v}_{\mathrm{z}} \quad$ velocity component of the film in the thickness $\mathrm{z}$ direction at any $x$ location $\left(\mathrm{m} \mathrm{s}^{-1}\right)$

W elastic potential in the modified Leonov model $(\mathrm{Pa})$

$\mathrm{X}$ take-up length (drawing distance and air-gap) (m)

$\mathrm{x}, \mathrm{y}, \mathrm{z}$ spatial coordinates in axial, transverse, and thickness directions, respectively $(\mathrm{m})$

$\mathrm{x} \quad$ position in the axial $\mathrm{x}$-direction $(\mathrm{m})$

$\mathrm{Z} \quad$ function in the modified Giesekus model (1)

\section{Greek symbols}

a

$\alpha_{i}$

$\beta$

$\beta_{c}$

$\beta_{\mathrm{i}}$

$\dot{\gamma}$

$\Delta \underline{\underline{\varepsilon}}$

$\Delta \underline{\underline{\varepsilon}}^{\mathrm{c}}$

$\Delta \underline{\underline{\sigma}} \quad$ stress increment in Hooke's law $(\mathrm{Pa})$

$\underline{\delta} \quad$ the Kronecker delta, unit tensor (1)

$\overline{\bar{\delta}}_{0}$

$\varepsilon_{\mathrm{p}}$

$\dot{\varepsilon}_{\mathrm{p}}$

$\eta, \eta_{s}$

$\eta_{0}$

$\eta_{b}$

$\eta_{\mathrm{p}}$

$\eta_{\infty}$

$\eta_{E}, \mathrm{P}, \eta_{\mathrm{P}}$ (1) parameter in the K-BKZ model (1) model (1)

parameter in the K-BKZ model (1)

shear strain rate $\left(\mathrm{s}^{-1}\right)$

(1)

parameter in the PTT model (1)

extensional strain rate $\left(\mathrm{s}^{-1}\right)$

steady shear viscosity ( $\mathrm{Pa} \mathrm{s}$ )

Giesekus model ( $\mathrm{Pa} \mathrm{s}$ ) anisotropy parameter in the Giesekus and XPP model non-linear Leonov model parameter (1)

convective constraint release coefficient in the RP-S

total strain increment in Hooke's law (1)

modified Perzyna creep strain increment in Hooke's law

fitting scalar parameter in the RP-S model (1)

newtonian viscosity, zero-shear viscosity (Pa s)

steady biaxial extensional viscosity ( $\mathrm{Pa} \mathrm{s}$ )

polymer viscosity in the Giesekus model (Pa s)

infinite-shear-rate viscosity, solvent viscosity in the

steady planar extensional viscosity (Pa s)
$\eta_{\mathrm{E}}, \mathrm{U}, \eta_{\mathrm{U}}$

$\eta_{\mathrm{E}, \mathrm{U}, \max }$

$\frac{\eta_{\mathrm{E}, \mathrm{U}, \text { max }}}{3 \eta_{0}}$

$\theta$

$\Lambda$

$\underline{\lambda}, \lambda_{1}$

$\bar{\lambda}$

$\lambda_{0}$

$\lambda_{0 \mathrm{~b}}$

$\lambda_{0 \mathrm{~s}}$

$\lambda_{\mathrm{d}}$

$\lambda_{\mathrm{r}}$

$\lambda_{\mathrm{t}}$

$\underline{\underline{\lambda(\tau)^{-1}}}$

$v$

$\xi$

$\xi_{\mathrm{p}}$

$\zeta$

$\stackrel{\tau}{=}$

$\underline{\underline{\tau}}$

$\underline{\tau}^{\nabla}$

$\stackrel{\tau}{=} \mathrm{p}$

$\underline{\tau}_{s}$

$\tau_{\mathrm{Xx}}$

$\bar{\tau}_{\mathrm{xx}}$

$\tau_{y y}$

$\bar{\tau}_{\text {yy }}$

$\tau_{\mathrm{zz}}$

$\bar{\tau}_{\mathrm{zZ}}$

$\nabla$ steady uniaxial extensional viscosity ( $\mathrm{Pa}$ s)

maximal steady uniaxial extensional viscosity (Pa s)

uniaxial extensional strain hardening (1)

parameter in the K-BKZ model (1)

backbone tube stretch in the XPP model (1)

melt relaxation time (s)

average relaxation time (s)

adjustable parameter in the relaxation time function in

the generalized UCM model (s)

orientation relaxation time in the XPP model (s)

stretch relaxation time in the XPP model (s)

reptation relaxation time in the RP-S model (s)

Rouse relaxation time in the RP-S model (s)

adjustable parameter in the relaxation time function in the generalized UCM model (s)

relaxation time tensor in the XPP model (s)

non-linear Leonov model parameter (1)

non-linear Leonov model parameter (1)

parameter in the PTT model (1)

non-linear model parameter in the Larson model (1)

extra stress tensor $(\mathrm{Pa})$

Gordon-Schowalter convected time derivative of the stress tensor in the PTT model $\left(\mathrm{Pa} \mathrm{s}^{-1}\right)$

upper-convected time derivative of the stress tensor $(\mathrm{Pa}$ $\left.\mathrm{s}^{-1}\right)$

polymer contribution to the stress tensor in the Giesekus model $(\mathrm{Pa})$

solvent contribution to the stress tensor in the Giesekus model $(\mathrm{Pa})$

normal stress in the axial $\mathrm{x}$-direction $(\mathrm{Pa})$

dimensionless normal stress in the axial x-direction (1)

normal stress in the transverse $y$-direction $(\mathrm{Pa})$

dimensionless normal stress in the transverse $y$ direction (1)

normal stress in the thickness $\mathrm{Z}$-direction $(\mathrm{Pa})$

dimensionless normal stress in the thickness $\mathrm{z}$-direction (1)

gradient operator (1)

\section{Latin abbreviations and acronyms}

1D, 1.5D, 2D, and 3D model dimensionality, e.g., 1D: CHEBFUN framework within the MATLAB (-)

DE Doi-Edwards integral tube model (-)

EB edge-beading phenomenon (-)

EFC extrusion film casting (-)

FDM finite difference method (-)

FE finite element (-)

FEM finite element method (-)

FEM ALE FEM the arbitrary Lagrangian Eulerian method (-)

FEM EVSS FEM the elastic viscous stress splitting (-)

FIC

FVM

flow-induced crystallization (-)

finite volume method (-)

generalized Newtonian model (-) 
HDPE material: high-density polyethylene (-)

iPP, PP material: isotactic polypropylene (-)

K-BKZ Kaye-Bernstein-Kearsley-Zapas constitutive model (-)

LCB long chain branching (-)

LDPE material: low-density polyethylene (-)

LLDPE material: linear low-density polyethylene (-)

MWD molecular weight distribution (-)

mLLDPE material: linear metallocene-catalyzed low-density polyethylene (-)

ode15s differential equation solver within MATLAB software $(-)$

PBAT material: poly(3-hydroxybutyrate-co-3-hydroxyvalerate) $(-)$

PBS material: polybutylene succinate (-)

PES material: polyethersulfone (-)

PET material: polyethylene terephthalate (-)

PLA material: polylactide (-)

PP material: polypropylene (-)

PS material: polystyrene (-)

PSM Papanastasiou-Scriven-Macosko damping function for the K-BKZ constitutive model (-)

PTT Phan-Thien and Tanner constitutive model (-)

RP-S Rolie-Poly stretch constitutive model (-)

$\mathrm{SH} \quad$ strain hardening (-)

$\operatorname{tr}() \quad$ denotes the trace of a matrix (-)

UCM upper convected Maxwell constitutive model (-)

UL FEM updated Lagrangian FEM (-)

VE viscoelasticity $(-)$

XPP eXtended Pom-Pom constitutive model (-)

\section{INTRODUCTION}

Extrusion film casting is an industrially important process, which, in practice, has a solid place among polymer processing technologies. It can be classified as a continuous, high-speed manufacturing process during which monolayer or co-extruded multilayer thin, highly oriented films are produced. A wide range of plastic films and sheets produced by this technology are used in many different applications of daily and technical use: plastic bags, consumer packaging, magnetic tapes for storing audio-video content, optical membranes for liquid crystal displays, flexible electronics, foils for capacitors and microporous membranes used primarily in separation processes (from microfiltration to reverse osmosis or as separators in lithium-ion batteries for mobile devices and electric vehi$\operatorname{cles}^{1-4}$ ), or as a product for further processing by other technologies such as thermoforming and biaxial orientation. ${ }^{5}$

The growing demand for the quantity production and quality of manufactured films, together with the introduction of new materials, requires new approaches in production line. Of particular interest is to reach desirable properties of the produced films and to keep film thickness uniform and width as close as possible to the designed extrusion die width. In order to eliminate an expensive and time-consuming trial-and-error approach widely used in the plastics industry to optimize the film casting process, one can use a computer modeling for the optimization of die design and process conditions for a given polymer system. This strategy can provide a better insight into the problem, broaden the knowledge on relationships between process/rheological variables, and propose possible approaches to deal with them to optimize the process or provide a better understanding of basic underlying mechanics.

\section{A. Film casting process description}

The extrusion film casting is a technology in which polymer pellets are conveyed, homogenized, compressed, and melted in an extruder. Then, the polymer melt is pushed through the uniform slit die (center-fed $\mathrm{T}$ die or coat-hanger die) with typically about 1-2 mm gap size. ${ }^{5}$ The thick sheet is then intensively stretched in the machine direction using a constant rotary whose circumferential velocity, $v_{x}(X)$, is higher than the average polymer melt velocity at the die exit, $v_{x}(0)$. This leads to the orientation of macromolecules and reduced film thickness, and due to a sufficiently high cooling rate, the final film dimensions are fixed. The intensity of the stretching is given by a draw ratio, which is defined as $D R=v_{x}(X) / v_{x}(0)$. Additionally, an increase in $D R$, cooling rate, or stretching distance can cause temperature and/or stress induced crystallization, which can enhance the final film properties. The process is visualized in Fig. 1.

At the chill roll, several other technological devices can be used to provide a better contact line between the film and the chill roll and to increase the heat transfer rate, such as an air knife (a slit nozzle blows a jet of cooled air to film) or electrostatic pinning. In the latter device, a high voltage wire is positioned parallel to the grounded chill roll that generates an electrostatic discharge exerting electrostatic force on the film to increase the film-chill roll contact. Another alternative with the similar result is a vacuum box, which provides a vacuum between the film and the chill roll. ${ }^{7-9}$ In addition to cooling on the chill roll, the polymer film is naturally cooled to some extent, depending on the length of the drawing zone, by passing through the surrounding environment. This can be enhanced by introducing convection air or an inert gas source into this

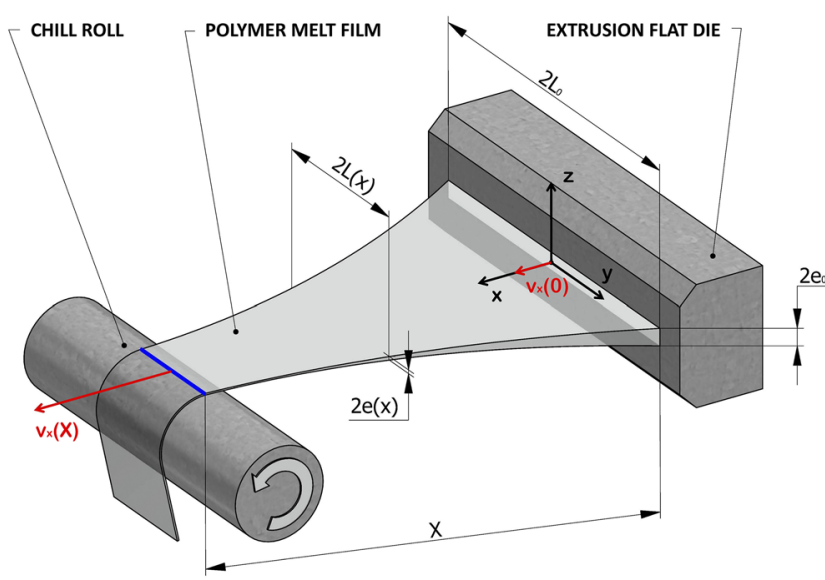

FIG. 1. Schematics of the extrusion film casting kinematics. Reproduced with permission from T. Barborik and M. Zatloukal, "Effect of second to first normal stress difference ratio at the die exit on neck-in phenomenon in polymeric flat film production," AIP Conf. Proc. 1843, 030010 (2017). Copyright 2017 AIP Publishing LLC. 
section or by passing the film through a fluid bath. ${ }^{10}$ Additionally, the produced polymeric film can also be subjected to treatment (plasma treating, heating, and biaxial orientation) depending on the desired properties and purpose of the final product. Polymer behavior and extensional conditions in the drawing zone have been shown to be key factors determining the final mechanical and optical properties of the film.

To produce highly functional films with tailored properties, multiple layers of different polymer melts can be coextruded and stretched, i.e., the properties of the film are given by each individual layer. In this way, multilayer films with enhanced properties, such as oxygen and moisture impermeability, strength, chemical resistance, or color, can be produced. ${ }^{12}$ An alternative continuous film production technology is called the extrusion film blowing process. In this process, the extruded tube is inflated by the internal pressure into a bubble shape having a thin wall thickness, which is simultaneously quenched and hauled off. ${ }^{13-17}$ In contrast to this competing film production technology, films made by extrusion film casting have good transparency, uniformity of thickness, and a smoother surface and are produced at a higher production rate.

According to the current industry practice, where a wide variety of films are produced with a requirement for use in heterogeneous applications, manufactures process a broad range of materials by using film casting technology. Frequently used polymeric materials include low-density polyethylene (LDPE), high-density polyethylene (HDPE), linear low-density polyethylene (LLDPE), polypropylene (PP), polyethylene terephthalate (PET), and polystyrene (PS). The extrusion film casting is also suitable for low viscosity polymers ${ }^{18}$ and biodegradable polymers such as polylactide (PLA) or its blends with polybutylene succinate (PBS) or poly(3-hydroxybutyrate-co-3hydroxyvalerate) (PBAT). ${ }^{19,20}$ Since these films have a wide range
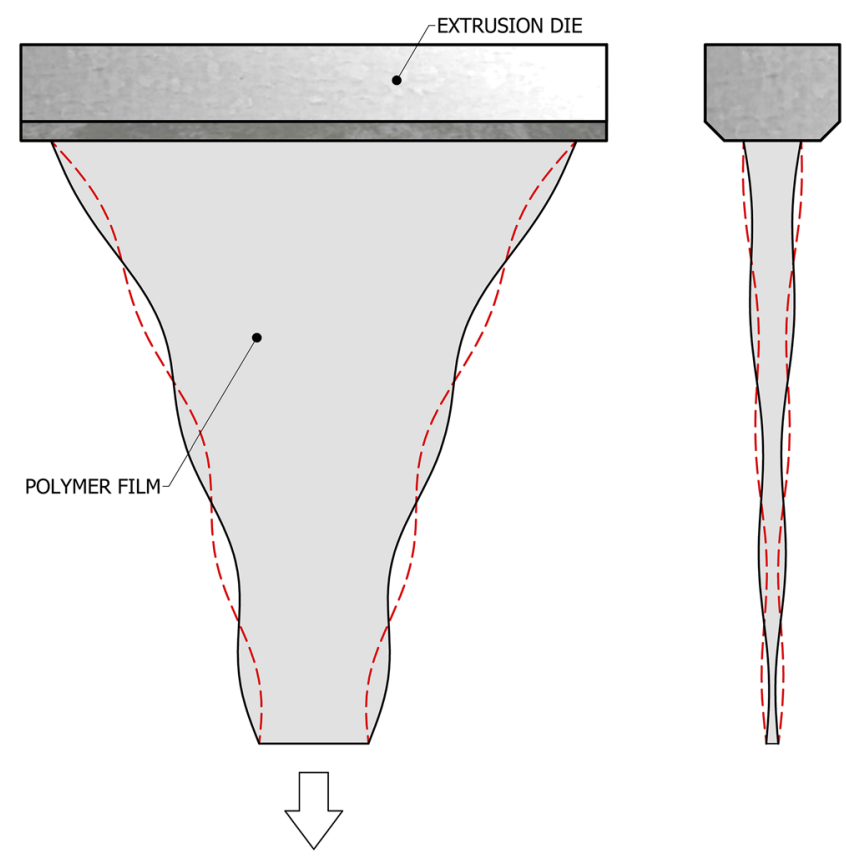

FIG. 2. Visualization of the effect of draw resonance on film width and thickness. of applications, there is a requirement to produce a wide range of sizes. The film width can typically range from $0.1 \mathrm{~m}$ to $10 \mathrm{~m}$, thicknesses from $20 \mu \mathrm{m}$ to $2000 \mu \mathrm{m}^{11}$ at production rates ranging from $70 \mathrm{~m} / \mathrm{min}$ to $200 \mathrm{~m} / \mathrm{min}$. Tolerable thickness variation is reported to be from $3 \%$ to $5 \% .{ }^{5}$ The plastics industry, which focuses on the production of plastic foils, is currently undergoing a major change due to the gradual transition from conventional commodity polymers to more advanced. ${ }^{6}$ These include metallocene polymers with an easily modifiable structure, which makes it possible to significantly improve the final properties of the film. Structural polymers such as polyethylene terephthalate, polycarbonate, polyamide, and polyphenylsulfide have become popular materials for producing films with high heat resistance. The line speed for the production of polymer films is gradually increasing for economic reasons and in some cases (e.g., polypropylene or polyethylene terephthalate) may reach up to $500 \mathrm{~m} / \mathrm{min}$.

\section{FLOW INSTABILITIES}

The presence of an air-polymer interface in the drawing zone makes it possible to develop various types of flow instabilities that

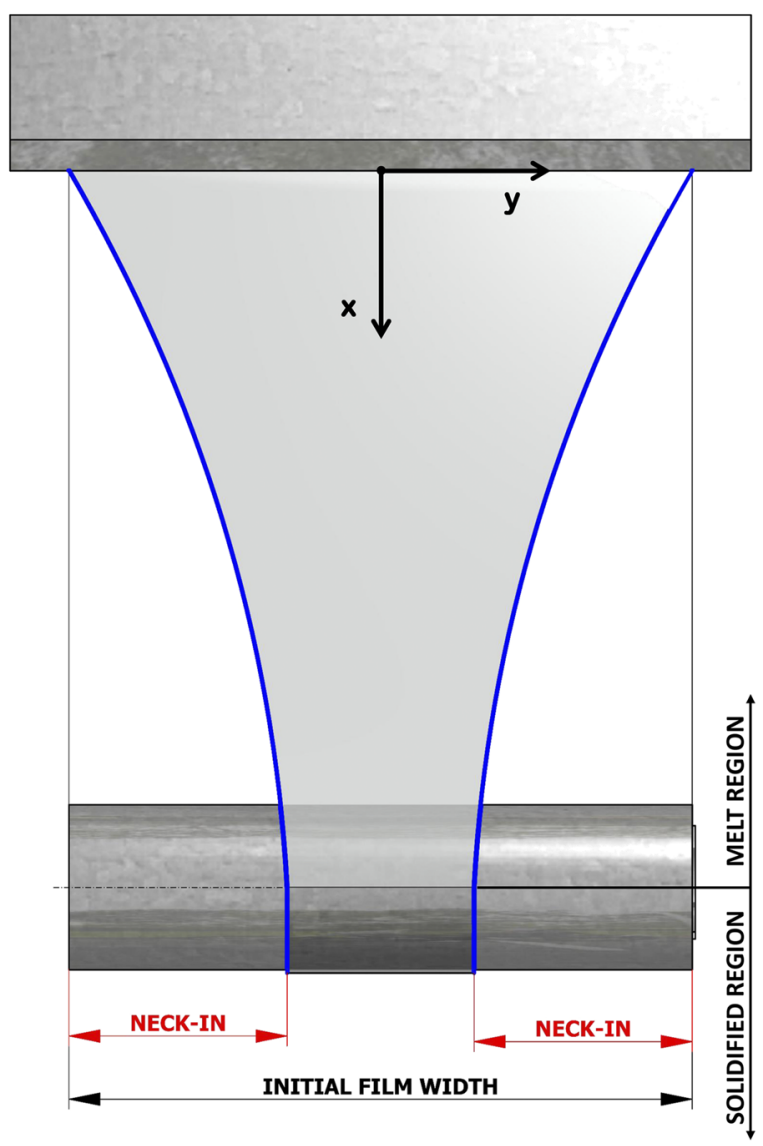

FIG. 3. Visualization of the neck-in phenomenon during extrusion film casting Reproduced with permission from Barborik et al., "On the role of extensional rheology and Deborah number on the neck-in phenomenon during flat film casting," Int. J. Heat Mass Transfer 111, 1296 (2017). Copyright 2017 Elsevier. 
TABLE I. Research work devoted to the experimental investigation of the neck-in phenomenon.

\begin{tabular}{|c|c|c|c|}
\hline Year & References & Material & Note \\
\hline 1974 & Kase $^{165}$ & PP & Experimental investigation of EFC aimed on process stability. \\
\hline 1986 & Dobroth and Erwin ${ }^{55}$ & LDPE & Enlightens the physical background of edge-bead formation. \\
\hline 1989 & Cotto et al. ${ }^{18}$ & PP & $\begin{array}{l}\text { Experimental and theoretical investigation of crystalline } \\
\text { phase development during EFC and modeling. }\end{array}$ \\
\hline 1990 & Barq et al. ${ }^{22}$ & PET & The work is aimed on transient phenomena of draw resonance. \\
\hline 1990 & Duffo et al. ${ }^{100}$ & $\mathrm{PP}$ & Effect of roll temperature on crystallization in the EFC process. \\
\hline 1991 & Duffo et al. ${ }^{87}$ & $\mathrm{PP}$ & $\begin{array}{l}\text { Extended experimental and theoretical investigation of } \\
\text { crystalline phase development during EFC and modeling. }\end{array}$ \\
\hline 1992 & Barq et al. ${ }^{88}$ & PET & $\begin{array}{l}\text { Experimental and model results are compared, } \\
\text { and influence of temperature is discussed. }\end{array}$ \\
\hline 1999 & Acierno et al. ${ }^{69}$ & PET; PP & Purely experimental study aimed on film temperature profiles and viscosity. \\
\hline 2000 & Acierno et al..$^{90}$ & PET & Role of temperature profile on $N I$, minor importance of temperature if $\mathrm{X}<1 / 10 \mathrm{~L}_{0}$. \\
\hline 2000 & Canning and $\mathrm{Co}^{48}$ & LDPE; LLDPE & $\begin{array}{l}\text { Purely experimental work deals with the effect of rheology, } D R \text {, } \\
\text { and } M F R \text { on } N I \text { and } E B \text {. }\end{array}$ \\
\hline 2001 & Canning et al. ${ }^{70}$ & LDPE & Experimental work capturing velocity, width, and thickness profiles during EFC. \\
\hline 2001 & Lamberti et al. ${ }^{91}$ & iPP & Effect of processing cond. On film development including crystallization. \\
\hline 2001 & Satoh et al. ${ }^{39}$ & LDPE & $\begin{array}{l}\text { Investigation of viscoelastic effects on } N I \text { and edge-beading, } \\
\text { relates } N I \text { to } S H \text { in the uni/pla extensional rate. }\end{array}$ \\
\hline 2002 & $\begin{array}{l}\text { Lamberti and } \\
\text { Titomanlio }^{71}\end{array}$ & $\mathrm{iPP}$ & $\begin{array}{l}\text { Experimental investigation of EFC including width, velocity, } \\
\text { temperature, and crystallinity profiles. }\end{array}$ \\
\hline 2002 & Lamberti et al. ${ }^{92}$ & $\mathrm{iPP}$ & $\begin{array}{l}\text { Experimental measuring and modeling of Hermans orientation factor } \\
\text { and crystallinity. Evaluation of Ziabicki crystallization kinetics from } \\
\text { measured film velocity, width, and temperature profiles. }\end{array}$ \\
\hline 2002 & Lamberti et al..$^{93}$ & iPP & Experimental measuring of film temperature profiles. \\
\hline 2002 & Toft and Rigdahl ${ }^{72}$ & $\begin{array}{l}\text { LDPE; LLDPE; } \\
\text { mLLDPE }\end{array}$ & Experimentally investigates the relationship between polymer elasticity and $N I$. \\
\hline 2003 & Ito et al. ${ }^{52}$ & LLDPE & $\begin{array}{l}\text { Experimental-oriented work using particle tracking. } \\
\text { Confirmation of planar-uniaxial flows. }\end{array}$ \\
\hline 2003 & Ito et al. ${ }^{53}$ & $\begin{array}{l}\text { LDPE; HDPE; } \\
\text { LLDPE }\end{array}$ & Relates the NI extent to the ratio of planar viscosities; axial to transverse. \\
\hline 2004 & Uvieghara $^{68}$ & LLDPE & $\begin{array}{l}\text { The experiment-oriented work in which the effects of the Deborah number } \\
\text { and the aspect ratio on the EFC were investigated. }\end{array}$ \\
\hline $2005^{\mathrm{a}}$ & Agassant et al. ${ }^{166}$ & $\ldots$ & Film casting review. \\
\hline $2005^{\mathrm{a}}$ & $\mathrm{Co}^{167}$ & $\ldots$ & Film casting review aimed on the draw resonance. \\
\hline 2005 & Lamberti and Titomanlio ${ }^{94}$ & iPP & Experimental part is accompanied by a new cooling model with radiant heating. \\
\hline 2006 & Aniunoh and Harrison ${ }^{73}$ & $\mathrm{PP}$ & Effects of $D R$ and die temperature on temperature, velocity, and width profiles. \\
\hline 2006 & Bourrigaud et al. ${ }^{29}$ & LDPE & $\begin{array}{l}\text { Effect of processing cond. On film development in coating process: } \\
\text { divides the } D e-D r \text { plane into attainable and unattainable regions. }\end{array}$ \\
\hline 2006 & Lamberti and Titomanlio ${ }^{95}$ & iPP & Effect of processing cond. On film development; film solidification within the air-gap. \\
\hline 2007 & Aniunoh $^{107}$ & $\mathrm{PP}$ & $\begin{array}{l}\text { Experimentally aimed study on how material properties } \\
\text { and process conditions affect EFC. }\end{array}$ \\
\hline 2007 & Kometani et al. ${ }^{111}$ & PP; LDPE & $\begin{array}{l}\text { Study aims on } N I \text { and } E B \text { investigation; the utilized Giesekus equation was found } \\
\text { to be the most suitable model describing the experimental data. }\end{array}$ \\
\hline 2007 & Shin et al. ${ }^{36}$ & LDPE; HDPE & Effects of temperature and extensional-thinning and -thickening. \\
\hline 2008 & Kouda $^{74}$ & LDPE & Extrusion coating; linking neck-in degree with draw-down force. \\
\hline 2009 & Seay and Baird ${ }^{30}$ & $\begin{array}{l}\text { LDPE; LLDPE; } \\
\text { mLLDPE }\end{array}$ & Investigation of effects of $L C B$ and $M W D$ on $N I$ via Pom-Pom model. \\
\hline 2009 & McGrady et al. ${ }^{65}$ & HDPE; LDPE & Effects of $L C B$ and $M W D$ on NI. \\
\hline 2010 & Aniunoh and Harrison ${ }^{66}$ & $\mathrm{PP}$ & Effects of $M w, D R$, and temperature on film formation \\
\hline 2010 & Shiromoto et al. ${ }^{109}$ & LDPE & Deals with the extrusion lamination process. Relates the NI gauge to $\eta_{E, P} / \eta_{E, U}$. \\
\hline 2010 & Shiromoto et al. ${ }^{54}$ & LDPE & Relates the NI gauge to $\eta_{E, P} / \eta_{E, U}$ \\
\hline
\end{tabular}


TABLE I. (Continued.)

\begin{tabular}{|c|c|c|c|}
\hline Year & References & Material & Note \\
\hline 2011 & Lamberti $^{67}$ & iPP & Experimental study designed to check capabilities of the proposed FIC model. \\
\hline 2013 & Pol et al. ${ }^{41}$ & LDPE; HDPE; LLDPE & Effects of $L C B$ and $M W D$ on $N I$ \\
\hline $2014^{\mathrm{a}}$ & Demay and Agassant ${ }^{23}$ & $\ldots$ & Review targeting mainly transient instabilities during EFC. \\
\hline 2014 & Pol et al. ${ }^{42}$ & LDPE; HDPE; LLDPE & Effects of $L C B$ on $N I$. \\
\hline 2014 & Shiromoto $^{40}$ & LDPE & Effect of viscoelastisity on NI, relates the NI gauge to $\eta_{E, P} / \eta_{E, U}$. \\
\hline 2015 & Chikhalikar et al. ${ }^{43}$ & $\mathrm{PP}$ & Effects of $L C B$ on NI. \\
\hline 2015 & Zhou et al. ${ }^{96}$ & iPP & Effect of $D R$ on crystallization and development of crystal morphology. \\
\hline 2016 & Pol and Thete ${ }^{98}$ & LDPE; LLDPE & Investigation of NI dependence on $D e$ and $D R$. \\
\hline 2020 & $\mathrm{Mu}$ et al. ${ }^{110}$ & PP & Influence of processing conditions on film geometry. \\
\hline
\end{tabular}

${ }^{\mathrm{a}}$ The state of art in the EFC reviewing article.

severely limit the desired film quality and quantity. Their formation is influenced by processing conditions, heat transfer, and rheology of the processed polymer. For example, if the draw ratio reaches some critical value (for the given process conditions, die design and polymer used), transient hydrodynamic instability, called draw resonance, begins to occur. ${ }^{21}$ This instability causes oscillations of the film dimensions, although the volumetric flow supplied from the slit die and take-up speed are kept constant (see Fig. 2). These periodic fluctuations in film width and thickness (measured in the center of the film) are offset by the half-wavelength (i.e., maximum in width corresponds to the minimum thickness) and vice versa. ${ }^{22}$ Extension of the drawing distance, increased cooling effects, and the use of polymers with strong extensional strain hardening can stabilize the process and move the onset of draw resonance toward higher draw ratios.

Film breakage is another feature that can be observed during increasing the draw ratio. In this case, the chains cannot be reorganized to relieve local stresses within the time frame imposed by the deformation, resulting in a cohesive failure between the polymer chains and disintegration of the film. This can be seen in polymers containing long chain branches or a high molecular weight portion processed at high line speeds and cooling rates, leading to good process stability but also to the development of high tensile stress.

Neck-in and edge-beading are flow phenomena, which are the most common instabilities in the production of flat films because they occur and destabilize the flow at any processing conditions. These instabilities are described and reviewed below in greater detail.

\section{A. Neck-in}

Upon leaving the die, the extruded polymer in the form of a thick sheet exhibits swelling due to its viscoelastic nature. This relaxation of molecular stress is then influenced by the velocity rearrangement that occurs during the transition from a confined shear flow in the slit die to the downstream extension. When the polymer sheet is hauled off further downstream and stable processing conditions are met, its cross-sectional dimensions are monotonically reduced due to the external drawing force exerted on the sheet by the rotary winding drum. In addition to the desirable reduction in film thickness, the width of the film is reduced. This defect is called the neck-in and can be defined as the difference between the half-width of the film at the die exit and the final half-width of the solidified film (Fig. 3). The neck-in is considered to be a typical instability occurring in extensional flows as explained by Larson in Ref. 24, even if it occurs under steady-state extrusion conditions (i.e., the stress and the velocity are not time dependent at the given point of the stretched film) because it can have serious consequences since it might lead to breakage of the film.

The role of extrudate swell in the film drawing was investigated by using viscoelastic constitutive equations such as the Leonov model $^{25}$ and the linear PTT model. ${ }^{26}$ It was demonstrated that the negative value of the second normal stress difference causes swelling in the thickness direction much higher than in the width direction of the extrudate. ${ }^{26}$ Even if the intensity of the extrudate swell rapidly decreases by the increased take-up velocity, there might be "a certain amount of swelling persisting near the die exit," lowering the melt velocity at this region. ${ }^{26}$ This can increase the melt orientation because the actual $D R$ "expressed in terms of the velocity at the point of the film's maximum thickness" is higher than the conventional $D R$ based on the melt velocity at the die exit. $^{26}$

Based on experimental studies (Table I) and theoretical analyses (Tables II-V), the following material parameters and process variables have been identified to have a significant impact on the neck-in phenomenon: molecular weight $(M w)$, molecular weight distribution $(M W D)$, relaxation time $(\lambda)$, the ratio of the second and first normal stress difference at the die exit $\left(-N_{2} / N_{1}\right)$, long chain branching $(L C B)$, strain hardening in uniaxial extension $(S H$ in $\left.\eta_{E, U}\right)$, planar to uniaxial extensional viscosity ratio $\left(\eta_{E, P} / \eta_{E, U}\right)$, draw ratio $(D R)$, take-up length $(X)$, take-up rate $\left[v_{x}(X)\right]$, melt speed at the die exit $\left[v_{x}(0)\right]$, and temperature $(T)$. The role of each individual parameter in this phenomenon is summarized in Table VI. In order to clarify the reading of Table VI, let us provide here an example explaining its first line, which should be read as follows: In 1986, Dobroth and Erwin reported that the neck-in for LDPE increases if the draw ratio $(D R)$ [adjusted via the average polymer melt velocity at the die exit, $\left.v_{x}(X)\right]$ increases or if the take-up length $(X)$ increases.

As can be seen, the reduction of the neck-in can be achieved by increasing the polymer melt relaxation time $\lambda$ (via broadening 


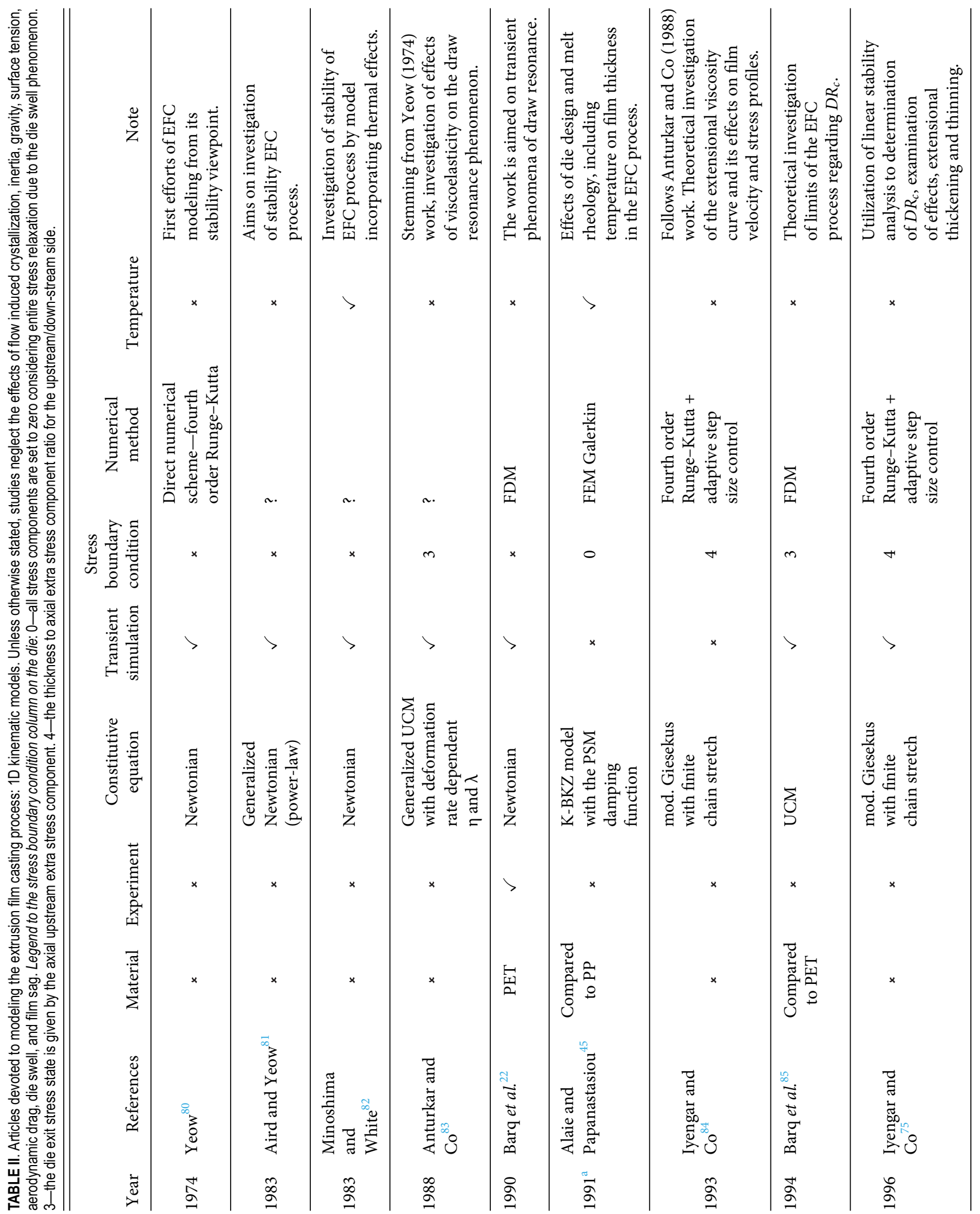




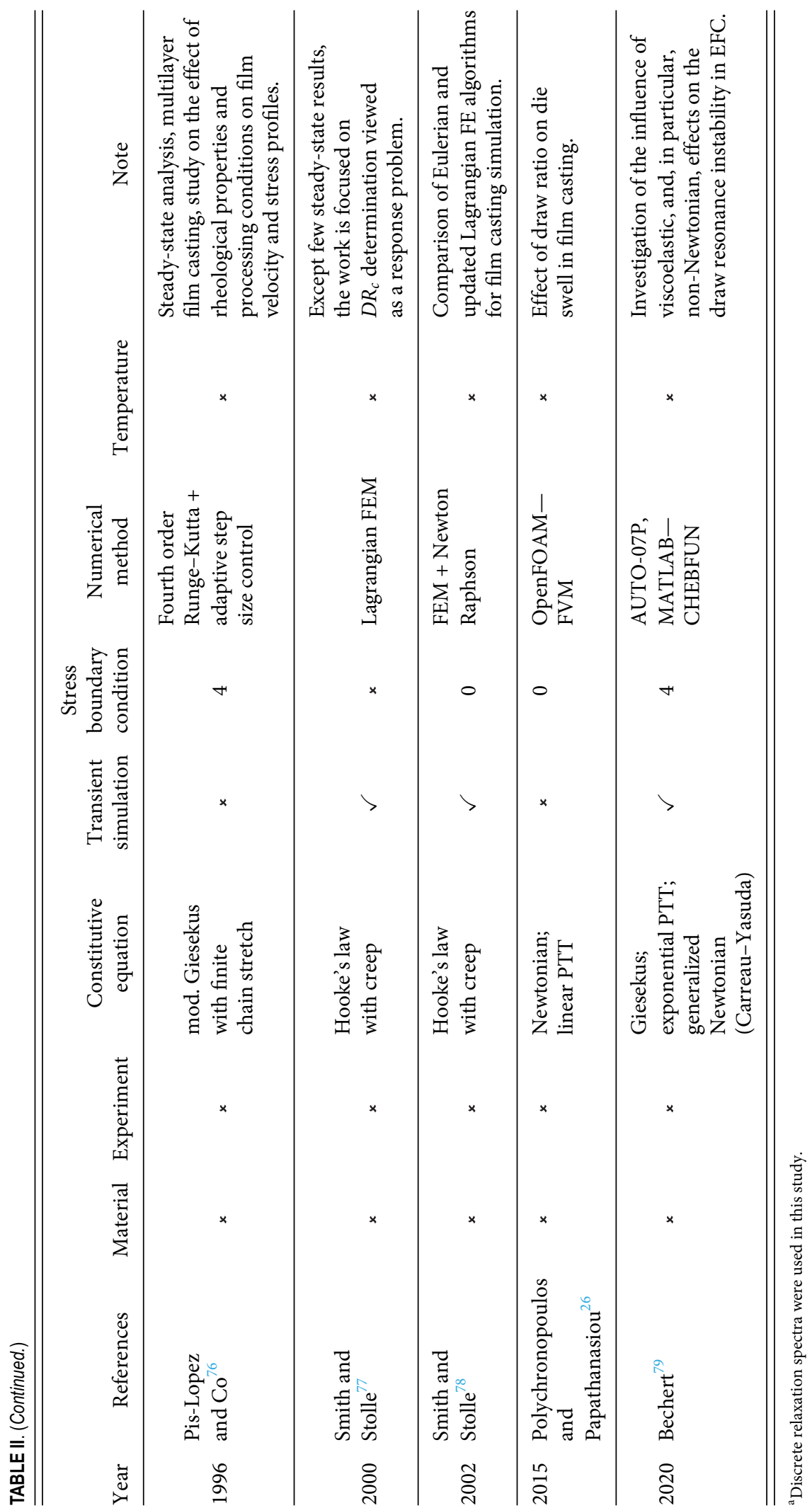




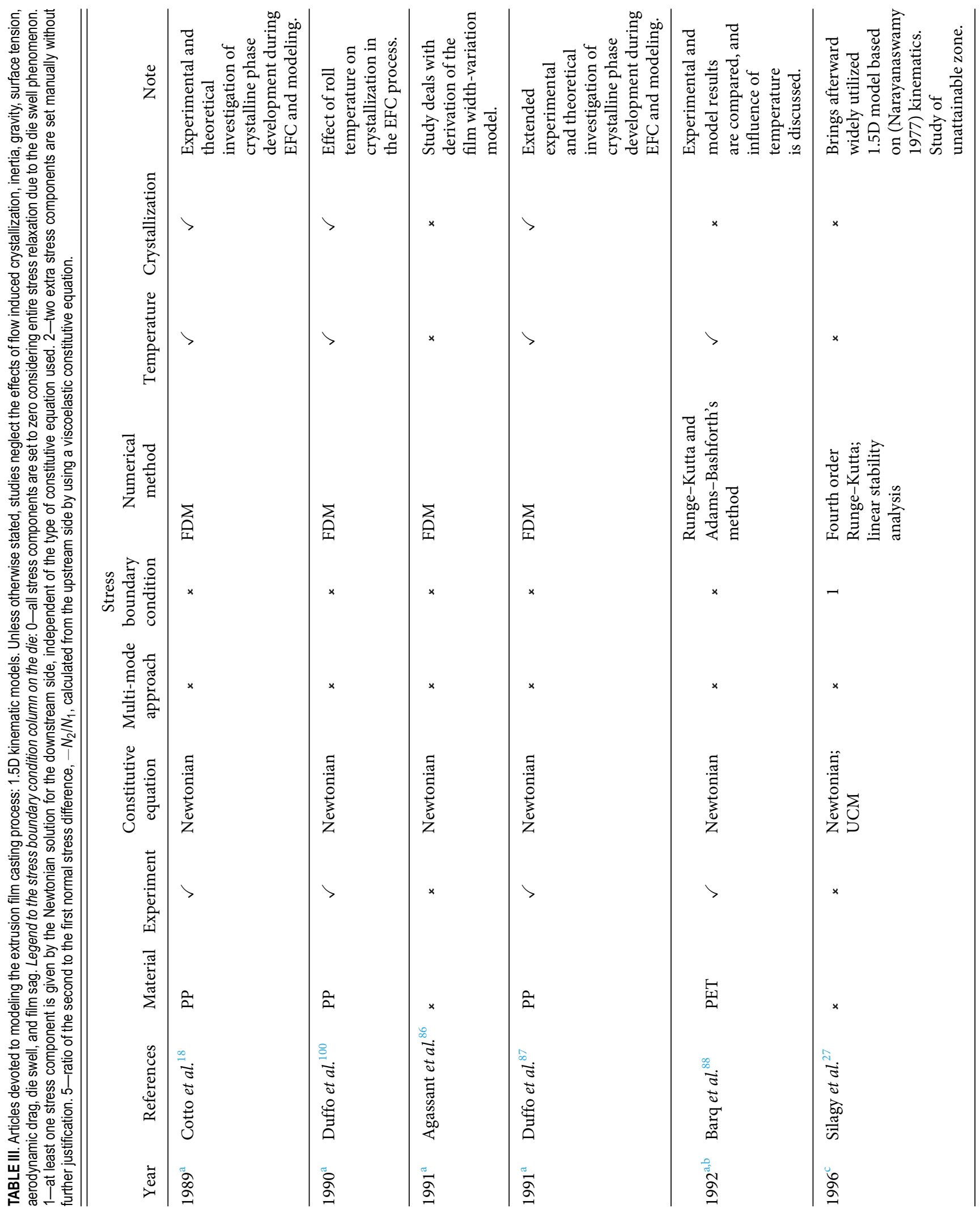




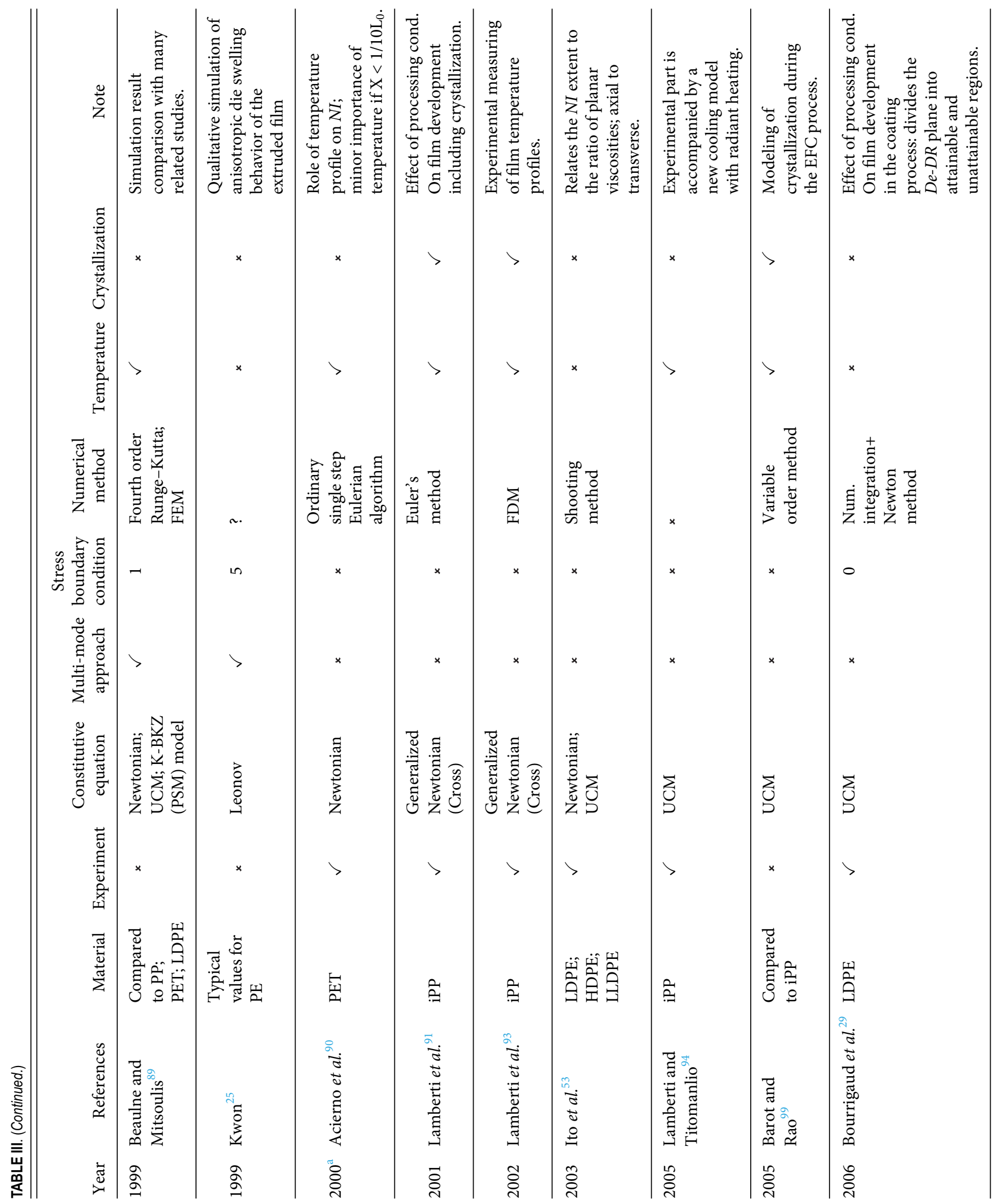




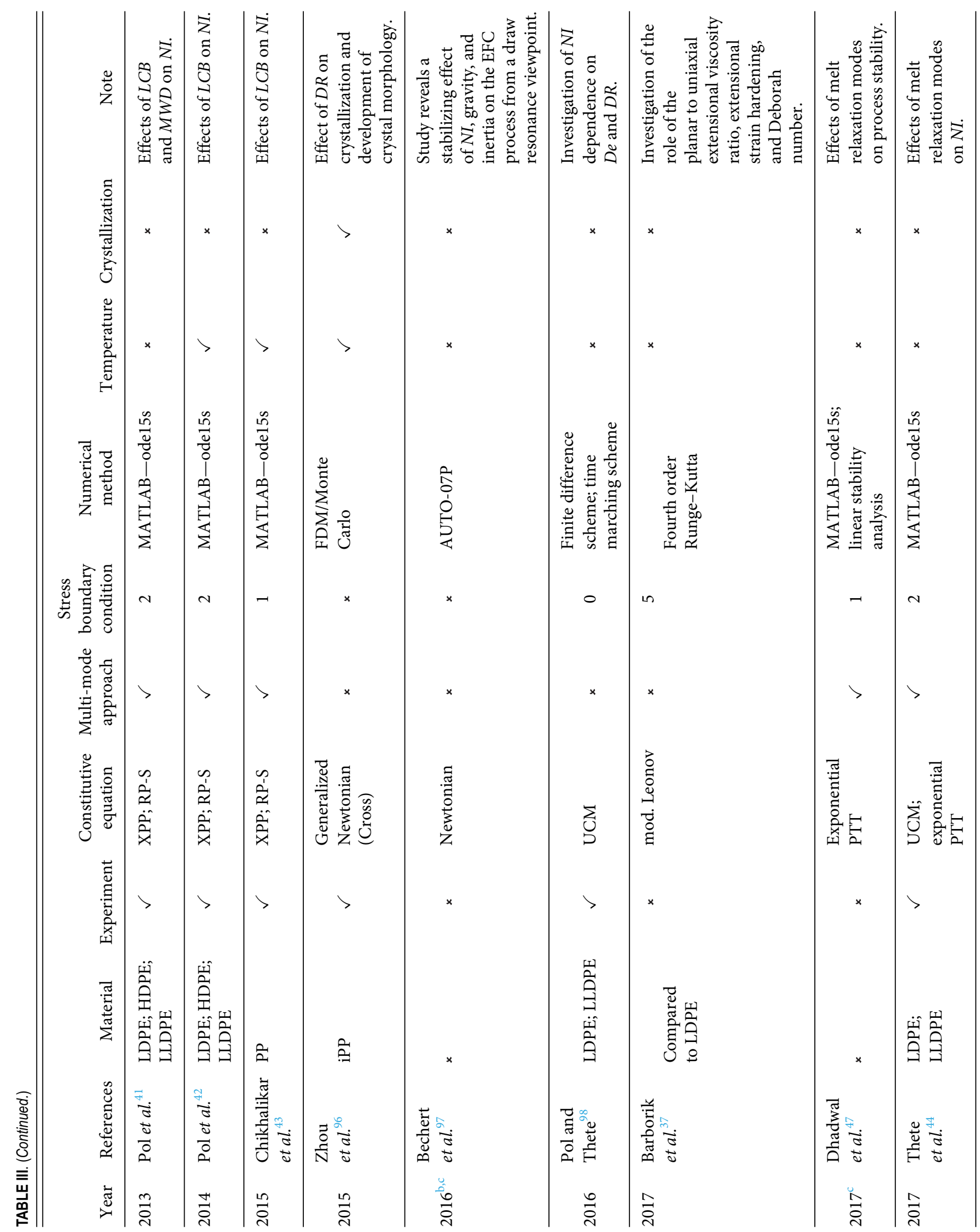




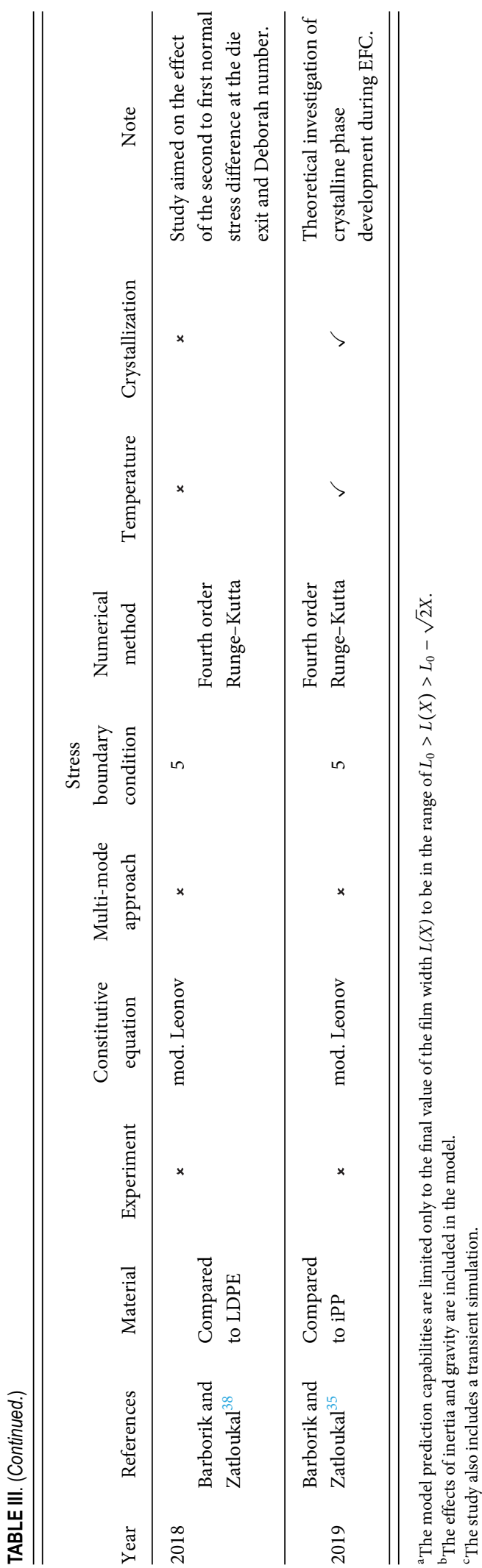

MWD and/or increasing $M w$ and/or decreasing $T$ ), increasing the melt speed at the die exit $v_{x}(0)$ (maintaining a constant $D R$ ), or reducing the air-gap (distance between die and roll), $X$. All these three variables determine the elasticity of the melt, which can be evaluated in terms of the Deborah number as

$$
\mathrm{De}=\frac{\lambda \mathrm{v}_{\mathrm{X}}(0)}{\mathrm{X}} .
$$

It is obvious that if the Deborah number (i.e., melt elasticity) increases, the neck-in decreases (although the stability of the process in terms of the maximum attainable draw ratio, $D R$, at which the film breaks may be lowered ${ }^{27-29}$ ). Thus, it is appropriate to maintain the level of elasticity reasonably high to minimize neck-in, which can be achieved by increasing the relaxation time and/or the melt speed at the die exit or by reducing the air-gap [see Eq. (1)]. The effect of relaxation time on the neck-in phenomenon determined experimentally for two linear low-density polyethylenes, LLDPEs, ${ }^{30}$ and two linear polypropylenes, PPs, ${ }^{31-34}$ is provided in Figs. 4 and 5. It is important to mention that a different definition of relaxation time can be found in the reviewed literature. In the studies based on single-mode constitutive equations, the utilized Maxwell relaxation time $\mathrm{e}^{27}$ and the shortest ${ }^{35}$ or characteristic relaxation time (determined by the reciprocal frequency at the intersection of the storage modulus $G^{\prime}$ and the loss modulus $G^{\prime \prime}$ curves $^{36}$ or by fitting the strain rate dependent steady uniaxial extensional viscosity data $^{37,38}$ ) are typically used to calculate $D e$. In the case of multi-mode constitutive equations, the relaxation time for each mode ${ }^{39-44}$ or an average relaxation time, $\bar{\lambda}$, is calculated to determine $D e$ by using the following expression: ${ }^{45-47}$

$$
\bar{\lambda}=\frac{\sum_{j=1}^{N} G_{j} \lambda_{j}^{2}}{\sum_{j=1}^{N} G_{j} \lambda_{j}},
$$

where $\lambda_{j}$ and $G_{j}$ are the relaxation time and the modulus, respectively, in the $j$-th relaxation mode. In addition, in some experimental studies, the longest relaxation time $\left(\lambda=\eta_{0} \mathrm{~J}_{\mathrm{E}}^{0}\right.$, where $\eta_{0}$ is the zeroshear viscosity and $J_{E}^{0}$ is the linear steady-state elastic compliance $)^{33}$ or the characteristic (reptation-mode) relaxation time representing the onset of shear-thinning ${ }^{30}$ is used.

The role of $D R$ in the neck-in is complex, depending whether the polymeric chains are linear or branched or if $D R$ is changed via $v_{x}(X)$ or $v_{x}(0)$. The current experimental studies showed that for linear polymers (i.e., for PP, PET, LLDPE, and HDPE), an increase in $D R$ [by an increase in $v_{x}(X)$ ] always increases the neckin, but for branched polymers (such as LDPEs), interestingly, the trend can even become opposite (see Table VI and Fig. 6). This unexpected trend was attributed to the strain-hardening behavior of LDPE in elongational flow. ${ }^{48}$ The situation also becomes complex, if $D R$ is increased by reduction in $v_{x}(0)$ [keeping the $v_{x}(X)$ constant]. It was reported for branched LDPE and linear PET that an increase in $D R$ [by a decrease in $v_{x}(0)$ ] reduces the neck-in, but for linear isotactic polypropylene (iPP), the trend was found to be surprisingly opposite for the given processing conditions. This unexpected trend for iPP was attributed to the increased crystallization rate, which caused quicker film solidification. 


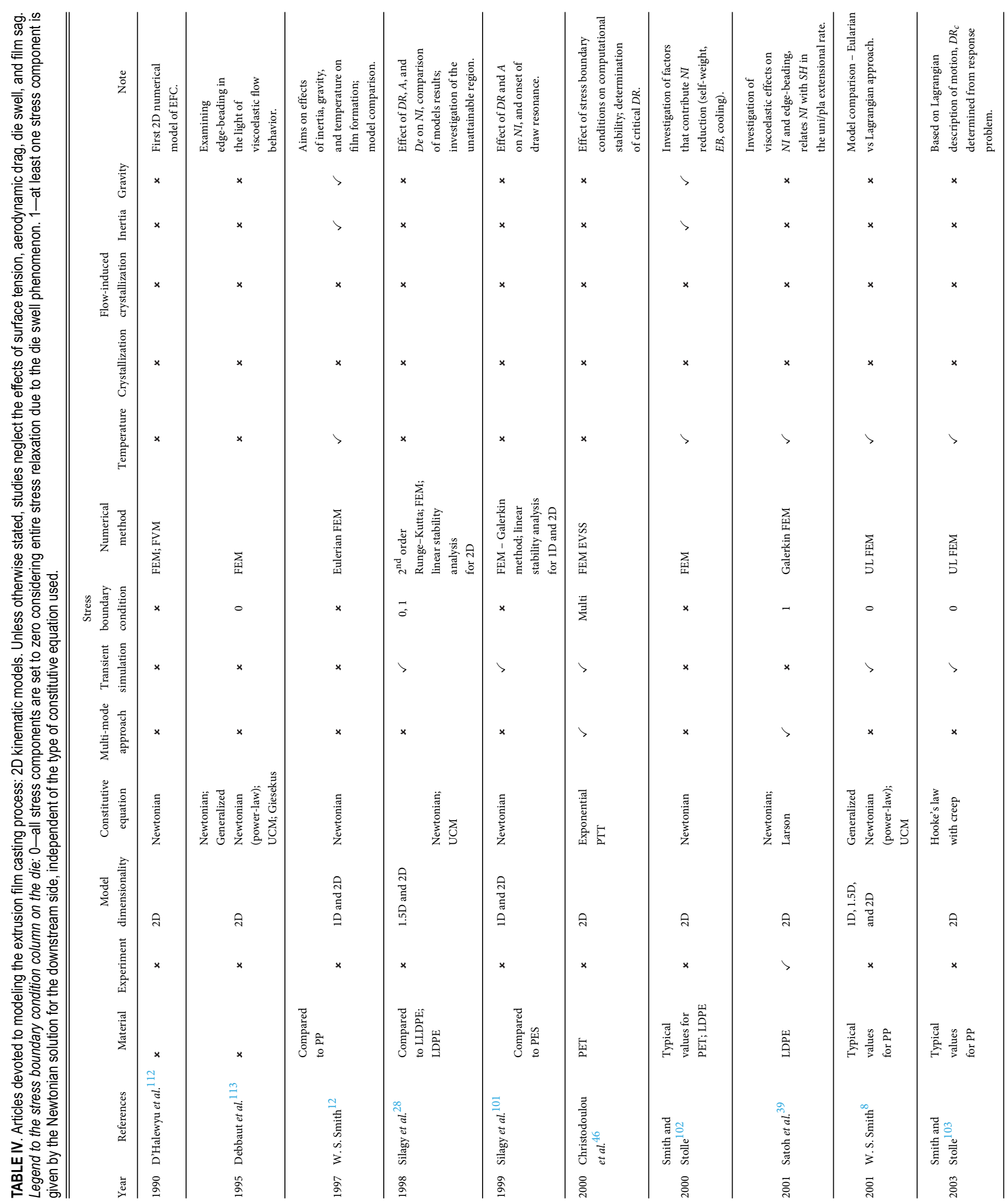




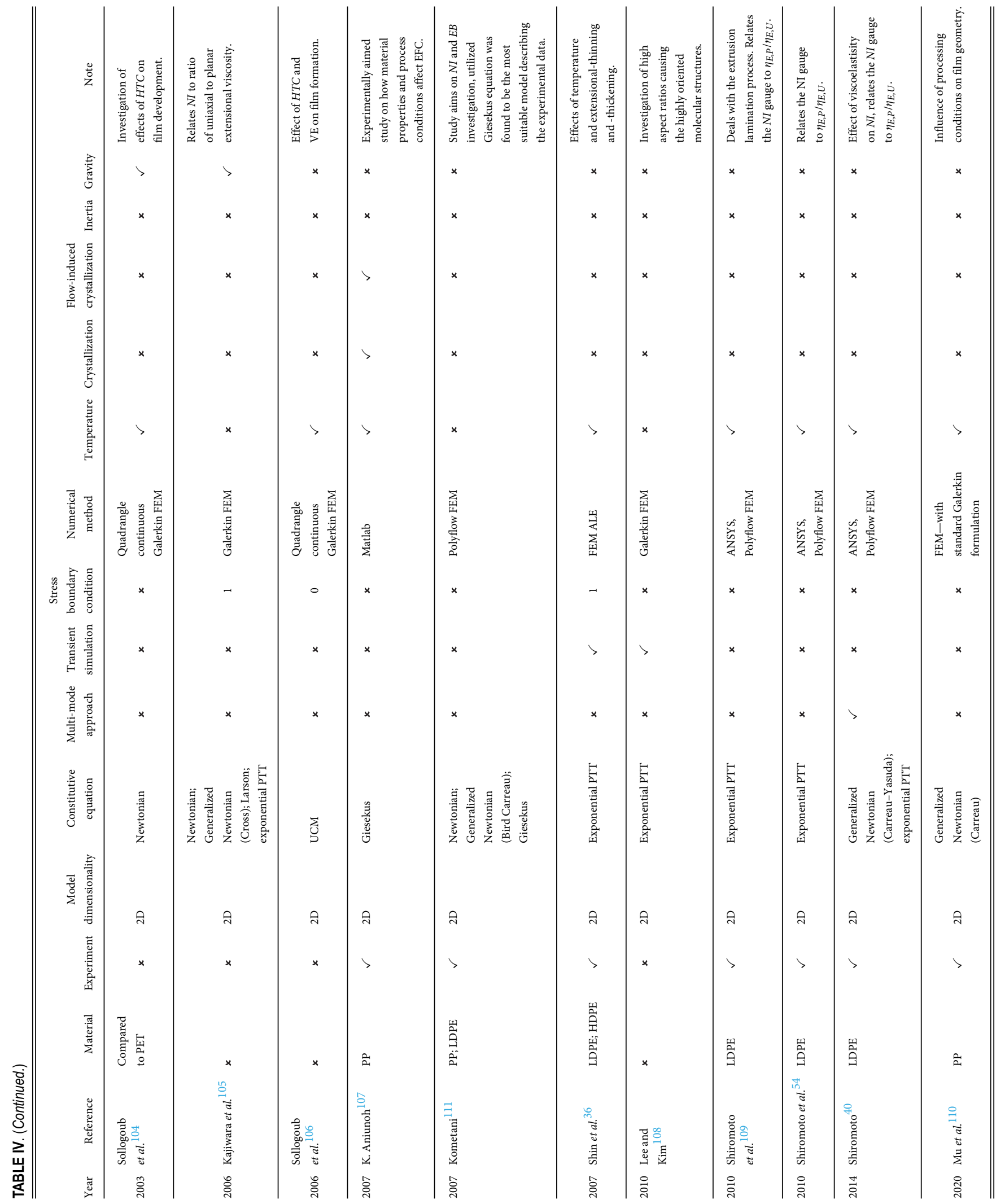


It was found that the introduction of strain hardening, $\mathrm{SH}$, in uniaxial extensional viscosity, $\eta_{E, U}$, by incorporating long chain branches into polymer backbone chains, reduces the neck-in phenomenon. This trend is illustrated in Fig. 7 for linear low-density polyethylene and highly branched low-density polyethylene. Seay and Baird ${ }^{30}$ revealed that the addition of sparse long chain branching $(L C B)$ to polymer chains, i.e., $S H$ in $\eta_{E, U}$, is more significant for film width conservation than broadening the molecular weight distribution $(M W D)$. In addition, they found that increasing $L C B$ of long and short chains reduced the neck-in at low and high draw ratios, respectively. This effect is sometimes used to improve the final width for films made from polymers prone to the neck-in (such as HDPE and LLDPE) using coextrusion technology in which the surface/edge portion of the film is made of a material having a long-chain branching (such as LDPE) and a core from a linear polymer. $^{49-51}$

Recent viscoelastic modeling of the extrusion film casting process, which followed the corresponding neck-in measurements, suggests that reduction in $\eta_{E, P} / \eta_{E, U}$ or $-N_{2} / N_{1}$ at the die exit (if De $>0.1$ ) can also reduce the neck-in phenomenon (see Table VI).

In order to understand the role of extensional rheology and the die exit stress state, it is necessary to discuss the mechanism and physical background of the neck-in in more detail. Ito et al., ${ }^{52}$ performed an experimental study on metallocene-catalyzed linear low-density polyethylene, mLLDPE, aimed to visualize the flow in the air-gap region during a film casting operation. They used small aluminum particles and made streamline measurements by using the particle tracking method. These particles were placed across the film width at the die exit (one particle for each measurement), and their movement was monitored by using a camera for different draw ratios $(\mathrm{DR}=4.4,7.5$, and 12.2). It has been found that streamlines at the film center are straight, regardless of the drawing intensity (i.e., there is planar extensional flow), whereas the streamlines at the near-edge region were found to be curved with a tapered transversal spacing in the flow direction confirming the presence of uniaxial extensional flow (see Fig. 8). Moreover, an increase in the draw ratio caused an increase in the streamlines tapering, which lead to a more pronounced neck-in phenomenon. Therefore, if $\eta_{E, U}$ increases due to $S H$ in such a way that $\eta_{E, P} / \eta_{E, U}$ is decreased (i.e., if the resistance against the uniaxial extensional flow becomes much higher than the resistance against the planar extensional flow), the polymer melt starts to prefer the planar extensional flow at the expense of the uniaxial elongation flow, and thus, the neck-in is decreased. Similarly, the reduction in $-N_{2} / N_{1}$ at the die exit physically means an induction of a planar prestretch inside the extrusion die (for example, by using converging instead of a parallel flow channel), which (if remembered by the melts, i.e., if $\mathrm{De}>0.1$ ) increases the dominance of the planar extensional flow in the post die area, and therefore, the neck-in is reduced.

In the industrial practice, it is useful to have a tool that can provide a reasonable evaluation of the neck-in for a particular polymeric material and processing conditions prior to film production itself, where its determination via a trial-and-error approach can be very expensive. It is therefore not surprising that considerable efforts have been made to relate the neck-in to the air-gap, extensional strain rate, and relaxation time ${ }^{53}$ [Eqs. (3) and (4)], both planar and uniaxial extensional viscosities ${ }^{54}$ [Eq. (5)], and to the strain 


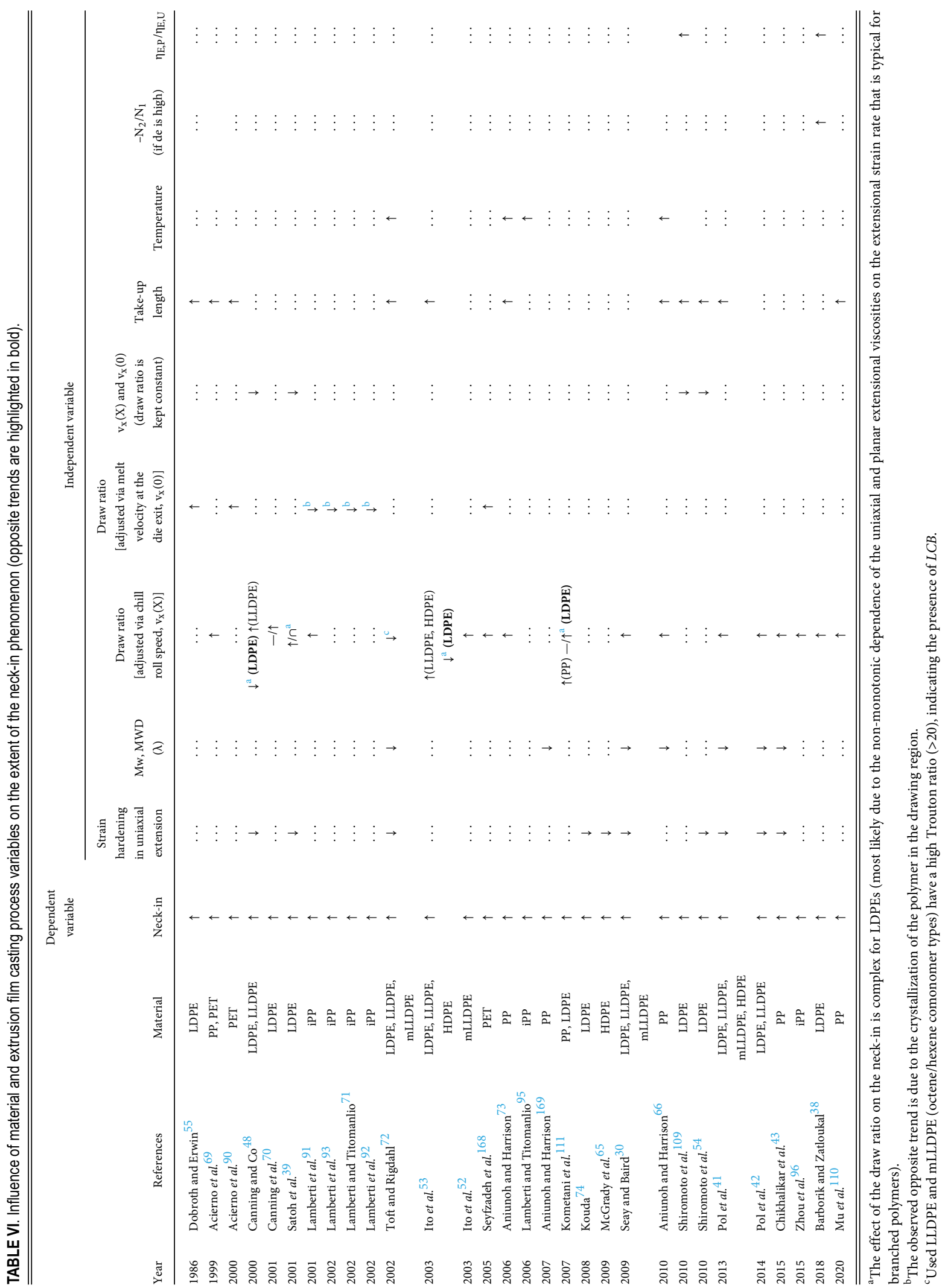




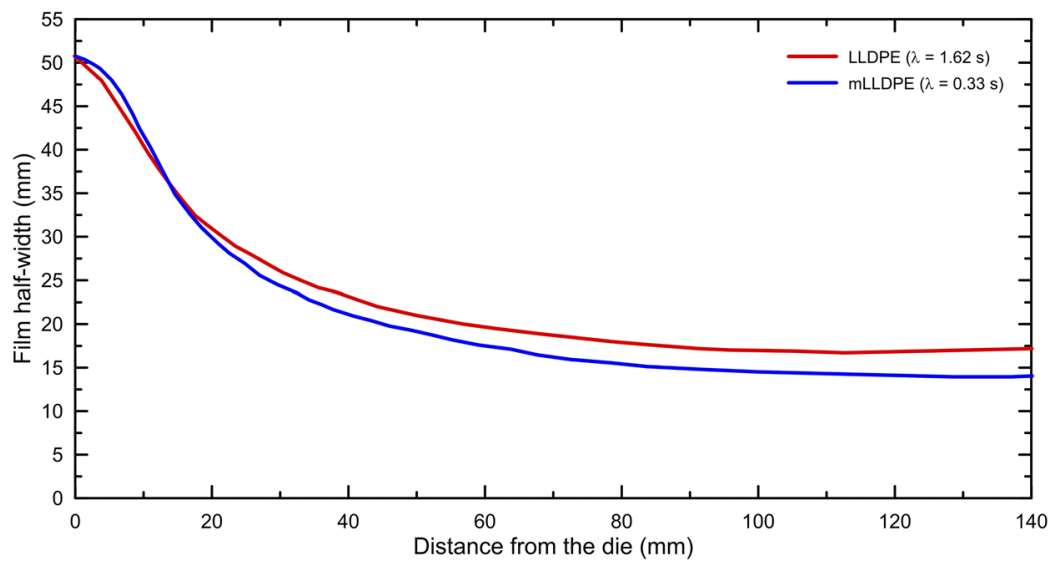

FIG. 4. Effect of Carreau relaxation time due to the increased MWD on the neck-in for linear metallocenecatalyzed low-density polyethylene (mLLDPE, $\lambda=0.33 \mathrm{~s}$ at $150^{\circ} \mathrm{C}, M w=110000 \mathrm{~g} / \mathrm{mol}, M w / M n=2.04, \mathrm{LCB} / 10000$ $C=0$ ) and Zieglar-Natta-catalyzed linear low-density polyethylene LLDPE $(\lambda=1.62 \mathrm{~s}, M w=122700 \mathrm{~g} / \mathrm{mol}$, $M w / M n=3.44, L C B / 10000 \mathrm{C}=0$ ). The process conditions for both samples were the following: die width was 101.6 $\mathrm{mm}$ and its gap size $0.57 \mathrm{~mm}$, the take-up length $141.4 \mathrm{~mm}$, the temperature $150^{\circ} \mathrm{C}$, the extrusion shear rate $8.62 \mathrm{~s}^{-1}$ and the drawdown ratio 15 . The flow direction is oriented left to right here. Selected and digitalized from Ref. 30 .

hardening, the ratio of planar to uniaxial extensional viscosity, the Deborah number, and the die exit stress state ${ }^{38}$ [Eq. (6)]. These simple analytical models are easy to use and have the advantage to gain a correlation between the particular model variables with the naked eye in order to identify key process and material parameters to optimize them for neck-in reduction. In more detail, Ito et al. ${ }^{53}$ in 2003 developed a model based on the Dobroth-Erwin model, ${ }^{55}$ which assumes a planar extensional flow in the middle of the film and a uniaxial extensional flow at the edge. According to their theory, the final film width is determined by the ratio of planar viscosities in the axial and transverse directions with respect to the flow. The proposed

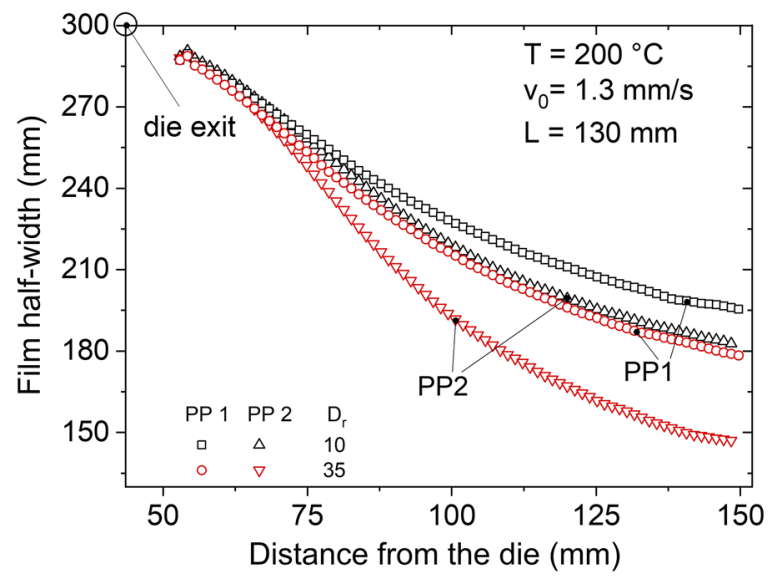

FIG. 5. Effect of the longest relaxation time (i.e., $\lambda=\eta_{0} \mathrm{~J}_{\mathrm{E}}^{0}$, where $J_{E}^{0}$ is the linear steady-state elastic compliance) due to the increased molecular weight on the neck-in for linear polypropylenes PP1 $\left(\lambda=15.5 \mathrm{~s}\right.$ at $230^{\circ} \mathrm{C}, M w=527000 \mathrm{~g} / \mathrm{mol}$, $M w / M n=5.3)$ and PP2 $\left(\lambda=4.2 \mathrm{~s}\right.$ at $\left.230^{\circ} \mathrm{C}, M w=359000 \mathrm{~g} / \mathrm{mol}, M w / M n=6.9\right)$ at two draw down ratios (10 and 35). The process conditions for both samples were as follows: the velocity at the die exit was $1.3 \mathrm{~mm} / \mathrm{s}$, the take-up length was 130 $\mathrm{mm}$, the temperature was $200^{\circ} \mathrm{C} .{ }^{31-34}$ Here, the flow direction is oriented from left to right. Reproduced with the permission from $\mathrm{H}$. Münstedt, "Elastic behavior and processing of polymer melts," AIP Conf. Proc. 2107, 030001 (2019). Copyright 2019 AIP Publishing LLC.

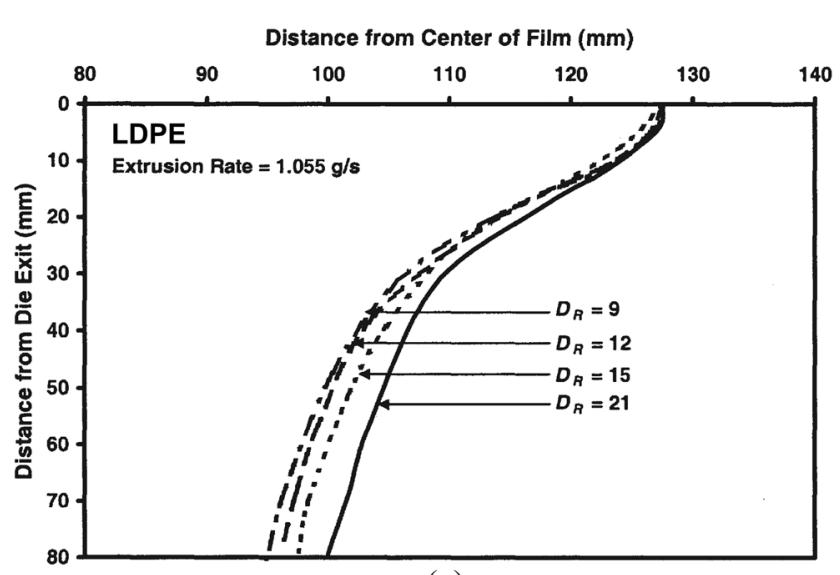

(a)

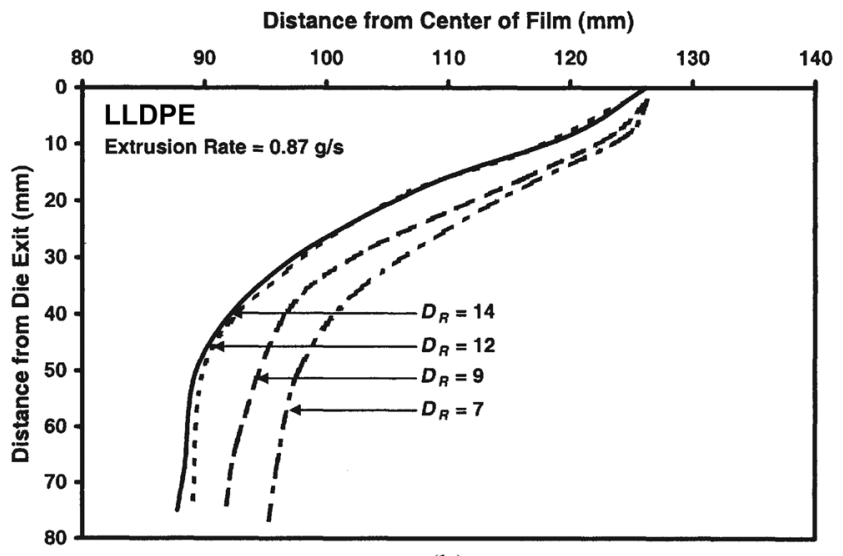

(b)

FIG. 6. Effect of long chain branching on the neck-in development at different draw ratios, experimental data: (a) LDPE with LCB and (b) LLDPE without LCB. The process conditions for both samples were the following: the die width was $254 \mathrm{~mm}$ and the temperature $240^{\circ} \mathrm{C}$. Here, the flow direction is oriented from top to bottom. Reproduced with permission from K. Canning and A. Co, "Edge effects in film casting of molten polymers," J. Plast. Film Sheeting 16(3), 188 (2000). Copyright 2000 SAGE Publications. 
relationship for the neck-in, NI, considering that the polymer melt behaves as a Newtonian fluid, is as follows:

$$
\mathrm{NI}=\sqrt{\frac{1}{2}} \mathrm{X}
$$

where the air-gap, $X$, is the only variable (i.e., draw ratio, deformation rate, relaxation time, or viscosity are not included). The model was tested using experimental data for linear HDPE, short chain branched LLDPE, and long chain branched LDPE melts expressed as the neck-in plotted against the air-gap at four different draw ratios. The model was shown to correctly predict the general trend between $N I$ and $X$, i.e., an increase in $X$ causes an increase in $N I$, and the predicted slope of the theoretical line was close to the experimental data for HDPE and LLDPE at short air-gap values and the highest draw ratios at given processing conditions. On the other hand, the model tended to overpredict NI (especially for LDPE) without the ability to predict the effect of draw ratio on NI, as expected due to the absence of deformation rate and any rheological parameters in Eq. (3). If the upper convected Maxwell model is used, the expression for NI yields the following form:

$$
\mathrm{NI}=\sqrt{\frac{1}{2}\left(1-2 \dot{\varepsilon}_{\mathrm{p}} \lambda\right) \mathrm{X}},
$$

where $\dot{\varepsilon}_{p}$ denotes the extensional strain rate of the planar part defined as $\dot{\varepsilon}_{p}=d \varepsilon_{p}(t) / d t$ ( $\varepsilon_{p}$ is the Hencky strain of the planar deformation) and $\lambda$ is the characteristic relaxation time. Although the neck-in trend predictions are consistent with the observations with respect to the melt elasticity or the air-gap, the model unrealistically predicts a neck-in decrease for the increased draw-down ratio, which was attributed to the used constitutive equation. Further works have moved further and tried to predict neck-in based on uniaxial and planar extensional viscosities. Shiromoto et al. ${ }^{54}$ in 2010 developed a theoretical model based on the force balance and film deformation in the post die area. The authors found that NI can be correlated with the planar to uniaxial extensional viscosity ratio rather than with the strain hardening in uniaxial extension or with the ratio of planar viscosities. These findings were transformed into the following expression for $N I$ :

$$
\mathrm{NI} \cong \mathrm{X}\left(\frac{\eta_{\mathrm{E}, \mathrm{P}}}{\eta_{\mathrm{E}, \mathrm{U}}}\right)^{0.5},
$$

where $\eta_{E, P}$ and $\eta_{E, U}$ denotes planar and uniaxial extensional viscosity. Equation (5) was validated using relevant experimental data for three long chain branched LDPEs having different $M w$ and $M W D$. The ratio $\eta_{E, P} / \eta_{E, U}$ was determined for all three samples using the multi-mode exponential type of the Phan-Thien and Tanner constitutive model, utilizing parameters identified on the experimental data obtained from rotational and capillary rheometers. $\eta_{E, U}$ at low deformation rates and high extensional rates was determined with a Meissner-type rheometer (ARES-EVF, TA Instruments) and the Cogswell method, ${ }^{56}$ respectively. The key limitation of Eq. (5) is the absence of variables allowing us to evaluate the role of the Deborah number and the die exit stress state in NI. Barborik and Zatloukal $^{37,38}$ continued the research of the neck-in phenomenon in the period 2017-2018 with respect to the ratio of the second and first normal stress difference at the die exit, $-N_{2} / N_{1}$, uniaxial extensional strain hardening, $\eta_{E, U, \max } / 3 \eta_{0}$, melt elasticity (captured via the Deborah number, $D e$ ), and the ratio of planar-to-uniaxial extensional viscosity, $\eta_{E, P} / \eta_{E, U}$. Using an isothermal 1.5-dimensional (1.5D) membrane model and viscoelastic modified Leonov constitutive equation, the following expression for maximum attainable neck-in was proposed:

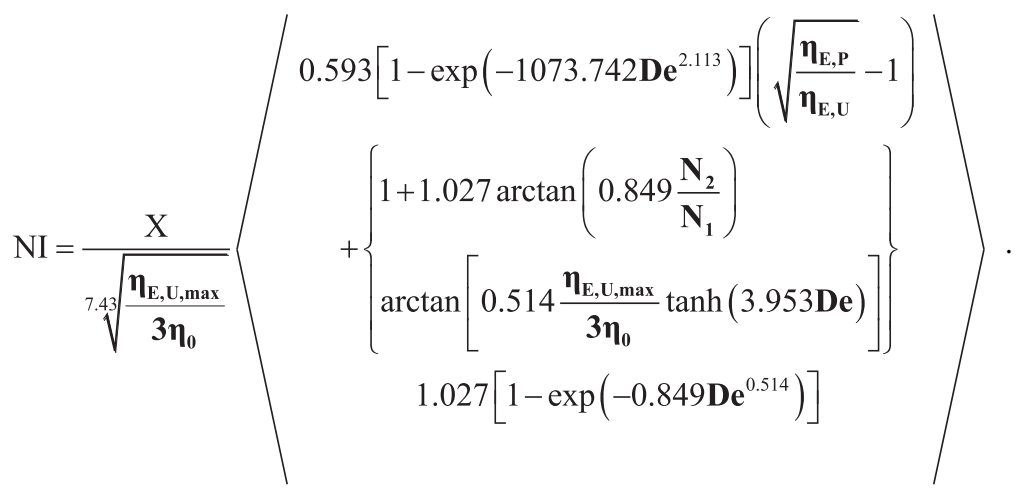

The predictions of the model were found to be in good agreement with the corresponding experimental data ${ }^{38}$ (see Fig. 9) capturing all the trends obtained numerically, i.e., $N I$ is reduced if

- $-N_{2} / N_{1}$ at the die exit decreases (i.e., for an increased planar pre-stretch of the melt inside the extrusion die),

- De increases,
- $\eta_{E, P} / \eta_{E, U}$ decreases, and

- $\eta_{E, U, \max } / 3 \eta_{0}$ increases.

It has also been revealed that there is a threshold of about 0.1 for $D e$ above which the neck-in phenomenon starts to be strongly dependent on the $-N_{2} / N_{1}$ ratio at the die exit. In other words, if De $>0.1$, the flow history inside the die (i.e., the die design) starts to 


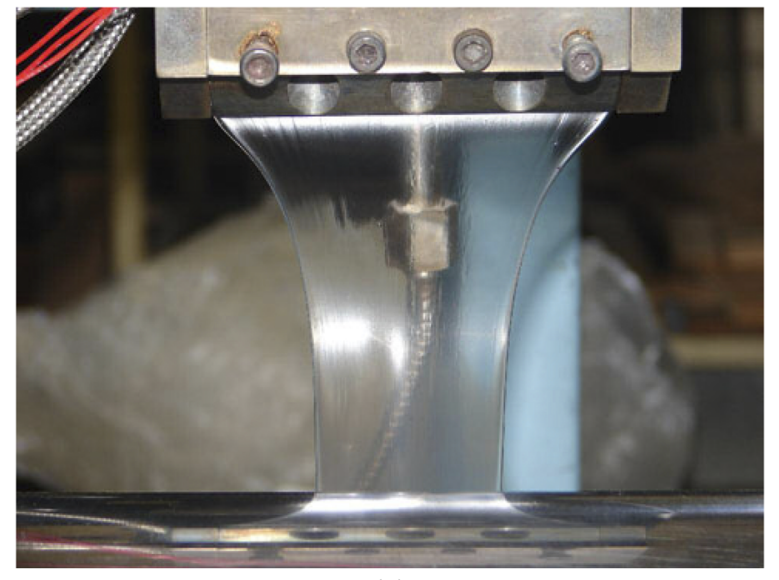

(a)

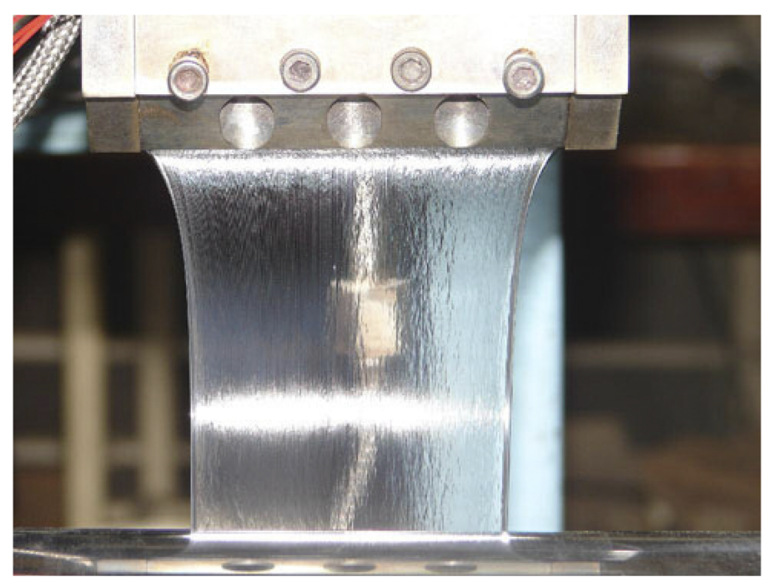

(b)

FIG. 7. Effect of the increased long chain branching on the neck-in: (a) linear metallocene-catalyzed low-density polyethylene (mLLDPE) and (b) highly branched low-density polyethylene (LDPE). The process conditions for both samples were as follows: the die width was $101.6 \mathrm{~mm}$ and its gap size $0.57 \mathrm{~mm}$, the take-up length $141.4 \mathrm{~mm}$, the temperature $150^{\circ} \mathrm{C}$, the extrusion shear rate $1.33 \mathrm{~s}^{-1}$, and the drawdown ratio 10. Here, the flow direction is oriented from top to bottom. Courtesy of Donald G. Baird for his permission to reprint this figure from Ref. 171.

significantly affect the neck-in phenomenon. It is important to mention that Eq. (6) represents an analytical approximation of numerical solutions based on an isothermal (1.5D) membrane model utilizing the modified Leonov constitutive equation (single mode) for the processing conditions in which the maximum attainable neckin is achieved (i.e., for very high draw ratios only), where 0.011 $\leq \mathrm{De} \leq 0.253,0.825 \leq \frac{\eta_{\mathrm{E}, \mathrm{P}}}{\eta_{\mathrm{E}, \mathrm{U}}} \leq 1.910,2.047 \leq \frac{\eta_{\mathrm{E}, \mathrm{U} \text { max }}}{3 \eta_{\mathrm{O}}} \leq 10.096$, and $0.017 \leq-\frac{N_{2}}{N_{1}} \leq 0.680$. The basic form of Eq. (6) has been derived from the assumed linear function between $N I$ and $\sqrt{\eta_{E, P} / \eta_{E, U}}$ in which its constants were allowed to vary with $D e$ according to the Avrami exponential functions. Detailed derivation of Eq. (6) is provided in Refs. 37 and 38. Validation of Eq. (6) was performed for different highly branched LDPEs. All rheological quantities

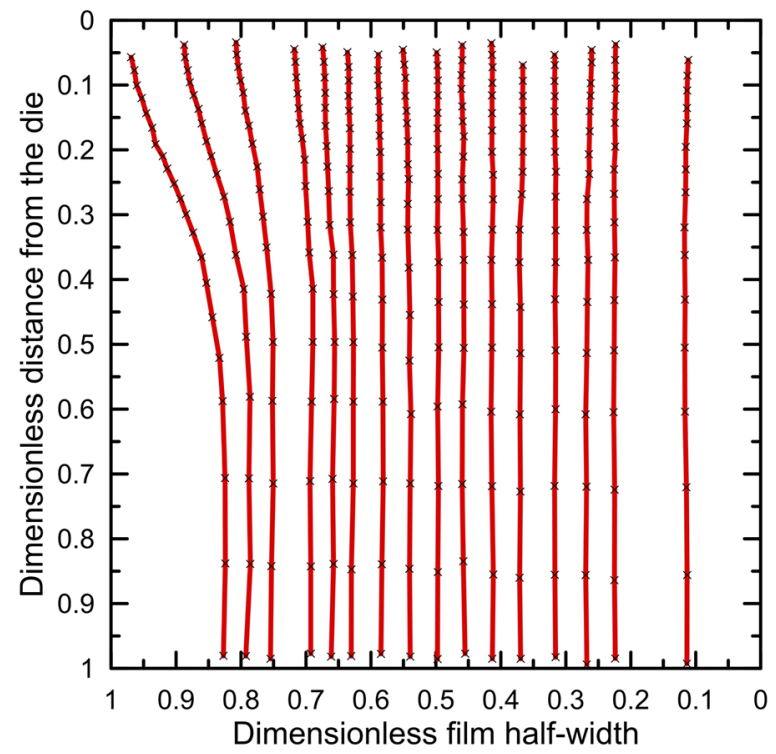

$\mathrm{DR}=4.4$

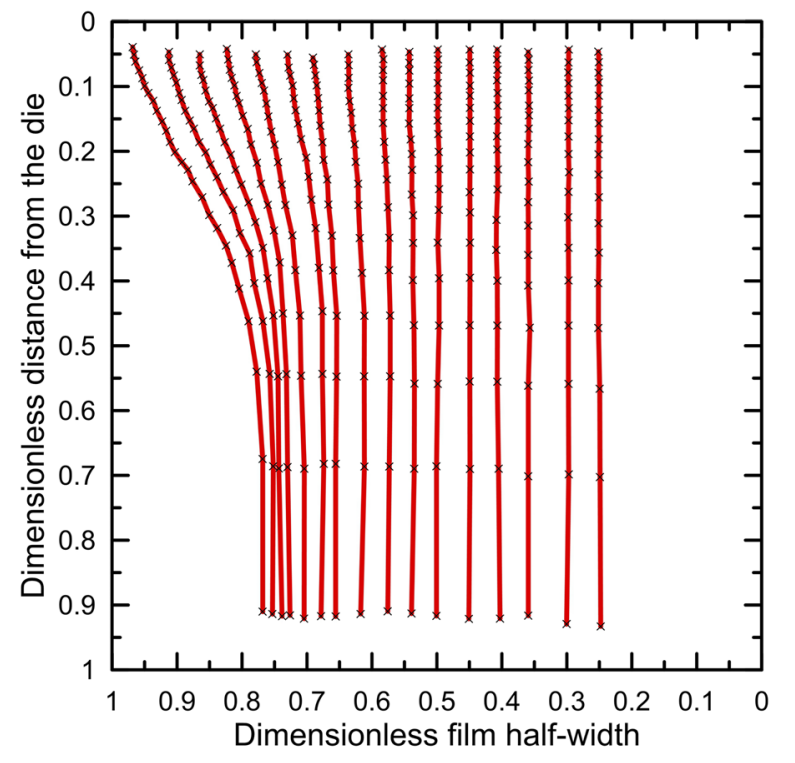

DR = 12.2

FIG. 8. Visualization of the polymer flow field in the air-gap during film casting of linear metallocene-catalyzed low-density polyethylene (mLLDPE, Mw $=57200$ $\mathrm{g} / \mathrm{mol}, \mathrm{Mw} / \mathrm{Mn}=2.26$ ) in which the flow direction is from top to bottom. The process conditions were as follows: the velocity at the die exit was $10.7 \mathrm{~mm} / \mathrm{s}$, the take-up length equal to $150 \mathrm{~mm}$, and the temperature $190^{\circ} \mathrm{C}$. Selected and digitalized from Ref. 52.

appearing in Eq. (6) were predicted by the single-mode modified Leonov model whose parameters were identified from uniaxial extensional viscosity data only. This procedure seems to be reasonable at least for the given LDPEs and applied processing 


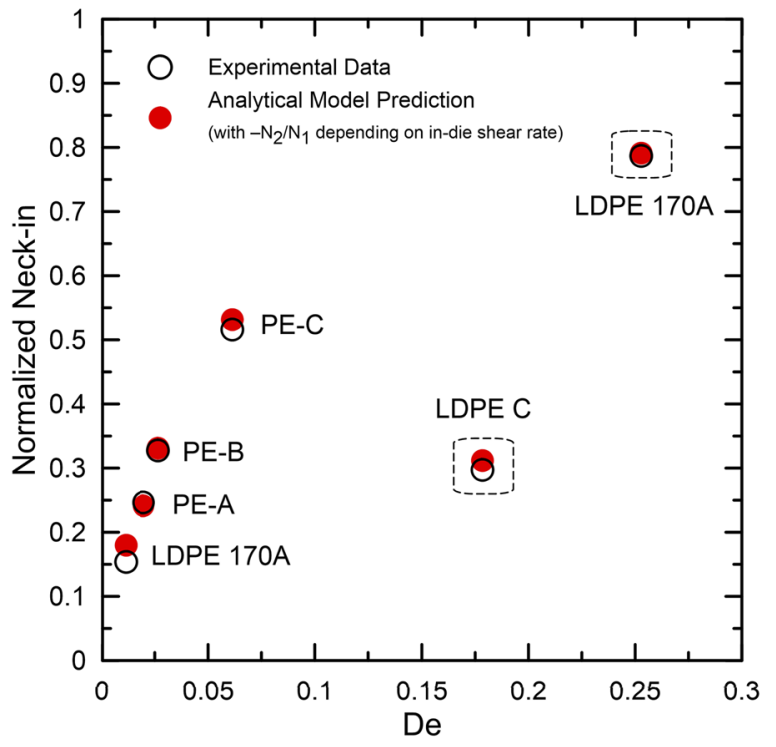

FIG. 9. Maximum attainable normalized neck-in (i.e., NI/X) for different LDPEs. Experimental data and proposed analytical model predictions [Eq. (6)] are presented here with open and filled symbols, respectively. Reproduced with permission from T. Barborik and M. Zatloukal, "Effect of die exit stress state, Deborah number, uniaxial and planar extensional rheology on the neck-in phenomenon in polymeric flat film production," J. Non-Newtonian Fluid Mech. 255, 39 (2018). Copyright 2018 Elsevier.

conditions. In order to experimentally evaluate $\eta_{E, P} / \eta_{E, U}$, one could use the Cogswell model and measured entrance pressure drops on a capillary rheometer by using circular and rectangle capillaries, ${ }^{57,58}$ whereas $-N_{2} / N_{1}$ can be evaluated using Han's methods utilizing exit pressure drop measures by using a capillary rheometer equipped by a slit die. ${ }^{59-64}$ The key advantage of Eq. (6) in contrast to Eqs. (3)(5) is a consideration of uniaxial and planar extensional viscosities along with the Deborah number and die exit stress state (quantified via $-N_{2} / N_{1}$ ). On the other hand, the model is only applicable to very high draw ratios and does not take into account the full relaxation spectrum, film cooling, and crystallization, which can be considered as its key limitations.

\section{B. Edge-beading}

In addition to the neck-in phenomenon, an interrelated defect, referred to as the edge-beading or the dog-bone defect, is formed making the edge portions of the film substantially thicker than its central part (Fig. 10). The size of these raised parts can be five times higher compared to the center and several centimeters wide. The predominant cause of the edge-bead formation is the edge-stress effect $^{55}$ arising due to the neck-in phenomenon, and its intensity increases with the draw ratio (see Fig. 11). The following equation was derived in Ref. 55 to evaluate the edge-beading:

$$
\frac{\mathrm{h}_{\mathrm{f}}^{\text {edge }}}{\mathrm{h}_{\mathrm{f}}^{\text {center }}}=\mathrm{B}=\sqrt{\mathrm{DR}},
$$

where $B$ is the bead ratio and $h_{f}^{\text {edge }}$ and $h_{f}^{\text {center }}$ represent edge and center final thickness, respectively. This equation was derived by simply comparing the strains of the center (undergoing planar stretch) and edge (undergoing uniaxial stretch) elements between the roll and the die neglecting surface tension, extrudate swell, and assuming melt incompressibility (i.e., without the need to use any constitutive equation). Equation (7) was successfully validated for LDPE for DR between 1 and $20^{55}$ (see Fig. 12). It has also been shown (when comparing simulations based on the Newtonian and UCM models) that increasing the melt elasticity (by increasing the Deborah number) decreases the intensity of the edge-beading.

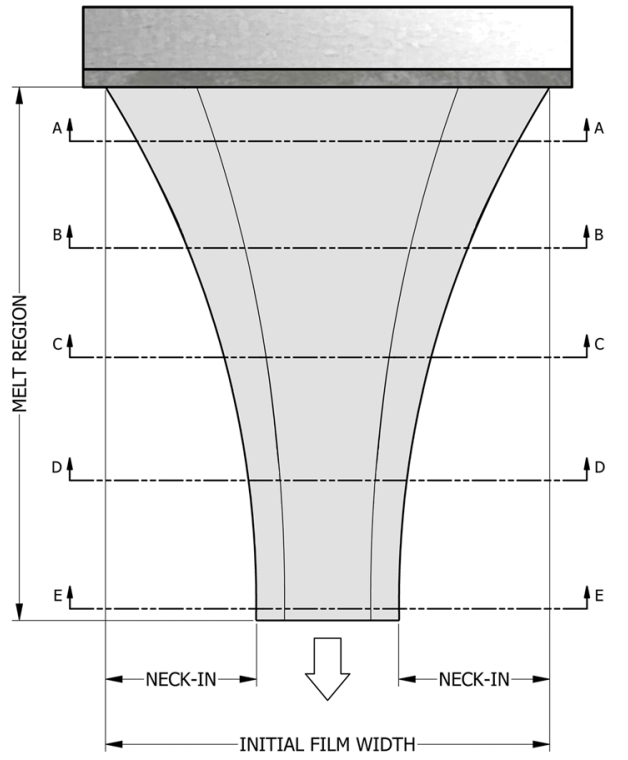

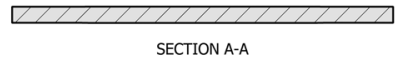

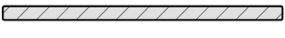

SECTION B-B
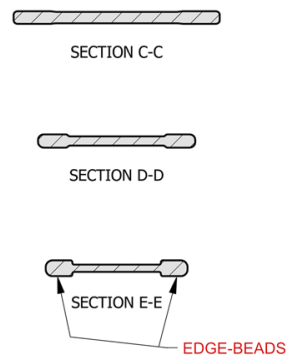

FIG. 10. Schematic illustration of the extrusion film casting process with the indicated film cross-sectional development (formation of edge-beads) in the air-gap. The curves within the film represent the borders between the planar extensional flow (center area) and the uniaxial extensional flow (edge areas). 


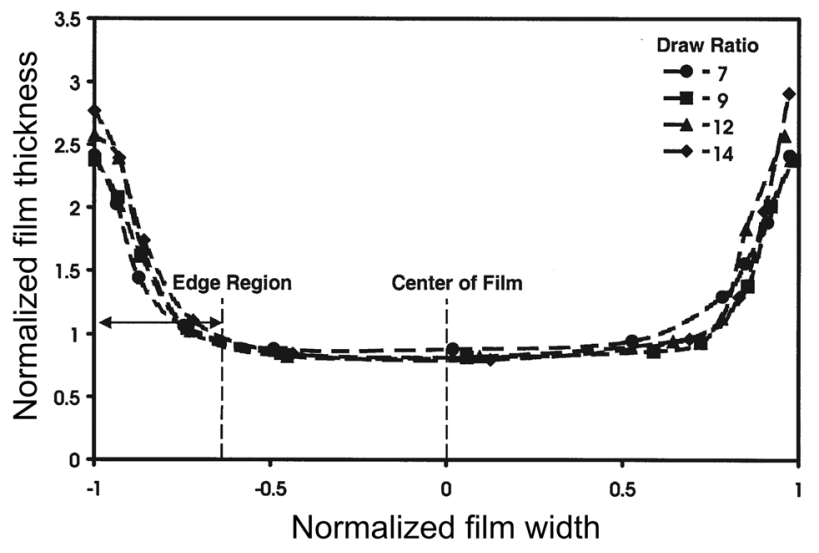

FIG. 11. Evolution of edge-beading at different draw ratios, experimental data for LLDPE without LCB [corresponding film width profiles are provided in Fig. 6(b)]. Process conditions were the following: the die width was $254 \mathrm{~mm}$ and the temperature $240^{\circ} \mathrm{C}$. Reproduced with permission from K. Canning and A. Co, "Edge effects in film casting of molten polymers," J. Plast. Film Sheeting 16(3), 188 (2000). Copyright 2000 SAGE Publications.

The raised edges are often trimmed with a slit razer, scrapped, and optionally reprocessed to achieve a uniform film surface. Regardless of the large amount of waste material, the occurrence of edge-beads also causes air entrapment between the film and the chill roll, which, in turn, results in poorer film quality. In the manufacturing practice, a technological procedure of opening lateral parts of the extrusion slit die (i.e., the gap size at the edge is bigger than in the center) can be found in order to create thicker edges that would restrain the neck-in level in comparison to the situations when the edge-beads and the neck-in would evolved in the natural way. ${ }^{1}$

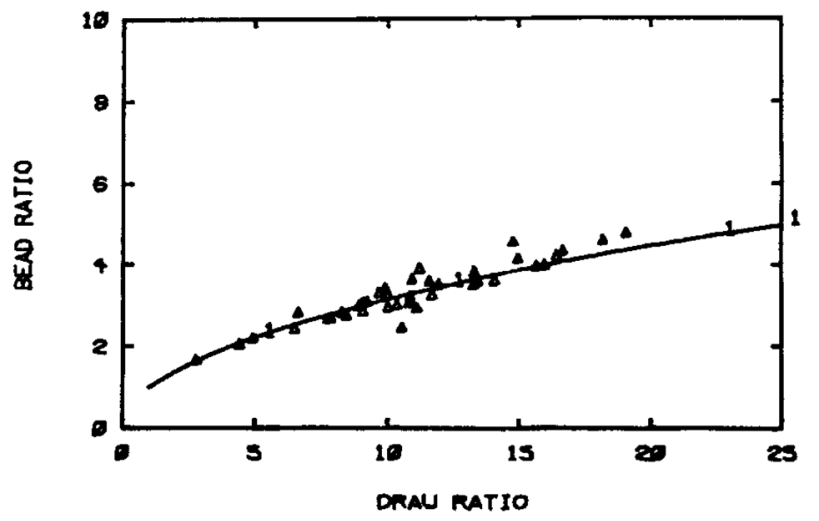

FIG. 12. Bead ratio as a function of DR for LDPE at $177^{\circ} \mathrm{C}$. The symbols represent experimental data, while the line represents the theoretical value predicted by Eq. (7). Reproduced with permission from T. Dobroth and L. Erwin, "Causes of edge beads in cast films," Polym. Eng. Sci. 26(7), 462 (1986). Copyright 1986 John Wiley and Sons.

\section{MATHEMATICAL MODELING OF THE EXTRUSION FILM CASTING PROCESS}

The drawing of polymer films or filaments has taken an enormous amount of attention and has been extensively studied both experimentally and theoretically in the past four decades because of its great importance in the polymer processing industry.

\section{A. Flow kinematics}

Individual research groups focused on experimental works $^{30,48,52,55,65-74}$ dealing with flow visualization, effects of temperature, crystallization, molecular weight distribution, or long chain branching on kinetics of the film casting process (see Table I). Theoretical research has not disappeared, and attention has been drawn to the development and use of numerical models (primarily considering steady-state conditions) of different dimensionalities such as $1 \mathrm{D},{ }^{22,25,26,45,75-85} 1.5 \mathrm{D},{ }^{18,27,29,35,37,38,41-44,47,53,86-100}$ $2 \mathrm{D},{ }^{8,12,28,36,39,40,46,54,101-113}$ and full $3 \mathrm{D}^{114-116}$ (see Tables II-V) using different types of constitutive equations taking into account nonisothermal effects, crystallization, inertia, and gravity. The 1D model here is based on the assumption of an infinite film width and assumes the following velocity field:

$$
\begin{gathered}
\mathrm{v}_{\mathrm{x}}=\mathrm{v}_{\mathrm{x}}(\mathrm{x}), \\
\mathrm{v}_{\mathrm{y}}=0, \\
\mathrm{v}_{\mathrm{z}}=-\mathrm{z} \frac{\partial \mathrm{v}_{\mathrm{x}}}{\partial \mathrm{x}},
\end{gathered}
$$

that is, the flow deformation in the drawing region is planar. ${ }^{52,55}$ The $1.5 \mathrm{D}$ model is simply the $1 \mathrm{D}$ model with variable film width proposed in Refs. 27 and 28. This simplified model, which retains the ability to cover the reduction in film width in the drawing length while reducing the dimensionality of the solved problem, is based on the assumption that all velocity components are an exclusive function of the drawing length position, $x$, and vary linearly with respect to its corresponding direction. In this case, a velocity field is assumed in the form of

$$
\begin{aligned}
v_{x} & =v_{x}(x), \\
v_{y} & =y f(x), \\
v_{z} & =-z g(x) .
\end{aligned}
$$

The 2D approximation developed in Refs. 112 and 113 is based on the so-called membrane hypothesis considering that one dimension of the film is small compared to the others. ${ }^{112}$ The film thickness is much smaller (several orders of magnitude) than the film width and the take-up length, so it can be assumed that the velocity component in the machine and the transversal direction are independent of the thickness direction, i.e., uniform across the thickness. The reduced velocity field is given in the following form:

$$
\begin{gathered}
\mathrm{v}_{\mathrm{x}}=\mathrm{v}_{\mathrm{x}}(\mathrm{x}, \mathrm{y}), \\
\mathrm{v}_{\mathrm{y}}=\mathrm{v}_{\mathrm{y}}(\mathrm{x}, \mathrm{y}), \\
\mathrm{v}_{\mathrm{z}}=-\mathrm{z}\left(\frac{\partial \mathrm{v}_{\mathrm{x}}}{\partial \mathrm{x}}+\frac{\partial \mathrm{v}_{\mathrm{y}}}{\partial \mathrm{y}}\right) .
\end{gathered}
$$


The 3D model utilizes velocity components without any restriction, which are given below,

$$
\begin{aligned}
& v_{x}=v_{x}(x, y, z), \\
& v_{y}=v_{y}(x, y, z), \\
& v_{z}=v_{z}(x, y, z) .
\end{aligned}
$$

\section{B. Constitutive equations}

Different types of constitutive equations were used to model film casting, as shown in Tables II-V. They are introduced and briefly discussed in this chapter. For simplicity, they are usually provided in a single mode version. Note that in the multi-mode approach, a discontinuous relaxation spectrum is used and the stress tensor is expressed as $\underline{\underline{\tau}}=\sum_{j=1}^{N} \underline{\underline{\tau}} j$, where $\underline{\tau}_{j}$ represents the stress tensor in the $\mathrm{j}$-th mode.

\section{Newtonian model}

This constitutive equation describes the behavior of ideal Newtonian fluids by the following equation:

$$
\underline{\underline{\tau}}=2 \eta_{0} \underline{\underline{D}} .
$$

Here, $\underline{\tau}$ is the extra stress tensor, $\eta_{0}$ is the Newtonian shear viscosity (zero-shear-rate viscosity), and $\underline{D}$ is the deformation rate tensor defined as

$$
\underline{\underline{\mathrm{D}}}=\frac{1}{2}\left(\underline{\underline{\mathrm{L}}}_{\mathrm{v}}+\underline{\underline{\mathrm{L}}}_{\mathrm{v}}^{\mathrm{T}}\right), \underline{\underline{\mathrm{L}}}_{\mathrm{v}}=\nabla \mathrm{v}
$$

where $v$ represents the velocity field, $T$ denotes the transpose of the tensor, and $\nabla$ is the gradient operator. The Newtonian model predicts constant steady shear viscosity $\left(\eta_{0}\right)$, steady uniaxial $\left(3 \eta_{0}\right)$, and planar $\left(4 \eta_{0}\right)$ extensional viscosities, which is correct also for polymer melts, but only at very low extensional rates, where they behave as Newtonian fluids. The key advantage of this model is its mathematical simplicity and utilization of only one adjustable parameter, $\eta_{0}$, which can be determined from simple shear flow measurements. On the other hand, the model does not have the ability to describe the elasticity and memory of fluids, the extensional strain thinning, or the extensional strain hardening, typically occurring for polymer melts at medium and high extensional strain rates. It has been found that the model provides reasonable $N I$ values only at low $D R$ values, and it predicts essentially a parabolic thickness profile across the film width as well as the increased NI values with increased $D R .^{105}$ The convergence is almost guaranteed. ${ }^{89}$ At high DRs, the Newtonian model predicts artificially high neck-in, and there are also discrepancies between experiments and temperature profile predictions, as shown for PET in Ref. 90 (see Fig. 13). This constitutive equation was used in the following studies: 1D (4 works), ${ }^{22,26,80,82} 1.5 \mathrm{D}(10$ works), ${ }^{18,27,53,86-90,97,100}$ 2D (10 works), ${ }^{12,28,39,101,102,104,105,111-113}$ and 3D (1 work). ${ }^{114}$

\section{Generalized Newtonian model}

The generalized Newtonian model is simply the Newtonian model given by Eq. (20) in which $\eta_{0}$ is replaced by a viscosity scalar

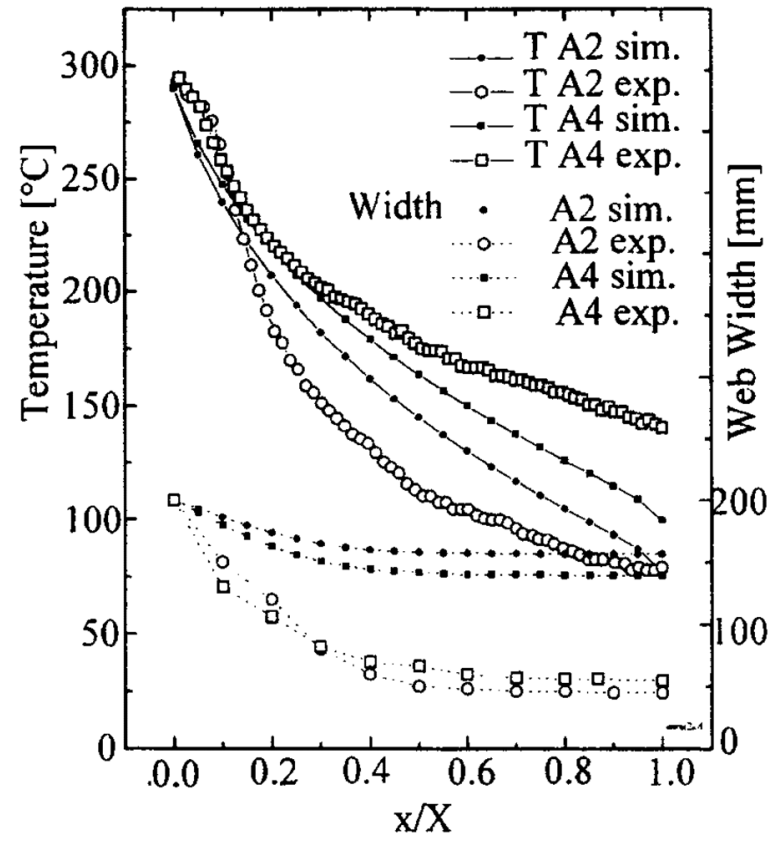

FIG. 13. Film temperature and width against dimensionless drawing distance for PET for DR $=10$ (A2 experiment) and DR $=20$ (A4 experiment), die width $=200$ $\mathrm{mm}$ and $X=150 \mathrm{~mm}$. The simulations are based on the Newtonian constitutive equation and 1.5D kinematic model. Reproduced with permission from Acierno et al., "Film casting of polyethylene terephthalate: Experiments and model comparisons," Polym. Eng. Sci. 40(1), 108 (2000). Copyright 2000 John Wiley and Sons.

function $\eta\left(I I_{\underline{\underline{D}}}\right)$, which is allowed to vary with the second invariant of the deformation rate tensor $I I_{\underline{\underline{D}}}$ defined as $2 \operatorname{tr}\left(\underline{\underline{D}}^{2}\right)$. In the simple shear flow, $I I_{\underline{\underline{D}}}=\dot{\gamma}^{2}$, uniaxial extensional flow, $I I_{\underline{\underline{D}}}=3 \dot{\varepsilon}^{2}$, and planar extensional flow, $I I_{\underline{\underline{D}}}=4 \dot{\varepsilon}^{2}$. Here, $\dot{\gamma}$ and $\dot{\varepsilon}$ represents shear and extensional strain rate, $\stackrel{=}{=}$ espectively.

Power-law (or Ostwald-de Waele) model: ${ }^{117-119}$

$$
\eta\left(\mathrm{II}_{\underline{\underline{D}}}\right)=\mathrm{m}\left(\sqrt{\mathrm{II}_{\underline{\underline{D}}}}\right)^{\mathrm{n}-1}
$$

where $m$ (the flow consistency index) and $n$ (the flow behavior index, which is lower than 1 for polymer melts) are adjustable parameters. This model allows us to model shear, uniaxial, and planar extensional viscosities plotted as a function of deformation rates as a simple line in the log-log scale with the slope equal to $n-1$. The key advantage of this model is mathematical simplicity and a low number of used parameters. A key disadvantage of this model is over prediction of shear and extensional viscosities at low deformation rates, the incapability to describe a smooth transition from the Newtonian to non-Newtonian flow regime, and the incapability to represent fluid elasticity, memory, and extensional rheology. It was found that model predictions start to significantly deviate from the Newtonian solution when the power-law index $n$ becomes less than $0.8{ }^{113}$ This model was utilized in the following studies within this review: $1 \mathrm{D}$ (1 work), ${ }^{81} 1.5 \mathrm{D}(0), 2 \mathrm{D}$ (2 works), ${ }^{8,113}$ and 3D (0). 
Cross model: ${ }^{120}$

$$
\eta\left(I_{\underline{\underline{D}}}\right)=\eta_{\infty}+\frac{\eta_{0}-\eta_{\infty}}{1+\left(\lambda \sqrt{I_{\underline{\underline{D}}}}\right)^{\mathrm{a}}} .
$$

The model was used in the following studies: $1 \mathrm{D}(0), 1.5 \mathrm{D}$ (3 works), ${ }^{91,93,96} 2 \mathrm{D}$ (1 work), ${ }^{105}$ and 3D (0).

Carreau model: ${ }^{121}$

$$
\eta\left(\mathrm{II}_{\underline{\underline{D}}}\right)=\eta_{\infty}+\frac{\eta_{0}-\eta_{\infty}}{\left[1+\left(\lambda \sqrt{\mathrm{II}_{\underline{\underline{D}}}}\right)^{2}\right]^{\frac{1-\mathrm{n}}{2}}} .
$$

The model was used in the following studies: $2 \mathrm{D}$ ( 2 works $)^{110,111}$ and 3D (1 work). ${ }^{115}$

Carreau-Yasuda model: ${ }^{122}$

$$
\eta\left(\mathrm{II}_{\underline{\underline{D}}}\right)=\eta_{\infty}+\frac{\eta_{0}-\eta_{\infty}}{\left[1+\left(\lambda \sqrt{\mathrm{II}_{\underline{\underline{D}}}}\right)^{\mathrm{a}}\right]^{\frac{1-\mathrm{n}}{\mathrm{a}}}} .
$$

The model was used in the following studies: $1 \mathrm{D}$ (1 work), ${ }^{79} 1.5 \mathrm{D}$ (0), $2 \mathrm{D}$ (1 work), ${ }^{40}$ and $3 \mathrm{D}(0)$.

The above viscosity models use the following parameters: $\eta_{0}$ (zero-shear-rate viscosity), $\eta_{\infty}$ (infinite-shear-rate viscosity), $\lambda$ (relaxation time), $a$ (characterizes the sharpness of the transition from the Newtonian to non-Newtonian flow regime), and $n$ (characterizes the slope between the viscosity and deformation rates in a log-log scale) are model parameters. Utilization of a low number of parameters, mathematical simplicity, and capability to represent steady shear viscosity of polymer melts in a wide range of shear rates and correct predictions of steady extensional viscosities at low extensional rates (i.e., equal to $3 \eta_{0}$ and $4 \eta_{0}$ for uniaxial and planar extensional viscosities, respectively) represent the advantages of these models. The main disadvantages are the inability to represent fluid memory and extensional rheology for branched polymers.

The use of generalized Newtonian models in film casting modeling has made it possible to capture some very important trends observed experimentally, namely, NI intensity and the edge bead increase with $D R$ or an increase in planar to uniaxial extensional viscosity ratio increases NI, in agreement with the viscoelastic PTT model. $^{40,110}$

\section{Upper-Convected Maxwell (UCM) model}

One of the simplest model allowing to represent some basic viscoelastic features of polymer melts is called the upper-convected Maxwell model, which is given by the following equation:

$$
\underline{\underline{\tau}}+\lambda \underline{\underline{\underline{\tau}}}=2 \eta_{0} \underline{\underline{D}}
$$

As can be seen, the key difference between the Newtonian and upper-convected Maxwell models is the elastic term $\lambda \underline{\underline{\tau}}$, which consists of the relaxation time, $\lambda$, and the upper-convected time derivative of the stress tensor, $\underset{\underline{\tau}}{\underline{\tau}}$, defined as

$$
\stackrel{\nabla}{\underline{\tau}}=\frac{\partial \underline{\underline{\tau}}}{\partial \mathrm{t}}+(\mathrm{v} \cdot \nabla) \underline{\underline{\tau}}-\underline{\underline{L}}_{\mathrm{v}}^{\mathrm{T}} \underline{\underline{\tau}}-\underline{\underline{\tau}} \underline{\underline{\mathrm{L}}}
$$

The key advantage of this model is its mathematical simplicity and a low number of used parameters $\left(\lambda, \eta_{0}\right.$, or, alternatively, $\lambda$ and the elastic modulus $G$, where $\eta_{0}=\lambda G$ ), taking into account the melt memory, the first normal stress difference, $N_{1}$, is predicted to be nonzero. Disadvantages: the model predicts unrealistically strong extensional strain hardening without the ability to predict the extensional strain thinning, and it yields an infinite steady uniaxial and planar extensional viscosities at $\dot{\varepsilon}=\frac{1}{2 \lambda}$, as can be deduced from Eqs. (28) and (29) resulting from this model for steady uniaxial, $\eta_{E, U}$, and planar, $\eta_{E, P}$, extensional viscosities,

$$
\begin{gathered}
\eta_{E, U}=\frac{3 \eta_{0}}{(1-2 \dot{\varepsilon} \lambda)(1+\dot{\varepsilon} \lambda)}, \\
\eta_{E, P}=\frac{4 \eta_{0}}{(1-2 \dot{\varepsilon} \lambda)(1+2 \dot{\varepsilon} \lambda)} .
\end{gathered}
$$

The model also unrealistically predicts a constant steady shear viscosity (equal to $\eta_{0}$ ), and the second normal stress difference, $N_{2}$, equals zero.

The use of the UCM model made it possible to reveal the qualitative role of melt elasticity in the film casting process. It was found that the edge bead defect was more pronounced in the Newtonian case than in the viscoelastic case (see Fig. 14) and that increasing the melt elasticity (i.e., the Deborah number) reduces $N I,{ }^{28}$ which is in good agreement with the experimental results. This constitutive equation was utilized in the following studies: 1D (2 works), ${ }^{83,85} 1.5 \mathrm{D}$ (8 works), ${ }^{27,29,44,53,89,94,98,99} 2 \mathrm{D}$ (4 works), ${ }^{8,28,106,113}$ and $3 \mathrm{D}(0)$.

\section{Generalized upper-convected Maxwell model}

The generalized Upper-Convected Maxwell model is simply the UCM model in which the relaxation time and the shear viscosity are

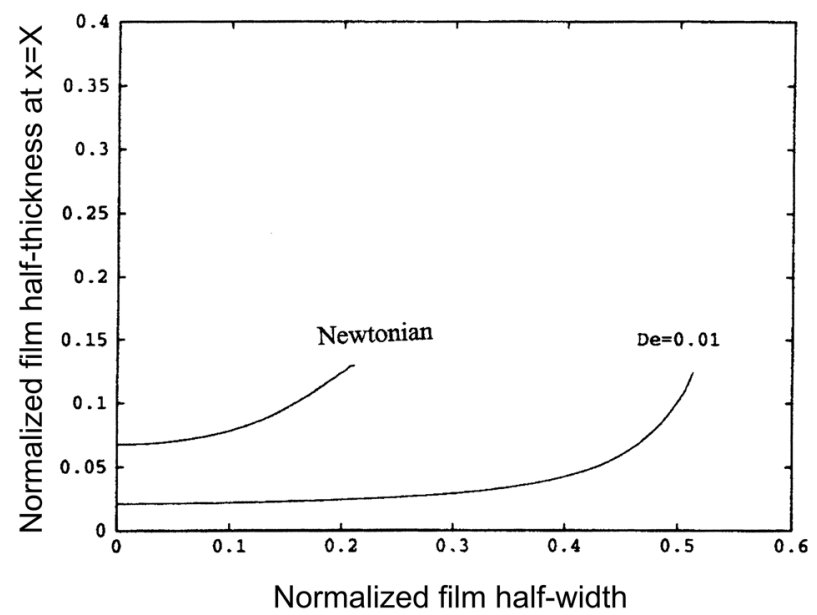

FIG. 14. Effect of elasticity on the edge-beading for $D R=50$ predicted by the $2 D$ film casting model considering Newtonian and UCM constitutive equations. The vertical axis represents the dimensionless film thickness (actual thickness divided by the die gap), and the horizontal axis represents the dimensionless film width (actual distance from the film center divided by the die width). Reproduced with permission from Silagy et al., "Stationary and stability analysis of the film casting process," J. Non-Newtonian Fluid Mech. 79(2-3), 563 (1998). Copyright 1998 Elsevier. 
allowed to vary with the second invariant of the deformation rate tensor,

$$
\underline{\underline{\tau}}+\lambda\left(\mathrm{II}_{\underline{\underline{D}}}\right) \underline{\underline{\tau}}=2 \eta\left(\mathrm{II}_{\underline{\underline{D}}}\right) \underline{\underline{D}}
$$

For the film casting modeling, the shear viscosity, $\eta\left(I I_{\underline{D}}\right)$, was chosen as the Carreau function [Eq. (24) with $\eta_{\infty}=0$ ] and the relaxation time, $\lambda\left(I I_{\underline{D}}\right)$, is given in the following form:

$$
\lambda\left(\mathrm{II}_{\underline{\underline{D}}}\right)=\frac{\lambda_{0}}{\left[1+\left(\lambda_{\mathrm{t}} \sqrt{\mathrm{II}_{\underline{\underline{D}}}}\right)^{2}\right]^{\mathrm{n}^{\prime}}} .
$$

In this equation, $\lambda_{0}, \lambda_{t}$, and $n^{\prime}$ are adjustable parameters. The model can represent steady shear viscosity, $N_{1}$, and extensional rheology more realistically than the UCM model, but it still shares the key disadvantages of the original model, i.e., $N_{2}$ is predicted to be zero, and steady uniaxial and planar extensional viscosities becomes infinite, if the extensional strain rate becomes equal to $\frac{1}{2 \lambda\left(I_{\underline{\underline{D}}}\right)}$. This model was used in the film casting modeling [1D ( 1 work in total $)^{83}$ ] to understand the role of the power-law exponent $n$ and the characteristic relaxation time in the velocity profile and the relationship between $D R$ and tensile force.

\section{Giesekus model}

The Giesekus model was proposed in 1966 from the simple dumbbell theory for dilute solutions considering the anisotropic drag. ${ }^{19,123-125}$ The model is given as follows:

$$
\begin{gathered}
\underline{\tau}=\underline{\underline{\tau}} \mathrm{p}+\underset{\underline{\tau}}{=}, \\
\underline{\underline{\tau}}_{\mathrm{s}}=2 \eta_{\infty} \underline{\underline{D}}, \\
\underline{\underline{\tau} \mathrm{p}}+\lambda_{1} \frac{\alpha}{\eta_{\mathrm{p}}} \frac{\tau^{2}}{=}+\lambda_{1} \frac{\nabla}{=\mathrm{p}}=2 \eta_{\mathrm{p}} \underline{\underline{D}}, \\
\eta_{0}=\eta_{\mathrm{p}}+\eta_{\infty}, \\
\eta_{0}=\lambda_{1} \mathrm{G}, \\
\eta_{\infty}=\eta_{0} \frac{\lambda_{2}}{\lambda_{1}},
\end{gathered}
$$

where $\underline{\underline{\tau}}$ is the extra-stress tensor, $\underline{\underline{\tau}}_{\mathrm{p}}$ and $\underline{\underline{\tau}}_{s}$ are the polymer and solvent contributions to the stress tensor, $\eta_{\infty}$ is the solvent viscosity, $\eta_{p}$ is the polymer viscosity, $D$ is the deformation rate tensor, $\lambda_{1}$ is the relaxation time, the symbol $\nabla$ represents the upper-convected time derivative, $\eta_{0}$ is the zero-shear-rate viscosity, $G$ is the modulus, and $\alpha$ is the parameter characterizing the anisotropic hydrodynamic drag. The minimum and maximum anisotropies correspond to $\alpha=0$ and $\alpha=1$, respectively, ${ }^{125}$ but as shown by Bird, ${ }^{119}$ the model behaves realistically only if $\alpha \leq 0.5$. This model can represent a steady shear viscosity of polymer melts in a very wide shear rate range, and it correctly predicts non-zero values of $N_{1}$ as well as a negative value of $N_{2}$. On the other hand, its behavior in an extensional flow is not realistic. The key disadvantage of this model is the inability to predict the decrease in extensional viscosity, if the extensional strain rate increases. The model has been found to provide reasonable predictions for the film neck-in, the centerline velocity profile and the temperature drop in the air-gap, and it also predicts an increase in film neck-in and the temperature drop in the air-gap as the air-gap length is increased. ${ }^{107}$

This constitutive equation has been used in the following studies: $1 \mathrm{D}$ (1 work), ${ }^{79} 1.5 \mathrm{D}(0), 2 \mathrm{D}$ (3 works), ${ }^{107,111,113}$ and 3D (0).

\section{Modified Giesekus model}

The original Giesekus model is not able to realistically represent extensional flows because the polymeric chains are assumed to be infinitely extensible. In order to overcome this model drawback, Wiest ${ }^{126}$ modified the original Giesekus model ${ }^{124}$ by incorporating the finite extensibility of polymer molecules by using the Peterlin approximation. The set of equations remains the same as in the case of the original Giesekus model except for Eq. (34), which must be replaced by the following expression:

$$
\left[\mathrm{Z}-\lambda_{1} \frac{\mathrm{D} \ln (\mathrm{Z})}{\mathrm{Dt}}\right]_{=\mathrm{p}}+\frac{a \lambda_{1} \mathrm{Z}}{\eta_{\mathrm{p}}} \tau_{=\mathrm{p}}^{2}+\lambda_{1} \underset{=\mathrm{\tau}}{\stackrel{\nabla}{\tau}}=2 \eta_{\mathrm{p}}\left[\underline{\underline{D}}+\frac{1}{2} \frac{\mathrm{D} \ln (\mathrm{Z})}{\mathrm{Dt}} \underline{\underline{\delta}}\right],
$$

where $\underline{\underline{\delta}}$ is the Kronecker delta and $Z$ is the function defined as

$$
\mathrm{Z}=\frac{1}{\mathrm{~b}_{\mathrm{c}}}\left[\mathrm{b}_{\mathrm{c}}+3+\frac{\operatorname{tr}\left(\frac{\tau}{=\mathrm{p}}\right)}{\mathrm{G}}\right] .
$$

The term $\mathrm{D}() / \mathrm{Dt}$ represents substantial time derivative, which is defined as

$$
\frac{\mathrm{D}()}{\mathrm{Dt}}=\frac{\partial()}{\partial \mathrm{t}}+\mathrm{v} \cdot \nabla()
$$

In this model, $b_{c}$ represents the chain extensibility parameter. Note that if $b_{c} \rightarrow \infty, Z \rightarrow 1$, the modified model is reduced to the original Giesekus model, whereas for $\alpha=0$, the "FENE-P" dumbbell constitutive equation is recovered. ${ }^{126}$ This model shares the same advantages with the original Giesekus model with the additional ability to describe extensional strain hardening as well as extensional strain thinning for steady uniaxial as well we as planar extensional viscosities. In addition, the model is derived from kinetic theory, which allows us to relate model parameters with molecular characteristics. On the other hand, the model predicts that both uniaxial and planar extensional viscosities are very similar at high deformation rates, ${ }^{84}$ which might not be realistic, as indicated in Ref. 127.

The model was used to investigate the role of the uniaxial extensional strain hardening in velocity and stress profiles and film tension in a single layer as well as the multilayer film casting process by using 1D flow kinematics.

\section{7. eXtended Pom-Pom model}

The eXtended Pom-Pom (XPP) model was proposed by Verbeeten et al. ${ }^{128}$ This model represents an approximation of the original Pom-Pom model proposed by McLeish and Larson, ${ }^{129}$ which is based on the Doi-Edwards reptation tube theory and uses the 
Giesekus anisotropy parameter $\alpha$. The model considers a simplified $\mathrm{H}$ topology of branched molecules, and the relaxation time is expressed as a tensor to separate the stretch and orientation. The model is given by the following set of equations:

$$
\underline{\underline{\underline{\tau}}}+\underline{\underline{\lambda(\tau)^{-1}}} \underline{\underline{\tau}}=2 \mathrm{G} \underline{\underline{D}}
$$

where the relaxation time tensor is defined as

$$
\underline{\underline{\lambda(\tau)}}^{-1}=\frac{1}{\lambda_{0 \mathrm{~b}}}\left\{\frac{\alpha}{\mathrm{G}} \underline{\underline{\tau}}+\mathrm{f}(\tau)^{-1} \underline{\underline{\delta}}+\mathrm{G}\left[\mathrm{f}(\tau)^{-1}-1\right] \underline{\underline{\tau}}^{-1}\right\} .
$$

Extra function:

$$
\mathrm{f}(\tau)^{-1}=\frac{2 \lambda_{0 \mathrm{~b}}}{\lambda_{\mathrm{s}}}\left(1-\frac{1}{\Lambda}\right)+\frac{1}{\Lambda^{2}}\left(1-\frac{\operatorname{atr}\left(\underline{\underline{\tau}}^{2}\right)}{3 \mathrm{G}^{2}}\right) .
$$

Backbone stretch and stretch relaxation time:

$$
\Lambda=\sqrt{1+\frac{\operatorname{tr}(\underline{\underline{\tau}})}{3 \mathrm{G}}}, \lambda_{s}=\lambda_{0 \mathrm{~s}} \mathrm{e}^{-v(\Lambda-1)} v=\frac{2}{\mathrm{q}},
$$

where $q$ (number of arms) and $\lambda_{0 S}$ (stretch relaxation time) are adjustable parameters, which are allowed to vary with the orientation relaxation time, $\lambda_{0 b}$. Note that the Maxwell parameters are $G$ and $\lambda_{0 \mathrm{~b}}=\lambda$. The model has an excellent capability to describe the shear and extensional rheology for long-chain branched polymers such as LDPE, which is widely used in the film casting technology. The model also predicts non-zero values of $N_{1}$ and $N_{2}$ as it should be. Additionally, the model parameters are directly related to the molecular characteristics because the model is derived from molecular arguments. On the other hand, the model is not suitable for linear polymers due to the assumed structural topology and uses a very high number of adjustable parameters, which makes it difficult to identify them from the measured experimental data. The model (similarly to the original Pom-Pom model) also predicts that steady uniaxial and planar extensional viscosities become practically identical at high extensional strain rates, which might not be realistic for some LDPEs, as indicated in Ref. 127 (see Fig. 15). The XPP model correctly predicts that increasing $D R$ and the air-gap reduce NI. According to the authors, the agreement between the experimental data (LDPE ${ }^{41,42}$ and long chain branched $\mathrm{PP}^{43}$ ) and the simulation results was qualitative rather than quantitative in terms of necking behavior (see Fig. 16 as an example for LDPE; here, the 8 mode XPP model, where all model parameters were allowed to vary with the relaxation mode, was used; step shear and step uniaxial extensional experiments were used to validate the XPP model). This constitutive equation was utilized in the following studies: 1D (0), 1.5D (3 works), ${ }^{41-43} 2 \mathrm{D}(0)$, and $3 \mathrm{D}(0)$.

\section{Rolie-Poly Stretch (RP-S) model}

The Rolie-Poly (ROuse LInear Entangled POLYmer) stretch model is a tube-based model proposed by Likhtman and Graham, ${ }^{130}$ which takes into account the convective constraint release, reptation, and chain retraction. The model is given as

$$
\stackrel{\nabla}{\underline{\tau}}=-\frac{1}{\lambda_{\mathrm{d}}}(\underline{\underline{\tau}}-\underline{\underline{\delta}})-\frac{2(1-\sqrt{3 / \operatorname{tr} \underline{\underline{\tau}}})}{\lambda_{\mathrm{r}}}\left(\underline{\underline{\tau}}+\beta_{\mathrm{c}}\left(\frac{\operatorname{tr} \underline{\underline{\tau}}}{3}\right)^{\delta_{0}}(\underline{\underline{\tau}}-\underline{\underline{\delta}})\right),
$$

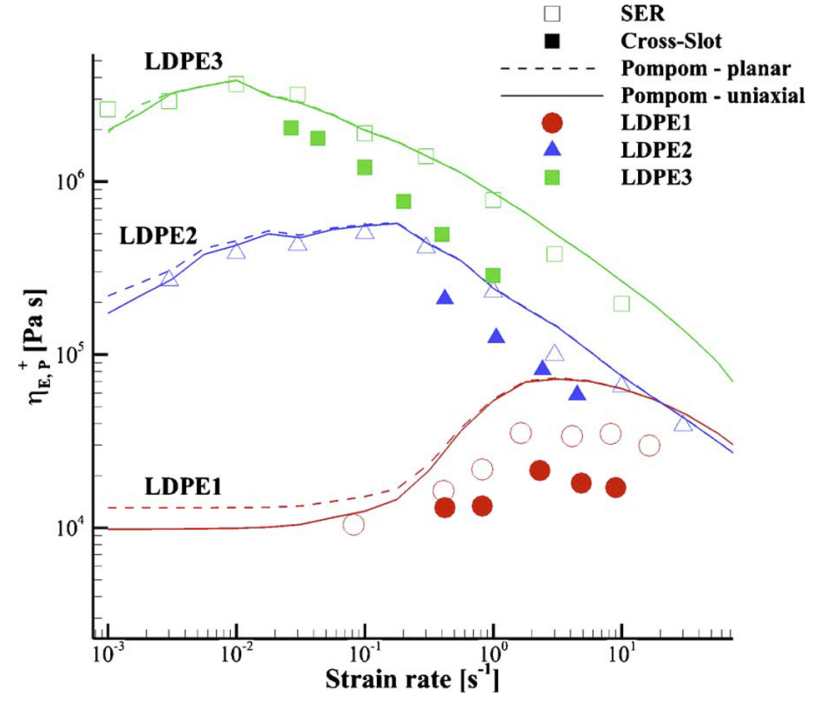

FIG. 15. Comparison between experimentally measured uniaxial (open symbols) and planar (closed symbols) extensional viscosities together with the multimode Pom-Pom model predictions for the uniaxial (solid lines) and planar (dashed lines) extensional viscosity for the LDPE series. Reproduced with permission from Auhl et al., "Cross-slot extensional rheometry and the steady-state extensional response of long chain branched polymer melts," J. Rheol. 55(4), 875 (2011). Copyright 2011 Society of Rheology.

where $\lambda_{d}$ and $\lambda_{r}$ are the reptation and the Rouse relaxation times, respectively; $\beta_{c}$ is the convective constraint release coefficient; and $\delta_{0}$ is a fitting scalar parameter. Being $\beta_{c}$ equal to zero, the $\delta_{0}$ parameter does not have to be specified. This model has showed good

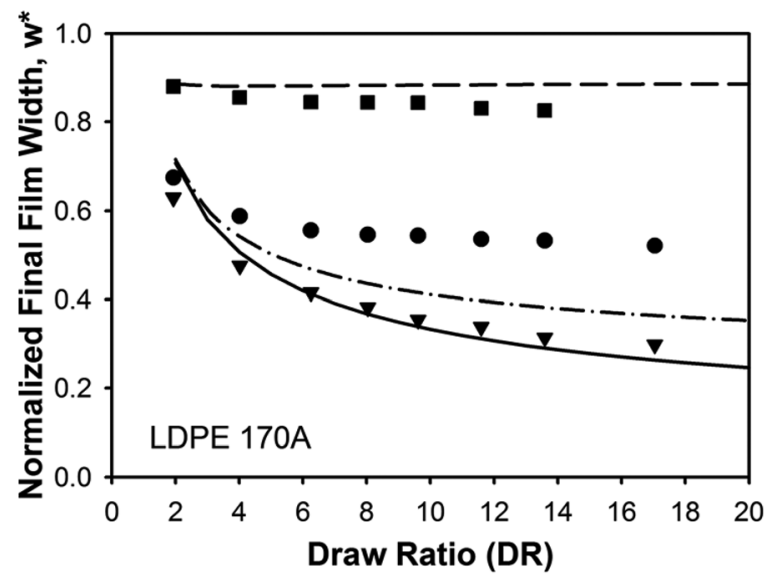

FIG. 16. Normalized film width vs draw ratio for branched LDPE at three different air-gaps (squares: $X=10 \mathrm{~mm}$; circles: $X=90 \mathrm{~mm}$; inverted triangles: $X=228 \mathrm{~mm}$; die width $=100 \mathrm{~mm}$ ). The symbols represent experimental data, and the lines are predictions based on the XPP constitutive equation and the 1.5D kinematic model. Reproduced with permission from Pol et al., "Necking in extrusion film casting: The role of macromolecular architecture," J. Rheol. 57(2), 559 (2013). Copyright 2013 Society of Rheology. 
capability to describe the transient shear and extensional rheology of linear film casting resins (namely, LLDPE and HDPE), and it is mathematically simple and gives a non-zero value of $N_{1}$. On the other hand, the model is not able to describe the rheological behavior of branched polymers and unrealistically predicts $\mathrm{N}_{2}=0 .{ }^{131}$ This constitutive equation was utilized in the following theoretical studies summarized in this review: $1 \mathrm{D}(0), 1.5 \mathrm{D}$ (3 works), ${ }^{41-43} 2 \mathrm{D}(0)$, and $3 \mathrm{D}(0)$. The model predicted an increase in $N I$ with the increased $D R$ and the air-gap. According to the authors, the agreement between the experimental data (HDPE, ${ }^{41}$ LLDPE, ${ }^{41,42}$ and linear $\mathrm{PP}^{43}$ ) and the simulation results was qualitative rather than quantitative with respect to NI (see Fig. 17 as an example for LLDPE; here, the 8 mode RP-S model, where $\lambda_{d}$ and $\lambda_{r}$ were allowed to vary with the relaxation mode, was used; $\beta=0$ and $\delta_{0}=-0.5$; step shear and step uniaxial extensional experiments were used to validate the RP-S model).

\section{Modified Leonov model}

The modified Leonov model is based on heuristic thermodynamic arguments resulting from the theory of rubber elasticity. ${ }^{132-137}$ In this constitutive equation, a fading memory of the melt is determined by an irreversible dissipation process driven by the dissipation term, $b$. This model relates the stress and elastic strain stored in the polymer melt as

$$
\underline{\underline{\tau}}=2\left(\underline{\underline{c}} \frac{\partial \mathrm{W}}{\partial \mathrm{I}_{\underline{\underline{c}}}}-\underline{\underline{c}}^{-1} \frac{\partial \mathrm{W}}{\partial \mathrm{II}_{\underline{\underline{c}}}}\right)
$$

where $W$ is the elastic potential, which depends on the invariants $I_{\underline{\underline{c}}}$ and $I I_{\underline{\underline{c}}}$ of the recoverable Finger tensor $\underline{\underline{\mathrm{c}}}$,

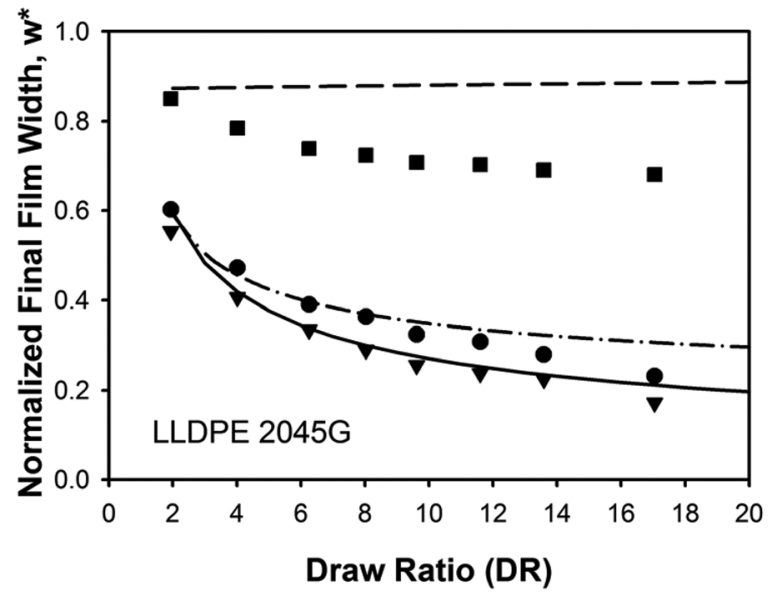

FIG. 17. Normalized film width vs draw ratio for linear LLDPE at three different air-gaps (squares: $X=10 \mathrm{~mm}$; circles: $X=90 \mathrm{~mm}$; inverted triangles: $X=228 \mathrm{~mm}$; die width $=100 \mathrm{~mm}$ ). The symbols represent experimental data, and the lines are predictions based on the RP-S constitutive equation and the 1.5D kinematic model. Reproduced with permission from Pol et al., "Necking in extrusion film casting: The role of macromolecular architecture," J. Rheol. 57(2), 559 (2013). Copyright 2013 Society of Rheology.

$$
\mathrm{W}=\frac{3 \mathrm{G}}{2\left(\mathrm{n}_{\mathrm{L}}+1\right)}\left\{(1-\beta)\left[\left(\frac{\mathrm{I}_{\underline{\underline{c}}}}{3}\right)^{\mathrm{n}_{\mathrm{L}}+1}-1\right]+\beta\left[\left(\frac{\mathrm{II}_{\underline{\underline{c}}}}{3}\right)^{\mathrm{n}_{\mathrm{L}}+1}-1\right]\right\},
$$

where $G$ denotes the linear Hookean elastic modulus and $\beta$ and $n_{L}$ are numerical parameters. Leonov assumed that the dissipative process acts to produce an irreversible rate of strain $\underset{-p}{e}$,

$$
\stackrel{\mathrm{e}}{=}=\mathrm{b}\left[\underline{\underline{\mathrm{c}}}-\frac{\underline{\underline{\underline{c}}}}{3} \underline{\underline{\delta}}\right]-\mathrm{b}\left[\underline{\underline{c}}^{-1}-\frac{\mathrm{II}_{\underline{\underline{c}}}}{3} \underline{\underline{\delta}}\right]
$$

which spontaneously reduces the rate of elastic strain accumulation. Here, $\underline{\delta}$ is the unit tensor and $b$ stands for the dissipation function define $\bar{d}$ by Eq. (50). This elastic strain $\underline{\underline{c}}$ is related to the deformation rate tensor $\underline{\mathrm{D}}$ as follows:

$$
\stackrel{\circ}{\underline{\mathrm{c}}}-\underline{\underline{\mathrm{c}}} \cdot \underline{\underline{\mathrm{D}}}-\underline{\underline{\mathrm{D}}} \cdot \underline{\underline{\mathrm{c}}}+2 \underline{\underline{\mathrm{c}}} \cdot \underline{\underline{\mathrm{e}}}=\underline{\mathrm{p}}=0
$$

where $\stackrel{\circ}{\underline{c}}$ is the Jaumann (corotational) time derivative of the recoverable $\overline{\bar{F}}$ inger strain tensor. The dissipation function $b$ proposed in Ref. 64 is given as

$$
\mathrm{b}\left(\mathrm{I}_{\underline{\underline{c}}}\right)=\frac{1}{4 \lambda}\left\{\exp \left[-\xi \sqrt{\underline{\underline{\mathrm{I}_{\underline{\underline{c}}}}}-3}\right]+\frac{\sinh \left[v\left(\mathrm{I}_{\underline{\underline{\underline{c}}}}-3\right)\right]}{v\left(\mathrm{I}_{\underline{\underline{c}}}-3\right)+1}\right\}
$$

where $\xi$ and $v$ are adjustable parameters of the model.

The model has a very good capability to describe shear viscosity, $N_{1}, N_{2}$, uniaxial and planar extensional viscosities for linear as well as branched polymers. ${ }^{57,58,62-64,138}$ The model also offers an independent control of uniaxial and planar extensional viscosities, which was used for systematic investigation of the role of the planar to uniaxial extensional viscosity ratio in the film casting process for different LDPEs. On the other hand, the interpretation of molecular meaning of the used model parameters is limited because the model is derived from thermodynamics rather than molecular arguments. Note that the original Leonov model is recovered if $\mathrm{n}_{\mathrm{L}}=\beta=\xi=v=0$.

The model demonstrated the ability to describe the film casting experimental data for linear (PP) and branched (LDPE) polymers even by using a single mode (i.e., utilizing a single pair of $\lambda$ and $G$ ) only $^{35,37,38}$ (see Fig. 18). (In the case of PP, the lowest relaxation time typical for polyolefins was chosen, and $G$ was calculated from the known $\eta_{0}$. The nonlinear model parameters were adjusted as the typical values for linear polymers, i.e., $\xi=0, \mathrm{n}_{\mathrm{L}}=0, v=0.5$, and $\beta=0.5$. In the case of LDPE, the model parameters, namely, $\lambda, G, \xi, v$, and $\beta$, were identified using deformation rate dependent "steady-state" uniaxial extensional viscosity experimental data and known $\eta_{0}$. The parameter $n_{L}$ was kept equal to zero.) The modified Leonov model was used in the following studies: 1D (0), 1.5D (3 works), ${ }^{35,37,38} 2 \mathrm{D}$ $(0)$, and $3 \mathrm{D}(0)$. The original Leonov model was used only in the following study: $1.5 \mathrm{D}$ (1 work).

\section{Phan-Thien-Tanner (PTT) model}

The model was derived by Phan-Thien and Tanner ${ }^{139}$ and Phan-Thien ${ }^{140}$ from the Lodge-Yamamoto network theory in which junctions are allowed to form and decay due to the flow. The model is given by the following equation: 

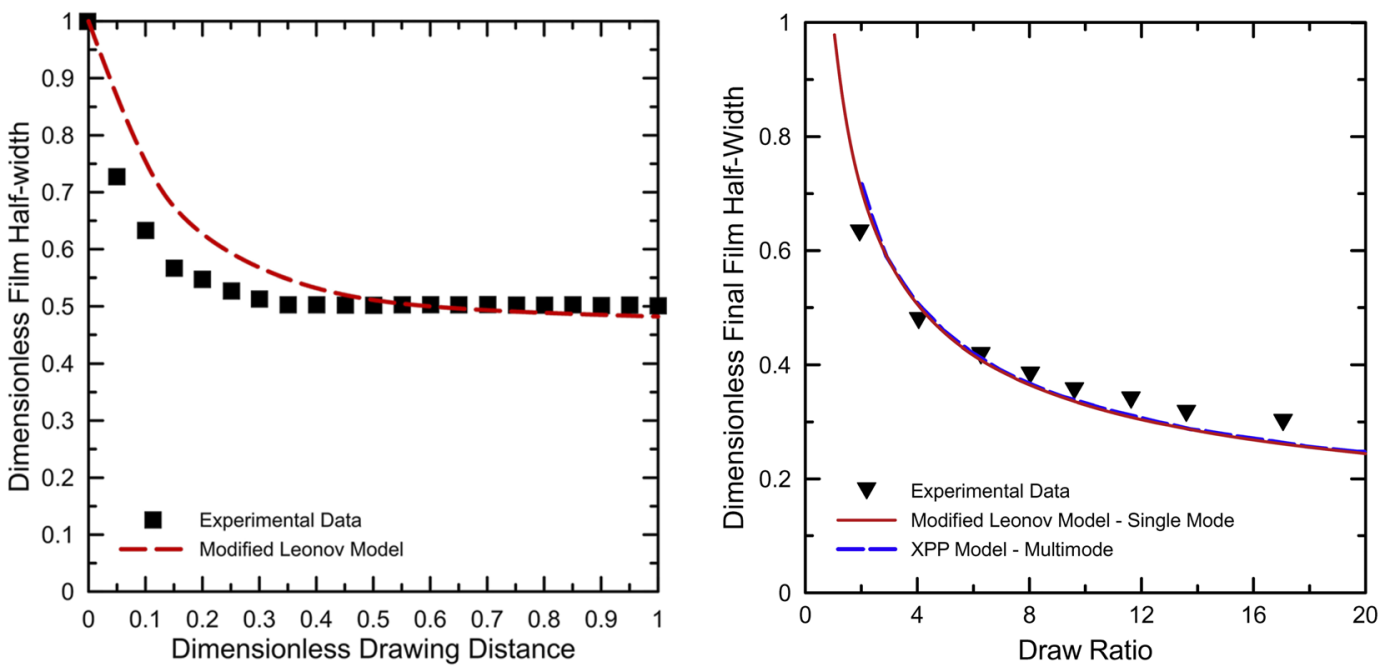

FIG. 18. Normalized film width vs drawing distance at $D R=34.7$, die width $=200 \mathrm{~mm}$, and $X=400 \mathrm{~mm}$ for linear PP (left) and normalized film width vs DR at die width $=100 \mathrm{~mm}$ at $X=230 \mathrm{~mm}$ for branched LDPE (right). The symbols represent experimental data, and the lines are predictions based on the modified Leonov constitutive equation and the 1.5D kinematic model. Left figure reproduced with permission from T. Barborik and M. Zatloukal, "Effect of heat transfer coefficient, draw ratio, and die exit temperature on the production of flat polypropylene membranes," Phys. Fluids 31(5), 053101 (2019). Copyright 2019 AIP Publishing LLC. Right figure reproduced with permission from Barborik et al., "On the role of extensional rheology and Deborah number on the neck-in phenomenon during flat film casting," Int. J. Heat Mass Transfer 111, 1296 (2017). Copyright 2017 Elsevier.

$$
\underline{\underline{\tau}}+\lambda(\underline{\underline{\tau}}) \underline{\underline{\tau}}=2 \eta_{0} \underline{\underline{D}} .
$$

This model uses the Gordon-Schowalter convected time derivative

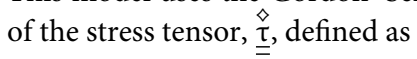

$$
\stackrel{\stackrel{\imath}{\underline{\tau}}}{=}=\frac{\partial \underline{\underline{\tau}}}{\partial \mathrm{t}}+(\mathrm{v} \cdot \nabla) \underline{\underline{\tau}}-\underline{\underline{\ell}}^{\mathrm{T}} \underline{\underline{\tau}}-\underline{\underline{\tau}} \underline{\underline{\ell}} \underline{\underline{\underline{\ell}}}=\underline{\underline{\mathrm{L}}}-\mathrm{v}-\xi_{\mathrm{p}} \underline{\underline{\mathrm{D}}}
$$

and the relaxation time, $\lambda(\underline{\underline{\tau}})$, which is allowed to vary with the trace of the stress linearly [Eq. (53)] or exponentially [Eq. (54)].

Linear PTT model:

$$
\lambda(\underline{\underline{\tau}})=1+\frac{\varepsilon_{\mathrm{p}}}{\mathrm{G}} \operatorname{tr}(\underline{\underline{\tau}}) .
$$

Exponential PTT model:

$$
\lambda(\underline{\underline{\tau}})=\exp \left[\frac{\varepsilon_{\mathrm{p}}}{\mathrm{G}} \operatorname{tr}(\underline{\underline{\tau}})\right]
$$

The model utilizes two parameters, $\xi_{p}$ and $\varepsilon_{p}$ (together with $\lambda$ and $G$, where $\eta_{0}=\lambda G$ ). The linear PTT predicts an unrealistically monotonically increasing extensional viscosity, while the exponential PTT has the ability to give a maximum in the extensional viscosity, when plotted as a function of the extensional strain rate. Thus, the exponential PTT model is used more in modeling of the film casting process than its linear version; it has good ability to describe shear as well as extensional rheology of linear as well as branched polymers and predicts non-zero values for $N_{1}$ and $\mathrm{N}_{2}$. On the other hand, steady uniaxial and planar extensional viscosities are predicted to be practically identical at high extensional strain rates, which might not be realistic for some polymers, as indicated in Ref. 127 (see Fig. 19). This model has been shown to

provide good agreement with the experimental data for LDPE over a wide range of the take-up velocity and the air-gap length ${ }^{54,109}$ (see Fig. 20). In this case, the exponential (6-7) mode PTT model using $\varepsilon_{p}$ and $\xi_{p}$ model parameters varying with each relaxation

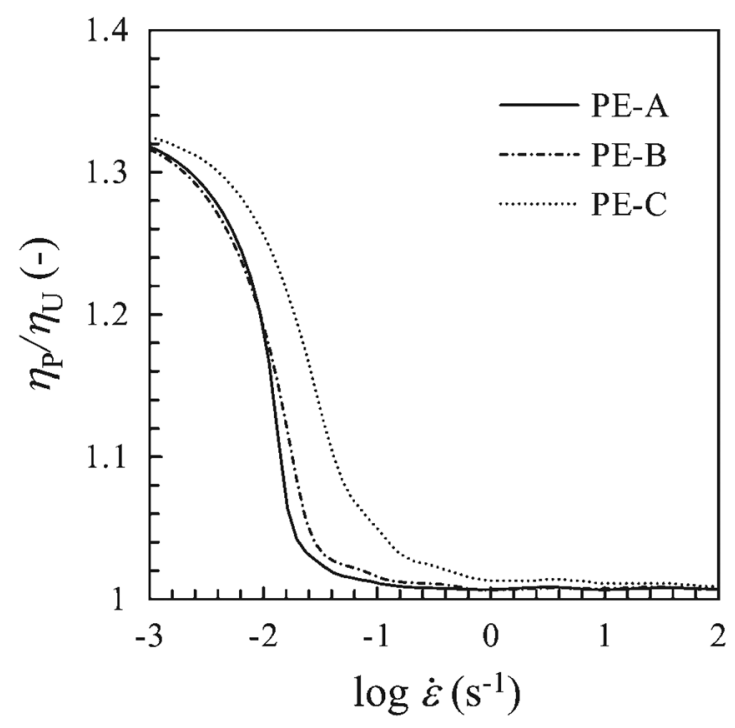

FIG. 19. The planar to uniaxial extensional viscosity ratio predicted by the PTT model for three different LDPEs plotted as a function of the extensional strain rate. Reproduced with permission from Shiromoto et al., "A neck-in model in extrusion lamination process," Polym. Eng. Sci. 50(1), 22 (2010). Copyright 2010 John Wiley and Sons. 

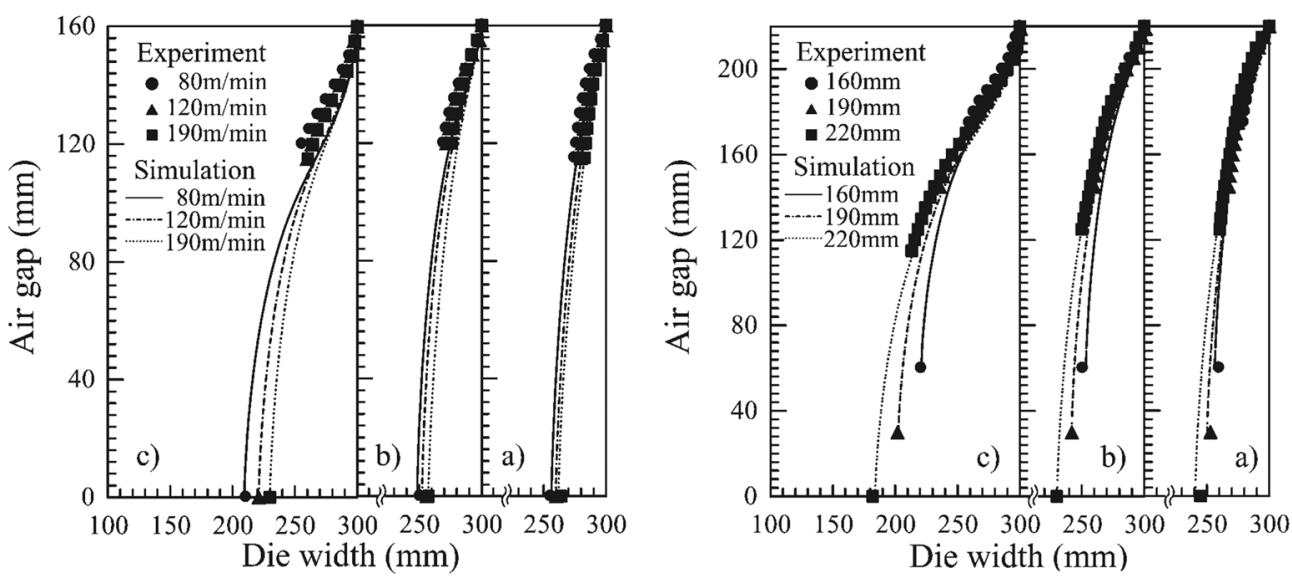

FIG. 20. Comparison of the film edge shapes for three LDPEs with different uniaxial extensional strain hardening (a-high, b-middle, c-low uniaxial extensional strain hardening) where die width $=600 \mathrm{~mm}$, and DR was kept the same, equal to 40 by proper adjusting of $\mathrm{v}_{\mathrm{x}}(0)$ and $\mathrm{v}_{\mathrm{X}}(\mathrm{X})$. Left: the role of take-up velocities $(80 \mathrm{~m} / \mathrm{min}, 120 \mathrm{~m} / \mathrm{min}$, and 190 $\mathrm{m} / \mathrm{min}), X=160 \mathrm{~mm}$; right: the role of air-gaps $(160 \mathrm{~mm}, 190 \mathrm{~mm}$, and $220 \mathrm{~mm})$ at the fixed take-up velocity $(120 \mathrm{~m} / \mathrm{min})$. The symbols represent experimental data, and the lines are predictions based on the multimode PTT constitutive equation and the 2D kinematic model. Reproduced with permission from Shiromoto et al., "A neck-in model in extrusion lamination process," Polym. Eng. Sci. 50(1), 22 (2010). Copyright 2010 John Wiley and Sons.

mode was necessary to adequately represent the measured shear and extensional data LDPEs reasonably. The discrete relaxation spectrum was determined from frequency-dependent loss and storage moduli, while $\xi_{p}$ and $\varepsilon_{p}$ parameters were identified from steady-state shear viscosity vs shear rate and steady uniaxial extensional viscosity vs extensional strain rate.

This constitutive equation was utilized in the following studies within this review: 1.D (1 work), ${ }^{79} 1.5 \mathrm{D}$ (2 works), ${ }^{44,47} 2 \mathrm{D}$ (7 works), ${ }^{36,40,46,105,108,109}$ and 3D (1 work). ${ }^{116}$ The linear variant of the PTT model was used only in the following studies: $2 \mathrm{D}$ ( 1 work). ${ }^{26}$

\section{Larson model}

This model represents a differential approximation of the DoiEdwards (DE) integral tube model proposed by Larson, ${ }^{141,142}$ which includes non-affine motion and is given by the following expression:

$$
\underline{\underline{\tau}}+\lambda \underline{\underline{\tau}}+\frac{2}{3} \frac{\zeta \lambda}{G} \underline{\underline{D}}: \underline{\underline{\tau}}(\underline{\underline{\tau}}+\mathrm{G} \underline{\underline{\delta}})=2 \eta_{0} \underline{\underline{D}}
$$

where $\varsigma$ is the only non-linear model parameter (note that the best approximation of the DE model is achieved, if $\varsigma=3 / 5^{125}$ ). The behavior of the model is comparable to that of the exponential PTT model meaning that it can capture shear and extensional viscosities for both linear and branched polymers, and $N_{1}$ is predicted to be a non-zero value. However, the model unrealistically predicts $\mathrm{N}_{2}=0$, steady uniaxial and planar extensional viscosities becomes comparable at high extensional strain rates, and $\varsigma$ must be varied with the relaxation time to capture uniaxial extensional strain hardening for commercial types of highly branched polyethylenes over a wide range of extensional strain rates. This model was successfully used in the film casting modeling for 4 different types of LDPEs, but 13 pairs of $\lambda, G$, and $\varsigma$ were needed to describe the experimental reality. ${ }^{39}$ The model provides reasonably good prediction for the neck-in and the film thickness (see Fig. 21). This model also predicts that the increase in the uniaxial extensional strain hardening first decreases $\mathrm{NI}$, in agreement with the experimental observations (see Fig. 22), and second, the edge beading region becomes narrower.

This constitutive equation was utilized in the following studies: 1D (0), 1.5D (0), 2D (2 works), ${ }^{39,105}$ and 3D (0).

\section{Integral constitutive equation of the $K-B K Z$ type with PSM strain-memory function}

The multi-mode Kaye-Bernstein-Kearsley-Zapas (K-BKZ) type of the integral model proposed by Papanastasiou, Scriven, and Macosko (PSM) ${ }^{143}$ and then modified by Luo and Tanner ${ }^{144}$ to account for $N_{2}$ through the parameter $\theta$ has the following expression:

$$
\begin{aligned}
\underline{\underline{\tau}}= & \frac{1}{1-\theta} \int_{-\infty}^{\mathrm{t}} \sum_{\mathrm{j}=1}^{\mathrm{N}} \frac{\mathrm{G}_{\mathrm{j}}}{\lambda_{\mathrm{j}}} \exp \left(-\frac{\mathrm{t}-\mathrm{t}^{\prime}}{\lambda_{\mathrm{j}}}\right) \frac{\alpha_{\mathrm{j}}}{\alpha_{\mathrm{j}}-3+\beta_{\mathrm{j}} \underline{\underline{\mathrm{C}}}^{-1}+\left(1-\beta_{\mathrm{j}}\right) \mathrm{II}_{\underline{\underline{C}}^{-1}}} \\
& \times\left[\underline{\underline{C}}^{-1}\left(\mathrm{t}^{\prime}\right)+\theta \underline{\underline{C}}\left(\mathrm{t}^{\prime}\right)\right] d \mathrm{dt}^{\prime},
\end{aligned}
$$

where $t$ and $t^{\prime}$ are the times present and past, respectively; $I_{\underline{C}^{-1}}$ and $I I_{\underline{C}^{-1}}$ are the first and second invariants of the Finger strain tensor $\underline{C}^{-1}$; and $\alpha_{j}, \beta_{j}$, and $\theta$ are the parameters of the model. The K- $\overline{\bar{B} K Z}$ model reduces to the upper-convected Maxwell model when $\theta=0$ and $\alpha \rightarrow+\infty$. The model has a very good ability to describe the shear viscosity, $N_{1}, N_{2}$, and uniaxial extensional viscosities for linear and branched polymers. The main disadvantage of the model is the inability to predict extensional strain hardening in planar extensional viscosity for branched polymers as $\mathrm{LDPE}^{14}$ (see Fig. 23).

The model showed good agreement between experimental data and previous film casting simulations based on the Newtonian and UCM results in terms of film thickness, width, and temperature. ${ }^{89}$ Note that in order to capture the shear and extensional rheology of 

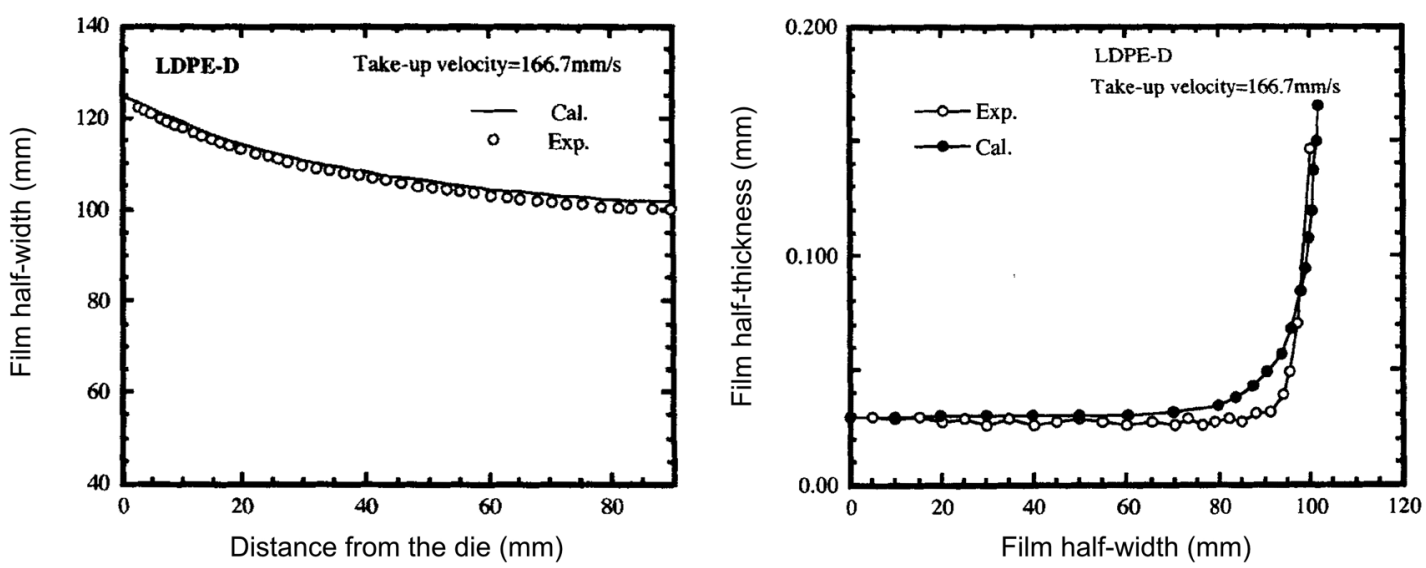

FIG. 21. Film width vs drawing distance (left) and final film thickness across the film width (right) at DR $=32.7$, die width $=0.25 \mathrm{~m}$, and $\mathrm{X}=0.09 \mathrm{~m}$ for branched LDPE. Open circles represent experimental data and lines (or lines with filled circles) are predictions based on the Larson constitutive equation and the 2D kinematic model. Reproduced with permission from Satoh et al., "Viscoelastic simulation of film casting process for a polymer melt," Polym. Eng. Sci. 41(9), 1564 (2001). Copyright 2001 John Wiley and Sons.

LDPE melts, the parameter $\beta$ in Eq. (56) needs to be varied with the relaxation time, otherwise the extensional strain hardening is overpredicted at high extensional strain rates (see Fig. 23).

This constitutive equation was utilized in the following studies: $1 \mathrm{D}$ (1 work), ${ }^{45} 5 \mathrm{D}$ (1 work), ${ }^{89} 2 \mathrm{D}(0)$, and $3 \mathrm{D}(0)$.

\section{Hooke's law with creep}

Smith and Stolle considered the viscoelastic polymer melt to be an elastic material that is creeping. For such a description, they have suggested the incremental form of Hooke's law of the following form: ${ }^{146}$

$$
\Delta \underline{\underline{\sigma}}=\underline{\underline{E}}\left(\Delta \underline{\underline{\varepsilon}}-\Delta \underline{\underline{\varepsilon}}^{\mathrm{c}}\right)
$$

where $\Delta \underline{\sigma}$ is the stress increment, $\underline{\underline{E}}$ is the elasticity matrix, $\Delta \underline{\underline{\varepsilon}}$ is the total strain increment, and $\Delta \underline{\varepsilon}^{c}$ is the modified Perzyna creep strain increment that depends on the time step, the effective creep strain rate, and the second invariant of the deviatoric stress tensor. This model was used to theoretically investigate the role of elasticity (by changing the relaxation time) and extensional strain hardening. It was found that the predictions were consistent with predictions
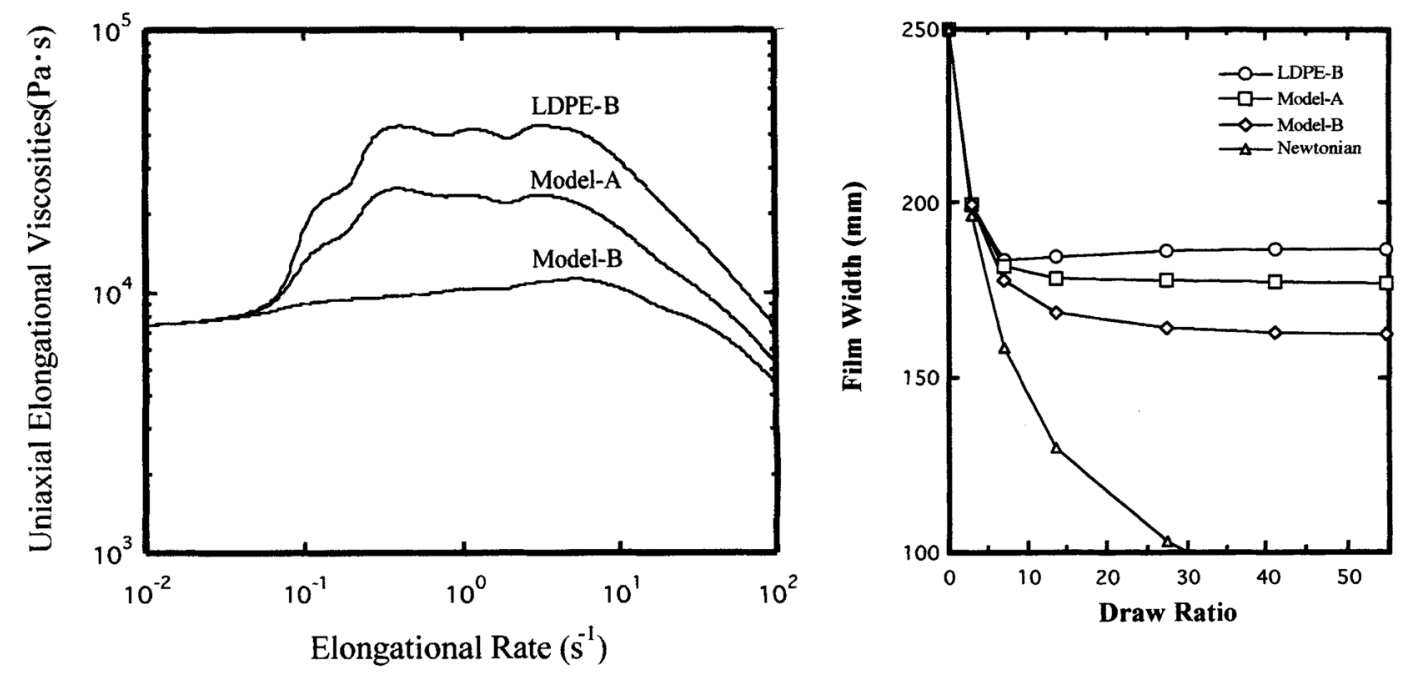

FIG. 22. Uniaxial extensional viscosity vs extensional strain rate predicted by the multimode PTT constitutive equation for LDPE-B: top; Model-A: middle; Model-B: bottom uniaxial strain hardening (left) and related predictions for film width vs DR including comparison with corresponding Newtonian predictions by using the 2D kinematic model (right), where $\mathrm{DR}=32.7$, die width $=250 \mathrm{~mm}$, and $\mathrm{X}=90 \mathrm{~mm}$. Reproduced with permission from Satoh et al., "Viscoelastic simulation of film casting process for a polymer melt," Polym. Eng. Sci. 41(9), 1564 (2001). Copyright 2001 John Wiley and Sons. 


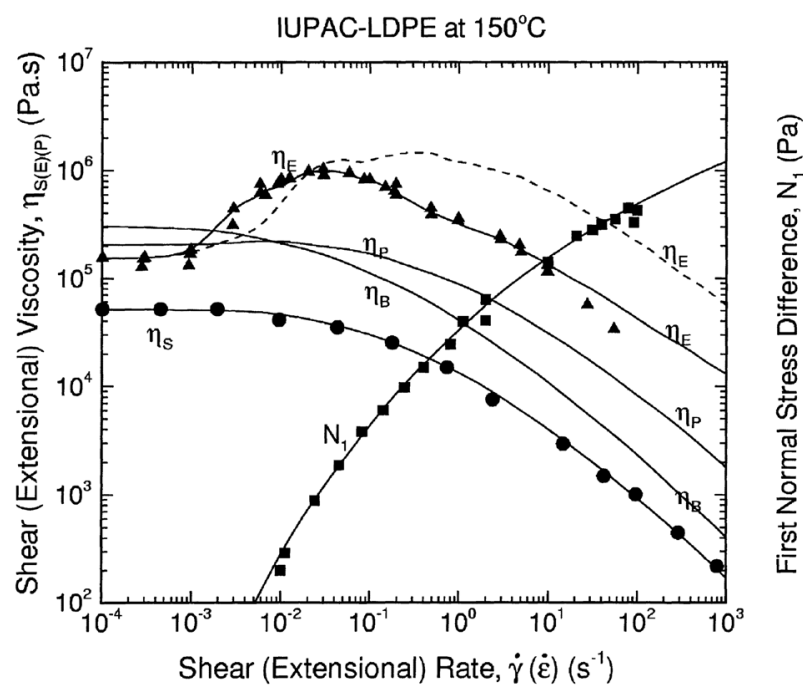

FIG. 23. Prediction of steady shear viscosity $\left(\eta_{S}\right)$, first normal stress difference $\left(N_{1}\right)$ uniaxial $\left(\eta_{E}\right)$, planar $\left(\eta_{P}\right)$, and biaxial $\left(\eta_{B}\right)$ extensional viscosities by using the integral constitutive equation of the K-BKZ type with the PSM strain-memory function [Eq. (56)] for IUPAC-LDPE melt $\mathrm{A}$ at $150^{\circ} \mathrm{C}$. Solid symbols visualize experimental data. Solid lines represent model predictions when the $\beta$ parameter in Eq. (56) is allowed to vary with the relaxation time; the dashed line corresponds to the uniaxial extensional viscosity predicted by using a single value of $\beta$. Reproduced with permission from E. Mitsoulis, "Numerical simulation of entry flow of the IUPAC-LDPE melt," J. Non-Newtonian Fluid Mech. 97(1), 13 (2001). Copyright 2001 Elsevier.

of the conventional viscoelastic model, i.e., NI decreases with the increased extensional strain hardening and the relaxation time. Note that the model uses only one constant relaxation time and modulus, and its ability to describe rheological experimental data has not been provided by the authors.

This constitutive equation was utilized in the following studies: $1 \mathrm{D}$ (2 works), ${ }^{77,78} 1.5 \mathrm{D}(0), 2 \mathrm{D}$ (1 work), ${ }^{103}$ and $3 \mathrm{D}(0)$.

\section{Boundary conditions for viscoelastic constitutive equations}

If viscoelastic constitutive equations are used, the additional boundary stress condition at the die exit must be specified. This boundary condition is given by both, the flow in the die (upstream) and the extensional flow in the drawing length (downstream). Accurate determination of this additional boundary stress value therefore requires an intensive numerical computation. ${ }^{46}$ The following paragraphs summarize the approaches used to determine these types of boundary conditions (see also Tables II-V).

Anturkar and $\mathrm{Co}^{83}$ in their study, using the generalized upperconvected Maxwell model, estimated the axial component of the stress tensor, $\tau_{x x}$, as the mean stress value for a fully developed slit flow in an infinitely wide die. Silagy et al. ${ }^{27,28}$ based on Denn et al. ${ }^{147}$ and Demay et al. ${ }^{88,148}$ assumed two different stress states at the end of the die. In the first case, the extra stress in the machine direction, $\tau_{x x}$, equals zero, so the extra stresses are completely released due to the die swell, or the second, which assumed the mean value of the extra stress after flow in an infinite die with a rectangular cross section, while the transversal extra stress, $\tau_{y y}$, is set to the value obtained from the Newtonian solution. They found that the initial stress conditions at the die exit had little effect on the final shape of the film, but calculations were performed only for low Deborah numbers. Iyengar and $\mathrm{Co}^{84}$ took a different approach, and, instead of specifying the axial stress component, set the ratio $\tau_{z z} / \tau_{x x}$ to the value between two extreme cases for planar extensional flow and a fully developed slit flow in the die noting that the true stress ratio should have lied in their range. Iyengar ${ }^{149}$ then reported that both extreme cases with corresponding stress ratios provide very similar velocity and stress profiles. Debbaut et al. ${ }^{113}$ in their viscoelastic study assumed initial stresses of zero, same as in Smith's work.

For a multilayer film casting analysis (based on a single-mode modified Giesekus model), Pis-Lopez and $\mathrm{Co}^{76,150}$ showed that if the aspect ratio (defined here as the ratio of the total film thickness at the die exit to the drawing distance $2 e_{0} / X$ ) is smaller than 0.05 , the velocity and stress profiles converge to the same values, regardless of whether the initial stress condition is based on the assumption of a fully developed slit flow or a fully developed planar extensional flow. In another study using a multi-mode model approach, Denn ${ }^{151}$ left the longest relaxation mode unspecified at the die exit, and rest of the modes were set with respect to this mode. In contrast, Christodoulou et al ${ }^{46}$ concluded that the shortest mode should be left unspecified with the reasoning that the longest mode $\tau_{x x(N)}^{p}$ is mainly determined by the flow inside the die, while the shorter modes $\tau_{x x(j)}^{p}$ are determined by the external flow in the air-gap.

Beris and $\mathrm{Liu}^{152,153}$ in their fiber spinning study for the single mode UCM viscoelastic liquid specified the die exit stress state through the ratio of normal to axial stress, $\tau_{y y} / \tau_{x x}$, and not each component separately. This value was approximated as the value below the homogeneous steady extensional flow at the effective extensional strain rate. For the viscoelastic multimode model, Denn ${ }^{151}$ also specified $\tau_{x x(j)}^{p} / \tau_{x x(N)}^{p}$ for $\mathrm{j}<\mathrm{N}$ as an extra condition to $\tau_{y y(j)}^{p} / \tau_{x x(j)}^{p}$ for all relaxation modes.

Devereux and Denn ${ }^{154}$ proposed the same distribution between partial stresses as in the case of a fully developed capillary flow with neglected radial partial stresses. The remaining initial stresses were adjusted to satisfy the downstream boundary condition [see Eq. (58)],

$$
\frac{\tau_{x x(j)}^{p}}{\tau_{x x(N)}^{p}}=\frac{\lambda_{j} G_{j}}{\sum_{j=1}^{N} \lambda_{j} G_{j}} .
$$

Note that Gagon and Denn ${ }^{155}$ simplified the above-mentioned relationship for the wedge spectrum into

$$
\frac{\tau_{\mathrm{xx}(\mathrm{j})}}{\tau_{\mathrm{xx}(\mathrm{N})}}=\frac{\lambda_{\mathrm{j}}}{\lambda_{\mathrm{N}}} .
$$

Barborik and Zatloukal ${ }^{37,38}$ recently defined the state of the stress at the die exit by the ratio of the second to the first normal stress difference, $-N_{2} / N_{1}$, calculated from the upstream side by using the viscoelastic modified Leonov constitutive equation,

$$
-\frac{\mathrm{N}_{2}}{\mathrm{~N}_{1}}=-\frac{\bar{\tau}_{\mathrm{zz}}(0)-\bar{\tau}_{\mathrm{yy}}(0)}{\bar{\tau}_{\mathrm{xx}}(0)-\bar{\tau}_{\mathrm{zz}}(0)} .
$$


It has been found that if the Deborah number is less than 0.1 , the choice of initial stress conditions at the die exit has little effect on the steady-state calculations. However, at higher Deborah numbers, the die exit stress state, which may be influenced, for example, by extrusion die design, starts to significantly affect the neck-in phenomenon.

\section{Overview on steady-state film casting modeling}

Initial efforts have been made for a fiber spinning process in which the flow kinematics are mathematically similar when considered as a one-dimensional flow for the Newtonian and Maxwell fluids by Gelder ${ }^{156}$ and Fisher, ${ }^{157,158}$ respectively. These studies focused on the draw resonance phenomenon that Christensen ${ }^{159}$ and Miller ${ }^{160}$ first encountered, and who postulated that the nature of this phenomenon is not of viscoelastic, as it can also be observed in Newtonian fluids. Extending the kinematics of the process to two or three dimensions, both processes become different and one can observe phenomena in the film casting, which have no counterpart in the fiber spinning, i.e., neck-in and edge-beading. The above preliminary studies provided the background for extended studies on the extrusion film casting (EFC). Initial attempts to simulate EFC operations were devoted to investigating the stability of the process and determining the onset of draw resonance, rather than quantifying the extent of the neck-in phenomenon. The very first study of EFC process modeling in this way was carried out by Yeow ${ }^{80}$ using numerical modeling. For the steady-state solution, he used a one-dimensional isothermal model for Newtonian fluid (planar extensional free surface flow) and investigated the effect of introduced small two-dimensional perturbances on flow stability (namely, transverse perturbations). The edge-effects, surface tension, aerodynamic drag, fluid inertia, and gravity were neglected. A small curvature of the film was assumed along with a uniform axial stress and axial velocity over the film thickness. Due to the assumed free surface flow kinematics in the drawing section, the model could not capture the edge-bead defect and the shrinkage in the width of the film, which was considered to be infinitely wide. The film thickness could only change in the machine direction.

Aird and Yeow ${ }^{81}$ continued this mathematical background for the 1-dimensional (1D) model and extended the analysis for power-law fluids. Consequently, Anturkar and $\mathrm{Co}^{83}$ and Iyengar and $\mathrm{Co}^{75,84}$ used isothermal generalized upper-convected Maxwell and Giesekus constitutive equations for linear and non-linear analysis in viscoelastic fluid simulations. The first isothermal attempts to model the necking phenomena were performed by Sergent ${ }^{161}$ in 1977 and then by Cotto, Duffo, and Barq ${ }^{18,87,88}$ for non-isothermal conditions.

Another milestone work was set by Dobroth and Erwin ${ }^{55}$ in 1986, who pointed out that there is a planar and uniaxial extensional deformation at the center of the film and at the edge, respectively, and that the extent of the edge-beads and the interrelated neckin phenomenon is determined by the interplay between these two regions through an edge stress effect. This idea was consequently confirmed experimentally by Ito et al. ${ }^{52}$ The assumption of a planaruniaxial distribution in the Dobroth and Erwin model can therefore be considered reasonable. Just note that, in the case of fiber spinning, only a uniaxial extensional flow can be observed.
Some authors have attempted to relate and quantify the gauge of the observed necking in terms of rheological parameters, such as shear, uniaxial, and planar extensional viscosity. Many authors have reported that the strain hardening in uniaxial extension may reduce the extent of the necking phenomena. ${ }^{39,72,74,113}$ This idea was continued by Ito, ${ }^{53}$ who related the neck-in intensity to rheological parameters, such as the ratio of planar viscosities in axial and transverse directions, and derived an analytical equation for the edge line of Newtonian and Maxwell fluids. In accordance with the article by Dobroth and Erwin, ${ }^{55}$ who, as the first recognized deformation type in the drawing area, Shiromoto ${ }^{7,8,33}$ recently presented the idea that the extent of the necking should not have been described by uniaxial extensional viscosity only in addition to take-up length but as the ratio of planar and uniaxial extensional viscosities reflecting the deformation type in the central and edge portions of the film in the drawing section. In addition to performing non-isothermal viscoelastic simulations, they also proposed a theoretical model based on the force balance and the deformation type of the film in order to predict necking behavior.

More recently, the 2-dimensional (2D) membrane model has been introduced by d'Halewyu ${ }^{112}$ and Debbaut ${ }^{113}$ for Newtonian and viscoelastic fluids, respectively. This frequently used model is able to predict the dog-bone defect, i.e., development of edge-beads under stationary conditions.

Silagy et al. ${ }^{27}$ improved and enriched the membrane model with a supplementary kinematic hypothesis originally provided by Narayanaswamy ${ }^{162}$ in his paper on float glass stretching and performed an extended isothermal study on the effect of processing conditions on film geometry and EFC stability analysis for Newtonian and Upper convected Maxwell (UCM) fluids. Due to the assumptions used in the flow kinematics, this model was able to cover the reduction in the film width and thus predict the neck-in phenomenon, but still could not predict the edge-beading. This limitation was removed in their subsequent work, ${ }^{28}$ where a $2 \mathrm{D}$ isothermal membrane model combined with the Phan-Thien and Tanner (PTT) constitutive equation was developed, and the obtained steady and transient stability results were compared with its $1.5 \mathrm{D}$ predecessor. In the following years, the $1.5 \mathrm{D}$ version of Sylagy's membrane model was used in many studies, and much work was done on EFC under non-isothermal conditions including crystallization effects (see Refs. 67, 91-95, 163, and 164). A three dimensional model for EFC simulation was further developed by Sakaki et al. ${ }^{114}$ To solve the model equations, it was necessary to use the finite element method. The problem was considered isothermal, steady state, and Newtonian. A process parameter space was chosen to reflect the industrial processing conditions. The model captured the development of both the neck-in and the edge beading, and the effect of $D R, X$, and die width was investigated. They found that the intensity of the neck-in and the edge beading was affected by $D R$ and $X$, but not by the width of the die. The extent of the neck-in increased with increasing $D R$ and $X$. Recently, this approach has been extended by Zheng et al. ${ }^{115}$ for a non-isothermal steady Newtonian fluid. Kometani et al. ${ }^{111}$ performed experimental and theoretical investigations of the effects of rheological properties on the neck-in in the film casting. For the two tested PP and LDPE materials, without significant differences in viscoelastic properties, except for extensional ones (LDPE showed a remarkable increase in extensional viscosity at high strain rates), the neck-in extent for PP under higher 
draw ratios increased over LDPE where the neck-in was constant and independent of the draw ratio. Based on these experiments, the authors concluded that the neck-in phenomenon in film casting depends on the extensional rheological properties. Furthermore, they utilized a simulation based on three different rheological models (the Newtonian, Bird-Carreau, and Giesekus model) to assess its applicability for film casting modeling. The results obtained by simulation based on the Giesekus model were in quantitative agreement with the experimental observations for both polymers, but the other two models used did not provide predictions well describing the measured data due to their inaccurate representation of extensional viscosities.

The influence of macromolecular architecture on the extent of the necking phenomenon has been investigated by Ito et al. . $^{5,53}$ (effects of the draw ratio and the take-up length on the necking for LDPE, HDPE, and mLLDPE) and Baird et al. ${ }^{68,69}$ (effects of long chain branching and molecular weight distribution on the necking for LDPE, mLLDPE, and Ziegler-Natta catalyzed LLDPE). Research on a multi-layer film casting considering Giesekus fluid has been performed in studies of Pis-Lopez and Co for the steady state ${ }^{76}$ and stability analysis. ${ }^{150}$

Recently, Pol et al. ${ }^{41,42}$ and Chikhalikar et al. ${ }^{43}$ published a number of articles in which they performed experimental and theoretical investigations of the effects of long chain branching and molecular weight distribution on the extent of the necking phenomenon. For this purpose, they used the 1.5D membrane model, originally proposed by Silagy, ${ }^{27}$ the multi-mode eXtended PomPom constitutive equation and the multi-mode Rolie-Poly stretch constitutive equation, respectively, for the long chain branched (LDPE and PP) and the linear (HDPE and PP) polymers. Fixing the $D R$ and $X$, they found that the extent of the necking was smaller for HDPE with a broader molecular weight distribution than for LLDPE with a narrower molecular weight distribution and further that long chain branched LDPE necks-in to lower extent than linear HDPE or LLDPE (i.e., an increase in long chain branching is more effective in neck-in suppression than just broadening MWD). In a subsequent study, Pol and Thete ${ }^{98}$ switched from the 1.5D model that was used in their predecessor works on this topic to the twodimensional model originally proposed by Ito et al. ${ }^{53}$ incorporating the UCM constitutive equation. In addition, they derived an analytical solution for low and high Deborah numbers. They found that while the film width of the modeled LLDPE continuously decreased with the increased draw ratio, the film width for LDPE decreased with the increased draw ratio for long take-up lengths and remained constant for shorter ones. This means that there is a locus of points in the attainable region that divides the $D R-D e$ plane into sections where the dependence of the neck-in on the draw ratio has opposite trends.

In their latest work, ${ }^{44}$ they focused on the effects of the individual viscoelastic relaxation modes of a polymer melt on its behavior in the polymer melt extrusion film casting process using UCM and PTT constitutive equations and the $1.5 \mathrm{D}$ isothermal membrane model. They found that the experimental data for long-chain branched LDPE was better described using the UCM model, while the PTT model provided better simulation results for the experimental data with linear LLDPE.

Although the actual EFC manufacturing process involves complex 3-dimensional (3D) kinematics whose numerical simulation can be very challenging, many authors have shown that the EFC $1.5 \mathrm{D}$ membrane model (originally proposed by Silagy) is able to provide results that are in good agreement with the experimental data (if appropriate constitutive equations are used).

\section{CONCLUSIONS}

Modeling of the steady-state film casting process began in 1974 using a $1 \mathrm{D}$ kinematic approach. $1.5 \mathrm{D}$ and $2 \mathrm{D}$ kinematic models were developed at 1990 and are currently the most commonly used (in more than 73\%). A full 3D kinematic approach was introduced in 1996, but due to its complexity, its use is very rare (less than 5\%) and usually only applies to viscous fluids. The following most commonly used simplifying assumptions are used to overcome numerical difficulties in steady-state cast film process modeling: reduction in dimensionality $(1 \mathrm{D}, 1.5 \mathrm{D}$, and $2 \mathrm{D})$ and isothermal conditionsconstant temperature field, non-transient description, incompressible fluid, constant density, excluded inertia effects, excluded effects of gravitational forces, constant boundary conditions, unrealistic or simplified constitutive equations, neglected aerodynamic drag, neglected surface tension, neglected die swell, neglected edge-effects, excluded crystallization (temperature and flow-induced), neglected the sag of the film in non-vertical installations (film curvature), and effects of other devices (air knife, vacuum box, and electrostatic pinning).

The following constitutive equations have already been used in the steady-state modeling of the extrusion cast film process: viscous-Newtonian model, generalized Newtonian model (utilizing Cross, Carreau and Carreau-Yasuda viscosity functions); elasticincremental Hooks law with creep; viscoelastic-upper convected Maxwell model, generalized upper convected Maxwell model with deformation rate dependent relaxation time and viscosity, linear and exponential PTT model, Larson model, K-BKZ model with Papanastasiou-Scriven-Macosko (PSM) damping function, Leonov model modified by specific type of recoverable strain dependent dissipation function, Giesekus model, modified Giesekus with finite chain stretch, eXtended Pom-Pom model (XPP), and Rolie-PolyStretch model (RP-S).

Intensive experimental research on extrusion film casting in relation to the neck-in began in 1986 and continues to this day. Most of the research reported in the open literature focuses on polyolefins such as LDPE, LLDPE, and PP, while experimental studies for other polymers (PET, HDPE, or polyethersulfone-PES) are very rare.

Based on experimental and theoretical studies presented in the open literature, the following variables were found to be the key with respect to the neck-in phenomenon: draw ratio, Deborah number (i.e., melt relaxation time, melt velocity at the die exit, and air-gap), film cooling, ratio of the second and first normal stress difference at the die exit, uniaxial extensional strain hardening, and planar-touniaxial extensional viscosity ratio. Uniaxial and planar extensional viscosities can be considered as key material parameters because during the polymer melt stretching in the post die area, the middle of the film undergoes planar elongation, while the material at the edge undergoes uniaxial elongation. However, measuring uniaxial and planar extensional viscosities at very wide deformation rates is still a very difficult task because the generation and control of extensional flows are difficult. Likewise, the role of draw ratio, heat 
transfer coefficients, flow induced crystallization, and flow history (generated inside the extrusion die as the $-N_{2} / N_{1}$ ratio), molecular architecture of polymer melts in the film formation and its stability is still not fully understood yet due to the absence of relevant experimental and theoretical studies.

There is a currently attempt to relate flow stability to the molecular characteristics of the polymers used through advanced molecular constitutive equations such as XPP and RP-S. However, their use is still limited because these models do not allow realistic rheological description of polymers or polymer mixtures with an internal structure, which does not correspond to the molecular assumptions under which these constitutional equations were derived. Another major problem in experimental and theoretical flow stability research is the neglect of the influence of memory and flow history of polymer melts in extrusion heads on the stability of film formation in the post die area, as evidenced by recently published work.

Further research in the following areas can be expected to help significantly understand the formation stability of polymeric flat films:

- development and use of suitable rheological techniques for the determination of uniaxial and especially planar extensional viscosities at high deformation rates;

- development/modification and use of advanced constitutive equations with the ability to handle measured extensional rheology data for polymers, polymer blends, and filled polymers;

- elucidation of the role of polymer molecular architecture, flow history, heat transfer coefficients, and flow induced crystallization; and

- understanding the role of the draw ratio in film formation for branched polymers.

\section{ACKNOWLEDGMENTS}

The authors would like to acknowledge the Institutional Support Project 2020 (Polymer Centre at Faculty of Technology, Tomas Bata University in Zlin).

\section{DATA AVAILABILITY}

Data sharing is not applicable to this review article as no new experimental data were generated.

\section{REFERENCES}

${ }^{1}$ R. W. Baker, Membrane Technology and Applications (John Wiley \& Sons, Ltd., 2012).

${ }^{2}$ P. Arora and Z. (John) Zhang, "Battery separators," Chem. Rev. 104(10), 4419 (2004).

${ }^{3}$ S. S. Zhang, "A review on the separators of liquid electrolyte Li-ion batteries," J. Power Sources 164(1), 351 (2007).

${ }^{4}$ M. Ulbricht, “Advanced functional polymer membranes," Polymer 47(7), 2217 (2006).

${ }^{5}$ T. Kanai and G. A. Campbell, Film Processing (Hanser Publishers, Munich, 1999).

${ }^{6}$ T. Kanai and G. A. Campbell, Film Processing Advances (Hanser Publishers, Munich, 2014).
${ }^{7}$ K. Christodoulou, S. G. Hatzikiriakos, and E. Mitsoulis, "Numerical simulation of the wire-pinning process in PET film casting: Steady-state results," AIChE J. 58(7), 1979 (2012).

${ }^{8}$ W. S. Smith, "Simulating the cast film process using an updated Lagrangian finite element algorithm," Ph.D. thesis, McMaster University, 2001

${ }^{9}$ K. Resch, G. M. Wallner, C. Teichert, and M. Gahleitner, "Highly transparent polypropylene cast films: Relationships between optical properties, additives, and surface structure," Polym. Eng. Sci. 47(7), 1021 (2007).

${ }^{10}$ Z. Tadmor and C. G. Gogos, Principles of Polymer Processing, 2nd ed. (John Wiley \& Sons, Hoboken, New Jersey, 2006).

${ }^{11}$ J. R. A. Pearson, Mechanics of Polymer Processing (Elsevier Applied Science Publishers, London, 1985).

${ }^{12}$ W. S. Smith, "Nonisothermal film casting of a viscous fluid," Ph.D. thesis, McMaster University, 1997.

${ }^{13}$ M. Zatloukal and R. Kolarik, "Investigation of convective heat transfer in 9-layer film blowing process by using variational principles," Int. J. Heat Mass Transfer 86, 258 (2015).

${ }^{14}$ R. Kolarik, M. Zatloukal, and M. Martyn, "The effect of polyolefin extensional rheology on non-isothermal film blowing process stability," Int. J. Heat Mass Transfer 56(1-2), 694 (2013).

${ }^{15}$ R. Kolarik and M. Zatloukal, "Modeling of nonisothermal film blowing process for non-Newtonian fluids by using variational principles," J. Appl. Polym. Sci. 122(4), 2807 (2011).

${ }^{16} \mathrm{M}$. Zatloukal and J. Vlček, "Application of variational principles in modeling of the film blowing process for high stalk bubbles," J. Non-Newtonian Fluid Mech. 133(1), 63 (2006)

${ }^{17} \mathrm{M}$. Zatloukal and J. Vlček, "Modeling of the film blowing process by using variational principles," J. Non-Newtonian Fluid Mech. 123(2-3), 201 (2004).

${ }^{18}$ D. Cotto, P. Duffo, and J. M. Haudin, "Cast film extrusion of polypropylene films," Int. Polym. Process. 4(2), 103 (1989).

${ }^{19} \mathrm{~S}$. A. Ashter, Introduction to Bioplastics Engineering, Plastics Design Library (William Andrew Publishing, Oxford, 2016).

${ }^{20}$ F. Wu, M. Misra, and A. Mohanty, in Annual Technical Conference - ANTEC, Conference Proceedings 2019-March (Society of Plastics Engineers, Detroit, USA, 2019).

${ }^{21}$ T. I. Burghelea, H. J. Grieß, and H. Münstedt, "An in situ investigation of the draw resonance phenomenon in film casting of a polypropylene melt," J. NonNewtonian Fluid Mech. 173-174, 87 (2012).

${ }^{22}$ P. Barq, J. M. Haudin, J. F. Agassant, H. Roth, and P. Bourgin, "Instability phenomena in film casting process," Int. Polym. Process. 5(4), 264 (1990).

${ }^{23}$ Y. Demay and J.-F. Agassant, "An overview of molten polymer drawing instabilities,” Int. Polym. Process. 29(1), 128 (2014).

${ }^{24}$ R. G. Larson, "Instabilities in viscoelastic flows," Rheol. Acta 31(3), 213 (1992).

${ }^{25}$ Y. Kwon, "One-dimensional modeling of flat sheet casting or rectangular fiber spinning process and the effect of normal stresses," Korea-Aust. Rheol. J. 11(3), 225 (1999).

${ }^{26}$ N. D. Polychronopoulos and T. D. Papathanasiou, "A study on the effect of drawing on extrudate swell in film casting," Appl. Rheol. 25(4), 42425 (2015).

${ }^{27}$ D. Silagy, Y. Demay, and J.-F. Agassant, "Study of the stability of the film casting process,” Polym. Eng. Sci. 36(21), 2614 (1996).

${ }^{28}$ D. Silagy, Y. Demay, and J. F. Agassant, "Stationary and stability analysis of the film casting process," J. Non-Newtonian Fluid Mech. 79(2-3), 563 (1998).

${ }^{29}$ S. Bourrigaud, G. Marin, V. Dabas, C. Dupuy, and D. Silagy, "The draw ratioDeborah number diagram: A useful tool for coating applications," Polym. Eng. Sci. 46(3), 372 (2006).

${ }^{30}$ C. W. Seay and D. G. Baird, "Sparse long-chain branching's effect on the filmcasting behavior of PE,” Int. Polym. Process. 24(1), 41 (2009)

${ }^{31}$ H. J. Grieß, "Fließverhalten von Polypropylenschmelzen innerhalb und außerhalb einer Kleiderbügeldüse (Flow properties of polypropylene melts inside and outside a coat-hanger die)," Ph.D. thesis, University Erlangen-Nuremberg, 2014.

${ }^{32}$ H. Münstedt, "Extensional rheology and processing of polymeric materials," Int. Polym. Process. 33(5), 594 (2018). 
${ }^{33} \mathrm{H}$. Münstedt, Elastic Behavior of Polymer Melts, Rheology and Processing (Hanser Publications, Munich, Cincinnati, 2019).

${ }^{34} \mathrm{H}$. Münstedt, "Elastic behavior and processing of polymer melts," AIP Conf. Proc. 2107, 030001 (2019).

${ }^{35}$ T. Barborik and M. Zatloukal, "Effect of heat transfer coefficient, draw ratio, and die exit temperature on the production of flat polypropylene membranes," Phys. Fluids 31(5), 053101 (2019).

${ }^{36}$ D. M. Shin, J. S. Lee, J. M. Kim, H. W. Jung, and J. C. Hyun, "Transient and steady-state solutions of $2 \mathrm{D}$ viscoelastic nonisothermal simulation model of film casting process via finite element method," J. Rheol. 51(3), 393 (2007).

${ }^{37}$ T. Barborik, M. Zatloukal, and C. Tzoganakis, "On the role of extensional rheology and Deborah number on the neck-in phenomenon during flat film casting," Int. J. Heat Mass Transfer 111, 1296 (2017).

${ }^{38}$ T. Barborik and M. Zatloukal, "Effect of die exit stress state, Deborah number, uniaxial and planar extensional rheology on the neck-in phenomenon in polymeric flat film production," J. Non-Newtonian Fluid Mech. 255, 39 (2018).

${ }^{39} \mathrm{~N}$. Satoh, H. Tomiyama, and T. Kajiwara, "Viscoelastic simulation of film casting process for a polymer melt," Polym. Eng. Sci. 41(9), 1564 (2001).

${ }^{40} \mathrm{~S}$. Shiromoto, "The mechanism of neck-in phenomenon in film casting process," Int. Polym. Process. 29(2), 197 (2014).

${ }^{41}$ H. V. Pol, S. S. Thete, P. Doshi, and A. K. Lele, "Necking in extrusion film casting: The role of macromolecular architecture," J. Rheol. 57(2), 559 (2013).

${ }^{42}$ H. Pol, S. Banik, L. B. Azad, S. Thete, P. Doshi, and A. Lele, "Nonisothermal analysis of extrusion film casting process using molecular constitutive equations," Rheol. Acta 53(1), 85 (2014).

${ }^{43}$ K. Chikhalikar, S. Banik, L. B. Azad, K. Jadhav, S. Mahajan, Z. Ahmad, S. Kulkarni, S. Gupta, P. Doshi, H. Pol, and A. Lele, "Extrusion film casting of long chain branched polypropylene," Polym. Eng. Sci. 55(9), 1977 (2015).

${ }^{44}$ S. S. Thete, P. Doshi, and H. V. Pol, "New insights into the use of multimode phenomenological constitutive equations to model extrusion film casting process," J. Plast. Film Sheeting 33(1), 35 (2017).

${ }^{45}$ S. M. Alaie and T. C. Papanastasiou, "Film casting of viscoelastic liquid," Polym. Eng. Sci. 31(2), 67 (1991).

${ }^{46}$ K. Christodoulou, S. G. Hatzikiriakos, and D. Vlassopoulos, "Stability analysis of film casting for PET resins using a multimode Phan-Thien-Tanner constitutive equation," J. Plast. Film Sheeting 16(4), 312 (2000).

${ }^{47}$ R. Dhadwal, S. Banik, P. Doshi, and H. Pol, "Effect of viscoelastic relaxation modes on stability of extrusion film casting process modeled using multi-mode Phan-Thien-Tanner constitutive equation," Appl. Math. Model. 47, 487 (2017).

${ }^{48} \mathrm{~K}$. Canning and A. Co, "Edge effects in film casting of molten polymers," J. Plast. Film Sheeting 16(3), 188 (2000).

${ }^{49}$ K. Frey, C. D. Cleaver, and G. Jerdee, in Proceedings of the 2000 TAPPI Polymers, Laminations, and Coating Conference (Tappi Press, Chicago, IL, USA, 2000), p. 709 .

${ }^{50}$ J. S. Lee, H. W. Jung, and J. C. Hyun, in Annual Technical Conference - ANTEC, Conference Proceedings (Society of Plastics Engineers, 2003), Vol. 1, p. 54.

${ }^{51} \mathrm{~J}$. S. Lee, H. W. Jung, and J. C. Hyun, "Stabilization of film casting by an encapsulation extrusion method," J. Non-Newtonian Fluid Mech. 117(2-3), 109 (2004).

${ }^{52}$ H. Ito, M. Doi, T. Isaki, M. Takeo, and K. Yagi, "2D flow analysis of film casting process," J. Soc. Rheol. Jpn. 31(3), 149 (2003).

${ }^{53} \mathrm{H}$. Ito, M. Doi, T. Isaki, and M. Takeo, "A model of neck-in phenomenon in film casting process," J. Soc. Rheol. Jpn. 31(3), 157 (2003).

${ }^{54}$ S. Shiromoto, Y. Masutani, M. Tsutsubuchi, Y. Togawa, and T. Kajiwara, "The effect of viscoelasticity on the extrusion drawing in film-casting process," Rheol. Acta 49(7), 757 (2010).

${ }^{55} \mathrm{~T}$. Dobroth and L. Erwin, "Causes of edge beads in cast films," Polym. Eng. Sci. 26(7), 462 (1986).

${ }^{56}$ F. N. Cogswell, "Measuring the extensional rheology of polymer melts," Trans. Soc. Rheol. 16(3), 383 (1972).

${ }^{57} \mathrm{M}$. Zatloukal, "Measurements and modeling of temperature-strain rate dependent uniaxial and planar extensional viscosities for branched LDPE polymer melt," Polymer 104, 258 (2016).
${ }^{58}$ M. Zatloukal, in Annual Technical Conference - ANTEC, Conference Proceedings (Society of Plastics Engineers, 2013), Vol. 3, p. 2275.

${ }^{59}$ C. Dae Han, Rheology in Polymer Processing (Academic Press, New York, 1976), p. 366.

${ }^{60}$ C. Dae Han, in Rheological Measurement, edited by A. A. Collyer and D. W. Clegg (Chapman \& Hall, London, 1998), Vol. 190.

${ }^{61} \mathrm{~J}$. Musil and M. Zatloukal, "Experimental investigation of flow induced molecular weight fractionation phenomenon for two linear HDPE polymer melts having same $M_{\mathrm{n}}$ and $M_{\mathrm{w}}$ but different $M_{\mathrm{z}}$ and $M_{\mathrm{z}+1}$ average molecular weights," Chem. Eng. Sci. 81, 146 (2012).

${ }^{62}$ R. Pivokonsky, M. Zatloukal, and P. Filip, "On the predictive/fitting capabilities of the advanced differential constitutive equations for linear polyethylene melts," J. Non-Newtonian Fluid Mech. 150(1), 56 (2008).

${ }^{63}$ R. Pivokonsky, M. Zatloukal, and P. Filip, "On the predictive/fitting capabilities of the advanced differential constitutive equations for branched LDPE melts," J. Non-Newtonian Fluid Mech. 135(1), 58 (2006).

${ }^{64} \mathrm{M}$. Zatloukal, "Differential viscoelastic constitutive equations for polymer melts in steady shear and elongational flows," J. Non-Newtonian Fluid Mech. 113(2-3), 209 (2003).

${ }^{65}$ C. D. McGrady, C. W. Seay, and D. G. Baird, "Effect of sparse long-chain branching on the film-casting behavior for a series of well-defined HDPEs," Int. Polym. Process. 24(5), 428 (2009).

${ }^{66} \mathrm{~K}$. Aniunoh and G. M. Harrison, "The processing of polypropylene cast films. I. Impact of material properties and processing conditions on film formation," Polym. Eng. Sci. 50(6), 1151 (2010).

${ }^{67} \mathrm{G}$. Lamberti, "Flow-induced crystallization during isotactic polypropylene film casting," Polym. Eng. Sci. 51(5), 851 (2011).

${ }^{68} \mathrm{M}$. N. Uvieghara, "The effect of Deborah number and aspect ratio on the film casting of LLDPE melts," Ph.D. thesis, University of Maine, 2004.

${ }^{69}$ D. Acierno, L. Di Maio, and G. Cuccurullo, "Analysis of temperature fields in film casting," J. Polym. Eng. 19(2), 75 (1999).

${ }^{70} \mathrm{~K}$. Canning, B. Bian, and A. Co, "Film casting of a low density polyethylene melt," J. Reinf. Plast. Compos. 20(5), 366 (2001).

${ }^{71}$ G. Lamberti and G. Titomanlio, "Evidences of flow induced crystallization during characterized film casting experiments," Macromol. Symp. 185(1), 167 (2002).

${ }^{72} \mathrm{~N}$. Toft and M. Rigdahl, "Extrusion coating with metallocene-catalysed polyethylenes," Int. Polym. Process. 17(3), 244 (2002).

${ }^{73}$ K. K. Aniunoh and G. M. Harrisony, "Experimental investigation of film formation: Film casting," J. Plast. Film Sheeting 22(3), 177 (2006).

${ }^{74} \mathrm{~S}$. Kouda, "Prediction of processability at extrusion coating for low-density polyethylene," Polym. Eng. Sci. 48(6), 1094 (2008).

${ }^{75}$ V. R. Iyengar and A. Co, "Film casting of a modified Giesekus fluid: Stability analysis,” Chem. Eng. Sci. 51(9), 1417 (1996).

${ }^{76}$ M. E. Pis-Lopez and A. Co, "Multilayer film casting of modified Giesekus fluids Part 1. Steady-state analysis," J. Non-Newtonian Fluid Mech. 66(1), 71 (1996).

${ }^{77}$ S. Smith and D. F. E. Stolle, "Draw resonance in film casting as a response problem using a material description of motion," J. Plast. Film Sheeting 16(2), 95 (2000).

${ }^{78}$ S. Smith and D. Stolle, "A comparison of Eulerian and updated Lagrangian finite element algorithms for simulating film casting," Finite Elem. Anal. Des. 38(5), 401 (2002).

${ }^{79} \mathrm{M}$. Bechert, "Non-Newtonian effects on draw resonance in film casting," J. NonNewtonian Fluid Mech. 279, 104262 (2020).

${ }^{80}$ Y. L. Yeow, "On the stability of extending films: A model for the film casting process," J. Fluid Mech. 66(3), 613 (1974).

${ }^{81}$ G. R. Aird and Y. L. Yeow, "Stability of film casting of power-law liquids," Ind. Eng. Chem. Fundam. 22(1), 7 (1983).

${ }^{82} \mathrm{~W}$. Minoshima and J. L. White, "Stability of continuous film extrusion processes," J. Polym. Eng. 2(3), 211 (1983).

${ }^{83} \mathrm{~N}$. R. Anturkar and A. Co, "Draw resonance in film casting of viscoelastic fluids: A linear stability analysis," J. Non-Newtonian Fluid Mech. 28(3), 287 (1988).

${ }^{84}$ V. R. Iyengar and A. Co, "Film casting of a modified Giesekus fluid: A steadystate analysis," J. Non-Newtonian Fluid Mech. 48(1-2), 1 (1993). 
${ }^{85}$ P. Barq, J. M. Haudin, J. F. Agassant, and P. Bourgin, "Stationary and dynamic analysis of film casting process," Int. Polym. Process. 9(4), 350 (1994).

${ }^{86}$ J. F. Agassant, P. Avenas, J. P. Sergent, and P. J. Carreau, Polymer Processing: Principles and Modeling (Hanser Gardner Publications, 1991).

${ }^{87}$ P. Duffo, B. Monasse, and J. M. Haudin, "Cast film extrusion of polypropylene. Thermomechanical and physical aspects," J. Polym. Eng. 10(1-3), 151 (1991).

${ }^{88}$ P. Barq, J. M. Haudin, and J. F. Agassant, "Isothermal and anisothermal models for cast film extrusion," Int. Polym. Process. 7(4), 334 (1992).

${ }^{89}$ M. Beaulne and E. Mitsoulis, "Numerical simulation of the film casting process," Int. Polym. Process. 14(3), 261 (1999).

${ }^{90}$ D. Acierno, L. Di Maio, and C. C. Ammirati, "Film casting of polyethylene terephthalate: Experiments and model comparisons," Polym. Eng. Sci. 40(1), 108 (2000).

${ }^{91}$ G. Lamberti, G. Titomanlio, and V. Brucato, "Measurement and modelling of the film casting process 1 . Width distribution along draw direction," Chem. Eng. Sci. 56(20), 5749 (2001).

${ }^{92}$ G. Lamberti, V. Brucato, and G. Titomanlio, "Orientation and crystallinity in film casting of polypropylene,” J. Appl. Polym. Sci. 84(11), 1981 (2002).

${ }^{93}$ G. Lamberti, G. Titomanlio, and V. Brucato, "Measurement and modelling of the film casting process: 2 . Temperature distribution along draw direction," Chem. Eng. Sci. 57(11), 1993 (2002).

${ }^{94} \mathrm{G}$. Lamberti and G. Titomanlio, "Analysis of film casting process: The heat transfer phenomena," Chem. Eng. Process.: Process Intensif. 44(10), 1117 (2005).

${ }^{95} \mathrm{G}$. Lamberti and G. Titomanlio, "Analysis of film casting process: Effect of cooling during the path in air," Ind. Eng. Chem. Res. 45(2), 719 (2006).

${ }^{96}$ Y.-G. Zhou, W.-B. Wu, J. Zou, and L.-S. Turng, "Dual-scale modeling and simulation of film casting of isotactic polypropylene," J. Plast. Film Sheeting 32(3), 239 (2015).

${ }^{97}$ M. Bechert, D. W. Schubert, and B. Scheid, "On the stabilizing effects of neck-in, gravity, and inertia in Newtonian film casting," Phys. Fluids 28(2), 024109 (2016).

${ }^{98}$ H. V. Pol and S. S. Thete, "Necking in extrusion film casting: Numerical predictions of the Maxwell model and comparison with experiments," J. Macromol. Sci. Part B 55(10), 984 (2016).

${ }^{99} \mathrm{G}$. Barot and I. J. Rao, "Modeling the film casting process using a continuum model for crystallization in polymers," Int. J. Non. Linear. Mech. 40(7), 939 (2005). ${ }^{100}$ P. Duffo, B. Monasse, and J. M. Haudin, "Influence of stretching and cooling conditions in cast film extrusion of PP films," Int. Polym. Process. 5, 272 (1990).

${ }^{101}$ D. Silagy, Y. Demay, and J. F. Agassant, "Numerical simulation of the film casting process," Int. J. Numer. Methods Fluids 30(1), 1 (1999).

${ }^{102}$ S. Smith and D. Stolle, "Nonisothermal two-dimensional film casting of a viscous polymer," Polym. Eng. Sci. 40(8), 1870 (2000).

${ }^{103}$ S. Smith and D. Stolle, "Numerical simulation of film casting using an updated Lagrangian finite element algorithm,” Polym. Eng. Sci. 43(5), 1105 (2003).

${ }^{104}$ C. Sollogoub, Y. Demay, and J. F. Agassant, "Cast film problem: A non isothermal investigation," Int. Polym. Process. 18(1), 80 (2003).

${ }^{105}$ T. Kajiwara, M. Yamamura, and T. Asahina, "Relationship between neck-in phenomena and rheological properties in film casting," Nihon Reoroji Gakkaishi 34(2), 97 (2006).

${ }^{106}$ C. Sollogoub, Y. Demay, and J. F. Agassant, "Non-isothermal viscoelastic numerical model of the cast-film process," J. Non-Newtonian Fluid Mech. 138(23), 76 (2006).

${ }^{107} \mathrm{~K}$. Aniunoh, "An experimental and numerical study of the film casting process," Ph.D. thesis, Clemson University, 2007.

${ }^{108}$ J. S. Lee and J. M. Kim, "Effect of aspect ratio and fluid elasticity on chain orientation in isothermal film casting process," Korean J. Chem. Eng. 27(2), 409 (2010).

${ }^{109}$ S. Shiromoto, Y. Masutani, M. Tsutsubuchi, Y. Togawa, and T. Kajiwara, “A neck-in model in extrusion lamination process," Polym. Eng. Sci. 50(1), 22 (2010).

${ }^{110}$ Y. Mu, L. Hang, G. Zhao, X. Wang, Y. Zhou, and Z. Cheng, "Modeling and simulation for the investigation of polymer film casting process using finite element method," Math. Comput. Simul. 169, 88 (2020).

${ }^{111}$ H. Kometani, T. Matsumura, T. Suga, and T. Kanai, "Experimental and theoretical analyses of film casting process," J. Polym. Eng. 27(1), 1 (2007).
${ }^{112}$ S. d'Halewyu, J. F. Agassant, and Y. Demay, "Numerical simulation of the cast film process," Polym. Eng. Sci. 30(6), 335 (1990).

${ }^{113}$ B. Debbaut, J. M. Marchal, and M. J. Crochet, "Viscoelastic effects in film casting," Z. Angew. Math. Phys. 46, 679 (1995).

${ }^{114}$ K. Sakaki, R. Katsumoto, T. Kajiwara, and K. Funatsu, "Three-dimensional flow simulation of a film-casting process," Polym. Eng. Sci. 36(13), 1821 (1996).

${ }^{115} \mathrm{H}$. Zheng, W. Yu, C. Zhou, and H. Zhang, "Three-dimensional simulation of the non-isothermal cast film process of polymer melts," J. Polym. Res. 13(6), 433 (2006).

${ }^{116} \mathrm{H}$. Zheng, W. Yu, C. Zhou, and H. Zhang, "Three dimensional simulation of viscoelastic polymer melts flow in a cast film process," Fibers Polym. 8(1), 50 (2007).

${ }^{117}$ A. de Waele, "Viscometry and plastometry," Oil Color Chem. Assoc. J. 6, 33 (1923).

${ }^{118}$ W. Ostwald, "Ueber die Geschwindigkeitsfunktion der Viskosität disperser Systeme. I," Kolloid-Z. 36(2), 99 (1925).

${ }^{119}$ R. B. Bird, R. C. Armstrong, and O. Hassager, Dynamics of Polymeric Liquids: Fluid Mechanics (John Wiley, New York, 1987), Vol. 1.

${ }^{120} \mathrm{M}$. M. Cross, "Rheology of non-Newtonian fluids: A new flow equation for pseudoplastic systems," J. Colloid Sci. 20(5), 417 (1965).

${ }^{121}$ P. J. Carreau, "Rheological equations from molecular network theories," Trans. Soc. Rheol. 16(1), 99 (1972).

${ }^{122}$ K. Yasuda, R. C. Armstrong, and R. E. Cohen, "Shear flow properties of concentrated solutions of linear and star branched polystyrenes," Rheol. Acta 20(2), 163 (1981).

${ }^{123}$ H. Giesekus, "Die elastizität von Flüssigkeiten," Rheol. Acta 5(1), 29 (1966).

${ }^{124} \mathrm{H}$. Giesekus, "A simple constitutive equation for polymer fluids based on the concept of deformation-dependent tensorial mobility," J. Non-Newtonian Fluid Mech. 11(1-2), 69 (1982).

${ }^{125}$ R. G. Larson, Constitutive Equations for Polymer Melts and Solutions (Butterworth-Heinemann, Boston, 1988).

${ }^{126} \mathrm{~J}$. M. Wiest, "A differential constitutive equation for polymer melts," Rheol. Acta 28(1), 4 (1989).

${ }^{127}$ D. Auhl, D. M. Hoyle, D. Hassell, T. D. Lord, O. G. Harlen, M. R. Mackley, and T. C. B. McLeish, "Cross-slot extensional rheometry and the steady-state extensional response of long chain branched polymer melts," J. Rheol. 55(4), 875 (2011).

${ }^{128}$ W. M. H. Verbeeten, G. W. M. Peters, and F. P. T. Baaijens, "Differential constitutive equations for polymer melts: The extended Pom-Pom model," J. Rheol. 45(4), 823 (2001).

${ }^{129}$ T. C. B. McLeish and R. G. Larson, "Molecular constitutive equations for a class of branched polymers: The pom-pom polymer," J. Rheol. 42(1), 81 (1998).

${ }^{130}$ A. E. Likhtman and R. S. Graham, "Simple constitutive equation for linear polymer melts derived from molecular theory: Rolie-Poly equation," J. NonNewtonian Fluid Mech. 114(1), 1 (2003).

${ }^{131}$ G. A. J. Holroyd, S. J. Martin, and R. S. Graham, "Analytic solutions of the Rolie Poly model in time-dependent shear," J. Rheol. 61(5), 859 (2017).

${ }^{132}$ A. I. Leonov, "Nonequilibrium thermodynamics and rheology of viscoelastic polymer media," Rheol. Acta 15(2), 85 (1976).

${ }^{133}$ A. I. Leonov, E. H. Lipkina, E. D. Paskhin, and A. N. Prokunin, "Theoretical and experimental investigation of shearing in elastic polymer liquids," Rheol. Acta 15(7), 411 (1976).

${ }^{134}$ A. I. Leonov and A. N. Prokunin, "An improved simple version of a nonlinear theory of elasto-viscous polymer media," Rheol. Acta 19(4), 393 (1980).

${ }^{135}$ A. I. Leonov and A. N. Prokunin, "On nonlinear effects in the extensional flow of polymeric liquids," Rheol. Acta 22(2), 137 (1983).

${ }^{136} \mathrm{M}$. Simhambhatla and A. I. Leonov, "On the rheological modeling of viscoelastic polymer liquids with stable constitutive equations," Rheol. Acta 34(3), 259 (1995).

${ }^{137}$ A. I. Leonov, "Constitutive equations for viscoelastic liquids: Formulation, analysis and comparison with data," Rheol. Ser. 8, 519 (1999).

${ }^{138}$ R. Pivokonsky, M. Zatloukal, P. Filip, and C. Tzoganakis, "Rheological characterization and modeling of linear and branched metallocene polypropylenes 
prepared by reactive processing," J. Non-Newtonian Fluid Mech. 156(1-2), 1 (2009).

${ }^{139}$ N. P. Thien and R. I. Tanner, "A new constitutive equation derived from network theory," J. Non-Newtonian Fluid Mech. 2(4), 353 (1977).

${ }^{140} \mathrm{~N}$. Phan-Thien, “A nonlinear network viscoelastic model," J. Rheol. 22(3), 259 (1978).

${ }^{141}$ R. G. Larson, "A constitutive equation for polymer melts based on partially extending strand convection," J. Rheol. 28(5), 545 (1984).

${ }^{142}$ S. A. Khan and R. G. Larson, "Comparison of simple constitutive equations for polymer melts in shear and biaxial and uniaxial extensions," J. Rheol. 31(3), 207 (1987).

143 A. C. Papanastasiou, L. E. Scriven, and C. W. Macosko, "An integral constitutive equation for mixed flows: Viscoelastic characterization," J. Rheol. 27(4), 387 (1983).

${ }^{144}$ X.-L. Luo and R. I. Tanner, "Finite element simulation of long and short circular die extrusion experiments using integral models," Int. J. Numer. Methods Eng. 25(1), 9 (1988).

${ }^{145}$ E. Mitsoulis, "Numerical simulation of entry flow of the IUPAC-LDPE melt," J. Non-Newtonian Fluid Mech. 97(1), 13 (2001).

${ }^{146}$ P. Perzyna, in Advances in Applied Mechanics, edited by G. G. Chernyi et al. (Elsevier, 1966), Vol. 9, p. 243.

${ }^{147}$ M. M. Denn, C. J. S. Petrie, and P. Avenas, "Mechanics of steady spinning of a viscoelastic liquid," AIChE J. 21(4), 791 (1975).

${ }^{148}$ Y. Demay, "Instabilité d'étirage et bifurcation de Hopf," Ph.D. thesis, Université de Nice, 1983.

${ }^{149}$ V. R. Iyengar, "Film casting of polymer melts," Ph.D. thesis, University of Maine, 1993.

${ }^{150}$ M. E. Pis-Lopez and A. Co, "Multilayer film casting of modified Giesekus fluids Part 2. Linear stability analysis," J. Non-Newtonian Fluid Mech. 66(1), 95 (1996).

${ }^{151}$ M. M. Denn, "Fibre spinning," in Computational Analysis of Polymer Processing (Applied Science Publishers Ltd., 1983).

${ }^{152}$ A. N. Beris and B. Liu, "Time-dependent fiber spinning equations. 1. Analysis of the mathematical behavior," J. Non-Newtonian Fluid Mech. 26(3), 341 (1988).

${ }^{153}$ B. Liu and A. N. Beris, "Time-dependent fiber spinning equations. 2. Analysis of the stability of numerical approximations," J. Non-Newtonian Fluid Mech. 26(3), 363 (1988).
${ }^{154}$ B. M. Devereux and M. M. Denn, "Frequency response analysis of polymer melt spinning,” Ind. Eng. Chem. Res. 33(10), 2384 (1994).

${ }^{155}$ D. K. Gagon and M. M. Denn, "Computer simulation of steady polymer melt spinning," Polym. Eng. Sci. 21(13), 844 (1981).

${ }^{156} \mathrm{D}$. Gelder, “The stability of fiber drawing processes," Ind. Eng. Chem. Fundam. 10(3), 534 (1971).

${ }^{157}$ R. J. Fisher and M. M. Denn, "Finite-amplitude stability and draw resonance in isothermal melt spinning," Chem. Eng. Sci. 30(9), 1129 (1975).

${ }^{158}$ R. J. Fisher and M. M. Denn, "A theory of isothermal melt spinning and draw resonance," AIChE J. 22(2), 236 (1976).

${ }^{159}$ R. E. Christensen, "Extrusion coating of polypropylene," SPE J. 18, 751 (1962).

${ }^{160}$ J. C. Miller, "Swelling behavior in extrusion," SPE Trans. 3(2), 134 (1963).

${ }^{161}$ J. P. Sergent, "Etude de deux procédés de fabrication de films. Le soufflage de gaine. L'extrusion de film à plat," Ph.D. thesis, Universite Louis Pasteur, 1977.

${ }^{162}$ O. S. Narayanaswamy, "A one-dimensional model of stretching float glass," J. Am. Ceram. Soc. 60(1-2), 1 (1977).

${ }^{163}$ G. Lamberti, F. De Santis, V. Brucato, and G. Titomanlio, "Modeling the interactions between light and crystallizing polymer during fast cooling," Appl. Phys. A 78(6), 895 (2004).

${ }^{164} \mathrm{G}$. Titomanlio and G. Lamberti, "Modeling flow induced crystallization in film casting of polypropylene," Rheol. Acta 43(2), 146 (2004).

${ }^{165}$ S. Kase, "Studies on melt spinning. IV. On the stability of melt spinning," J. Appl. Polym. Sci. 18(11), 3279 (1974).

${ }^{166}$ J. F. Agassant, Y. Demay, C. Sollogoub, and D. Silagy, "Cast film extrusion," Int. Polym. Process. 20(2), 136 (2005).

${ }^{167}$ A. Co, in Polymer Processing Instabilities: Control and Understanding, edited by S. G. Hatzikiriakos and K. B. Migler (CRC Press, 2005), p. 287.

${ }^{168}$ B. Seyfzadeh, G. M. Harrison, and C. D. Carlson, "Experimental studies on the development of a cast film," Polym. Eng. Sci. 45(4), 443 (2005).

${ }^{169} \mathrm{~K}$. Aniunoh and G. Harrison, in Annual Technical Conference - ANTEC, Conference Proceedings (Society of Plastics Engineers, 2007), Vol. 3, p. 1591.

${ }^{170}$ T. Barborik and M. Zatloukal, "Effect of second to first normal stress difference ratio at the die exit on neck-in phenomenon in polymeric flat film production," AIP Conf. Proc. 1843, 030010 (2017).

${ }^{171}$ C. W. Seay, C. D. McGrady, and D. G. Baird, in Annual Technical Conference ANTEC, Conference Proceedings (Society of Plastics Engineers, 2008), Vol. 1380. 